\title{
The Frog-Biting Midges of Borneo-From Two to Eleven Species (Corethrellidae: Diptera)
}

\author{
ART BORKENT ${ }^{1} \&$ T. ULMAR GRAFE ${ }^{2}$ \\ ${ }^{1}$ Research Associate, Royal British Columbia Museum, American Museum of Natural History and Instituto Nacional de Biodiversidad, \\ 691-8th Ave. SE, Salmon Arm, British Columbia, V1E 2C2, Canada. (e-mail: artborkent@telus.net) \\ ${ }^{2}$ Department of Biology, Universiti Brunei Darussalam, Tungku Link, Gadong BE 1410, Brunei Darussalam \\ (email: grafe@biozentrum.uni-wuerzburg.de)
}

\begin{abstract}
The Corethrella Coquillett of Borneo are described and interpreted, based primarily on material from Brunei Darussalam and a few locations in the Malaysian states of Sarawak and Sabah. The eleven species include three previously named (one newly discovered in Borneo) and eight newly named species. The following new species are attributed to Borkent \& Grafe: C. lutea, C. tigrina, C. gilva, C. nanoantennalis, C. mitra and C. bipigmenta. Two new species, $C$. bicincta and C. unizona are attributed to Borkent, Grafe \& Miyagi.

Of the eleven Bornean species, 10 are recorded from Brunei Darussalam and eight of these are also known from at least Sarawak. This distribution of species as well as comparison of species collected directly from calling frogs with those collected with frog-call traps (some with modified sound) indicate that diversity is not as high as in Central America (the only other tropical area intensely sampled). Surveys of aquatic habitats show that Corethrella are absent from phytotelmata (water bodies held by plants) in Borneo, other than C. calathicola Edwards which is present in some species of Nepenthes and a species most closely related to a relatively derived group of Neotropical species occupying treeholes (C. calathicola likely dispersed from the Neotropical Region). Phylogenetic analysis indicates that, other than C. calathicola, species are members of an early lineage called the drakensbergensis species group $(n=6)$, is the sister group of a large assemblage of Old and New World species $(n=1)$ or cannot be placed phylogenetically (probably because of lack of immatures and males) $(n=3)$.
\end{abstract}

\section{Abstrak (Bahasa Melayu)}

Corethrella Coquillett dari Borneo dideskripsikan dan ditafsirkan berdasarkan sampel-sampel yang diperolehi dari Brunei Darussalam dan beberapa lokasi di Malaysia iaitu Sarawak dan Sabah. Sebelas spesies termasuk tiga spesies yang telah dinamakan sebelumnya (satu spesies baru saja ditemui di Borneo) dan lapan spesies yang baru dinamakan. Spesies baru berikut merujuk kepada Borkent \& Grafe: C. lutea, C. tigrina, C. gilva, C. nanoantennalis, C. mitra dan $C$. bipigmenta. Sementara itu terdapat dua agi spesies baru iaitu $C$. bicincta dan $C$. unizona yang merujuk kepada Borkent, Grafe \& Miyagi.

Daripada sebelas spesies Corethrella yang didokumenkan di Borneo, 10 daripadanya direkodkan dari Brunei Darussalam dan lapan daripada spesies ini juga diketahui kewujudannya sekurang-kurangnya di Sarawak. Taburan spesies ini serta perbandingan di antara spesies yang dikumpulkan secara langsung dari katak-katak yang berbunyi dengan sampel-sampel yang dikumpulkan melalui perangkap yang telah dipasang dengan bunyi katak (beberapa dengan beberapa bunyi yang telah diubah suai) menunjukkan bahawa kepelbagaian spesies tidak setinggi yang terdapat di Amerika Tengah (iaitu satu-satunya kawasan tropika terperinci yang telah disampel secara mendalam). Penyiasatan ke atas habitat-habitat akuatik menunjukkan bahawa spesies Corethrella tidak wujud di dalam 'phytotelmata' (badan air yang dipegang oleh tumbuh-tumbuhan) di Borneo, kecuali $C$. calathicola Edwards yang telah didapati di dalam beberapa spesies Nepenthes dan juga satu spesies Corethrella yang berkait rapat dengan kumpulan yang berasal dari spesies Neotropika yang terdapat di dalam lubang di bahagian batang pokok (C. calathicola berkemungkinan berasal dari Wilayah Neotropika). Analisis filogenetik menunjukkan bahawa, selain daripada C. calathicola, spesies Corethrella ini adalah ahli dari keturunan awal yang dikenali sebagai kumpulan spesies drakensbergensis $(\mathrm{n}=6)$, adalah himpunan kelompok spesies yang terbesar di Dunia Lama dan Baru $(\mathrm{n}=1)$ atau tidak dapat diletakkan secara filogenetik (berkemungkinan disebabkan oleh kekurangan sampel yang tidak matang dan sampel jantan) $(n=3)$.

Key words: Brunei, Malaysia, Corethrella, frog, Anura, biodiversity, aquatic 


\section{Introduction}

The Corethrellidae, with its single, worldwide genus Corethrella Coquillett, is a remarkable group of biting flies. Unlike other blood-sucking nematocerous Diptera which are attracted at least initially by the $\mathrm{CO}_{2}$ emanating from their vertebrate hosts, female Corethrella are attracted by the call of male frogs. In a recently published monograph, Borkent (2008) described and synthesized current knowledge of the group, showing that there is an ancient relationship originating from at least the Early Cretaceous between frogs, species of Corethrella, and the trypanosomes they vector between male frogs. Using a frog-call trap for the first time in the tropics, Borkent reported that 38 species were discovered in Costa Rica, up from the three previously known. Although the group is largely pantropical and subtropical, the rarity of specimens in most collections has severely limited our understanding of the species occurring outside of Central America. Here we report the first taxonomic survey undertaken in the Old World tropics using frog-call traps and capturing female Corethrella attracted to and biting frogs. True to predictions (Borkent 2008; Grafe et al. 2008), eight new species were discovered and a previously described species newly recorded in Borneo.

Although we have incorporated all available material from Borneo, the reality is that our study is largely restricted to the species we collected in the small country of Brunei Darussalam, with the addition of a few further collecting localities in Sabah and Sarawak, Malaysia, the only other sites for which Corethrella are known in Borneo. We discuss the likelihood of discovering further species, based on interpretation of the distribution of the species we describe as well as a comparison of our two main collecting methods (frog-call traps, direct sampling from calling frogs).

\section{Materials and methods}

Specimens were examined, studied, measured and drawn using a Wild M3 dissecting microscope and a Zeiss Jenaval compound microscope. Photomicrographs were taken with a Nikon CoolPix 995 through a Zeiss Jenaval compound microscope. Terms for structures follows those used in the Manual of Central American Diptera (Cumming and Wood 2009) and Borkent (2008). Three species were previously named and their redescription here, including the descriptive statistics, incorporates all original material (Borkent 2008). The number of posterior anepisternal setae were not reported here because they were absent in all known species in this study. Specimens were primarily collected either by sampling directly from calling frogs or with a frog-call trap as described by Grafe et al. (2008). Frog-call traps generally used synthesized sound rather than recorded frog calls. Immatures of some C. calathicola Edwards were collected from species of Nepenthes (L.) and reared to adults. All specimens were collected into ethanol. Representative material was slide-mounted using the method described by Borkent and Spinelli (2007). Some of those slide-mounted specimens were previously treated to DNA extraction (Lim, 2007), and therefore partially cleared; these were not treated with $\mathrm{KOH}$ before slide mounting. Many of those remaining in alcohol were transferred to ethyl acetate, dried on blotting paper, and glued to pins. None of the remaining specimens in alcohol were considered to be paratypes of the species described here.

We attempted to sample immatures of species of Corethrella from a variety of aquatic habitats, both on the ground and in phytotelmata (water bodies held by plants) and, other than $C$. calathicola from some species of Nepenthes, we were unsuccessful.

To interpret the phylogenetic position of the species described here, we refer to the character states by number as given by Borkent (2008). Each Bornean species was examined in the light of all the character states reported by Borkent (2008) and which was used as a template for interpretation.

Several specimens have additional numbers listed in spreadsheets providing further bionomic information. Some specimens, including a number of type specimens had their DNA extracted (Lim 2007) and the date of extraction is given on some slide-mounted material as a six digit number representing day, month, and year. Numbers preceded by "CD" refer to the first author's field notes, ultimately to be deposited at the Canadian National Collection of Insects. In the interest of economy, in numerous places in the text (and on specimen labels), we refer to Brunei Darussalam simply as Brunei. Many localities include the term 'sungai' which means river or stream in Malay. Abbreviations for depositories are as follow:

ANIC Australian National Insect Collection, Division of Entomology, CSIRO, P.O. Box 1700, Canberra City, A.C.T. 2601, Australia. 
BMNH Department of Entomology, Natural History Museum, Cromwell Road, London, SW7 5BD, United Kingdom.

BPBM Department of Entomology, Bernice P. Bishop Museum, 1525 Bernice Street, P.O. Box 19000A, Honolulu, Hawaii, 96817 0916, USA.

CNCI Canadian National Collection of Insects, Agriculture \& Agri-Food Canada, K.W. Neatby Building, 960 Carling Ave., Ottawa, Ontario, K1A 0C6, Canada.

SMKM Sarawak Museum, Kuching, 93566, Sarawak, Malaysia.

UBD Zoological Museum at the Department of Biology, Universiti of Brunei, Darussalam, Bandar Seri Begawan, Brunei Darussalam (UBD).

USNM United States National Museum, Smithsonian Institution, Museum Support Center, 4210 Silver Hill Rd, Suitland, MD 20746, U.S.A.

\section{Results}

\section{Key to the species of Corethrella of Borneo}

This key will successfully identify material in either alcohol or slide-mounted specimens. Material in good condition, retaining their setae and scales, are significantly easier to identify than rubbed specimens. Nevertheless, pigmentation patterns, although not as clear, are yet present in the underlying cuticle of damaged material. Identification of the antennal sensilla coeloconica requires slide mounting but we have added other features to the key so they are not vital to identification. Readers should be aware that most of our material came from Brunei or nearby localities in Sarawak. It is very likely that undescribed species are yet to be found in Borneo, especially from elsewhere on the island. As such, slide mounting of at least representative material will increase the likelihood of accurate identification of the species.

The key below is based primarily on females because the males of only two of the 11 species are known, namely those of C. tigrina and C. calathicola. However, our use of colour patterns, likely shared by males and females, suggests that the key will work with both sexes. The pigmentation of the abdomen is described below based on cleared, slide-mounted specimens. At times, material in alcohol can be confusing because of underlying pigmentation of body tissues; in such instances, special care should be taken to study only the tergites and/or sternites.

Rubbed, pinned specimens of C. gilva, which otherwise have a midlength wing band (Fig. 12K), may appear to have no wing pigmentation. Such specimens would run to couple 2, but the combination of a scutum lighter than the dark pleura and pale abdominal tergites 2-6 (Fig. 5E) will correctly identify these.

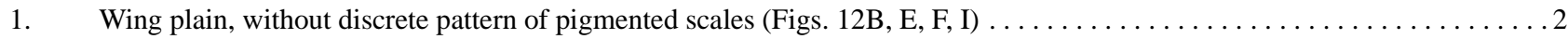
Wing with at least some pattern of pigmented scales (anterior margin always with at least one distinct and discrete band of dark

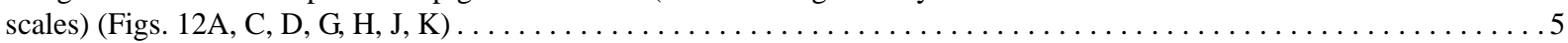

2 (1). Wing yellow (Fig. 4B); scutum yellow (Fig. 4B); katepisternum with at least some pale cuticle, contrasting with dark posterior anepisternum (Fig. 9B); base of hind femur dark brown, strongly contrasting with yellow base of midfemur (Fig. 9B) . . lutea

(Brunei, Malaysia (Sarawak))

- $\quad$ Wing brown (Figs. 4E, F, 5C); scutum brown; pleura (including katepisternum and posterior anepisternum) uniformly dark brown (scutum and pleura not equal in some) (Figs. 4E, 10A, D); bases of mid- and hind femora equally pigmented, medium to

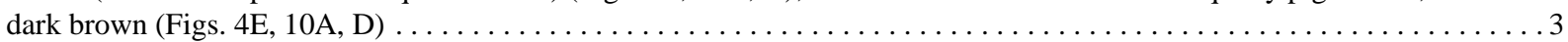

3 (2). Scutum more lightly pigmented than pleura (Fig. 10A); abdominal tergites and sternites uniformly pigmented or at least each of abdominal tergites $2-5$ more lightly pigmented posteriorly (Fig. 13E) $\ldots \ldots \ldots \ldots \ldots \ldots \ldots \ldots \ldots \ldots \ldots \ldots \ldots \ldots \ldots \ldots$

(Brunei, Malaysia (Sarawak, Sabah)) Scutum as dark brown as pleura (Figs. 4E, 5C, 10D); abdominal tergites uniformly brown (Figs. 4E, 13H) . . . . . . . .

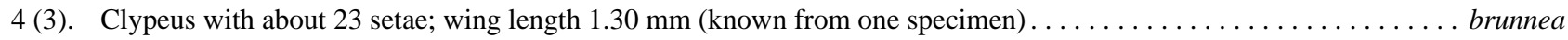

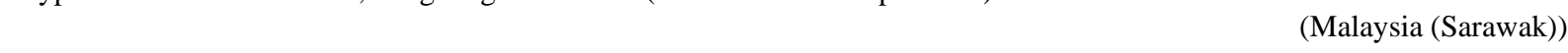
Clypeus with 2-5 setae; wing length of Bornean specimens less than $1.07 \mathrm{~mm} \ldots \ldots \ldots \ldots \ldots \ldots \ldots \ldots$. . . . . . . . . . . (Brunei, Malaysia (Sarawak), Papua New Guinea)

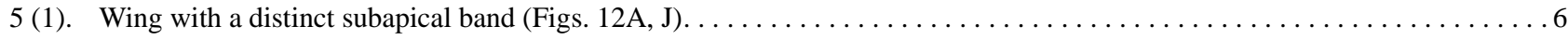
Wing with single midlength band represented by at least dark pigmentation on anterior margin of wing (Fig. 12C, D, G, H, K); with, at most, slightly darker pigmentation at very apex of veins $R_{2}, R_{3}$, and $R_{4+5}$ (Figs. $\left.12 \mathrm{H}\right) \ldots \ldots \ldots \ldots \ldots \ldots$

6 (5). Thorax uniformly brown (alcohol specimens with scutum with three narrow longitudinal vittae) (Fig. 11A); basal 0.7 of forefemur, all of midfemur and about basal half of hind femur similarly and uniformly brown (pigmentation not discrete) (Fig. 11A); 
Thorax with patterned pigmentation (Fig. 9A); forefemur with basal, midlength and apical darker pigmentation, mid- and hind femur with narrow basal and apical bands of dark pigmentation (pigmentation discrete) (Fig. 9A); at least each of abdominal tergites $2-6$ more lightly pigmented posteriorly $($ Fig. 13A) $\ldots \ldots \ldots \ldots \ldots \ldots \ldots \ldots \ldots \ldots \ldots \ldots \ldots \ldots \ldots \ldots \ldots$

(Brunei, Malaysia (Sarawak))

7 (5). Hind tibia with distinct basal and apical bands of dark pigmentation (Fig. 10C); palpus pale, contrasting with dark brown clypeus (Fig. 7A); midfemur with well-developed scales (Fig. 11C); wing with midlength band somewhat scattered, with scales on $\mathrm{R}_{4+5}$ pale (so that the dark scales on $\mathrm{C}, \mathrm{R}_{1}$ and $\mathrm{R}_{2+3}$ appear as a separate anterior darker spot), and with posterior portion of band situated separately at apex of $\mathrm{CuA}_{2}($ Fig. $12 \mathrm{H}) \ldots \ldots \ldots \ldots \ldots \ldots \ldots \ldots \ldots \ldots \ldots \ldots \ldots \ldots \ldots \ldots \ldots \ldots \ldots \ldots$ calacola

(Singapore, Malaysia (Pahang, Sarawak), Indonesia (East Kalimantan), Brunei) Hind tibia with, at most, some darker pigmentation at very base and at apex (Fig. 10B); palpus entirely medium brown or with segments 1 and 2 brown and contrasting with pale segments 3-5 (base of segment 3 may be brown in some) (Figs. 6C, D, F, 7D); midfemur without scales; wing with midlength band forming a single anterior to posterior band of uniform pigmentation

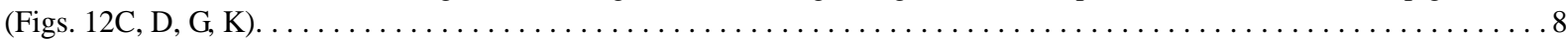

8 (7). Palpus with segments 1 and 2 (in some the very base of 3) dark brown, contrasting with light brown or pale segments 3 and 4 (5 grading apically to medium brown) (Figs. 6C, D); at least each of abdominal tergites 2-6 with darker pigmentation restricted to lateral margins, sternites $2-6$ more lightly pigmented posteriorly (Figs $13 \mathrm{C}$, D) $\ldots \ldots \ldots \ldots$ Palpus with all segments uniformly medium brown (Figs. 6F, 7D); abdominal tergites 2-6 uniformly pigmented, sternites 2-6

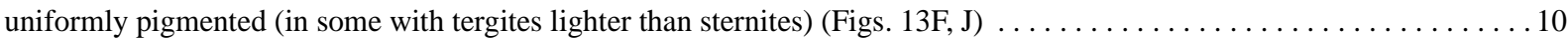

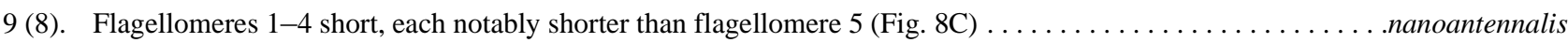

(Brunei, Malaysia (Sarawak))

Flagellomeres $1-4$ elongate, similar in length to flagellomere 5 (Fig. 8D) $\ldots \ldots \ldots \ldots \ldots \ldots \ldots \ldots \ldots \ldots$ bipigmenta

(Brunei)

10 (8). Hind tibia with dark pigment apically (Fig. 10B); 0-1 clypeal setae; flagellomeres 1, (sometimes 8), 9-13 with sensilla coeloconica and 9-12 (sometimes 13) with 2 sensilla coeloconica ( 1 with a few sensilla coeloconica) . . . . . .........unizona

(Brunei, Malaysia (Sarawak))

Hind tibia with, at most, lightly pigmented apex (Fig. 11B); with 13-25 clypeal setae; flagellomeres 1, 9-13 with sensilla coeloconica and only flagellomere 1 with more than one sensilla coeloconicum $\ldots \ldots \ldots \ldots \ldots \ldots \ldots \ldots \ldots \ldots$. . . . . . . . .

(Brunei)

\section{Key to eastern Palaearctic, Oriental, Oceanian and northern Australasian species}

The key below includes all species which we consider as possibly occurring in Borneo and draws in part on the keys in Borkent (2008). The key is based primarily on females because the males of most species are unknown. Corethrella inepta (Annandale) from Sri Lanka and C. towadensis Okada \& Hara, known only from the original description from Japan, are known only as males (and immatures). Because pigmentation patterns are generally shared by males and females in other species of Corethrella, we have attempted to base the key on such features to increase the likelihood that members of the presently unknown sex, once they are discovered, may yet be identified. This key must be seen as preliminary as it is very likely that more species await description in this region.

Corethrella towadensis from Japan is included in the key below even though no material was studied (types are lost) because the species was described in sufficient detail to do so. The types of $C$. japonica (Komyo) are also lost but the original description is insufficient to place the species here and it is not included in the key. These two species are discussed further by Borkent (2008).

We have not included the five known Australian species in this key, in large measure because some are known only from specimens in poor condition. Four have a distinctive pattern of wing pigmentation. The fifth, $C$. pallidula Bugledich has a midlength wing band but is known only from three bleached specimens; it has a laterally elongate head and apical pigmentation on each tibia (Borkent, 2008).

Reexamination of the type of $C$. canningsi Borkent showed that sternites 3-5 had darker pigmentation anteriorly (similar to some Bornean species) and this species is therefore keyed differently here than in Borkent (2008).

Additional figures of non-Bornean species are available in Borkent (2008).

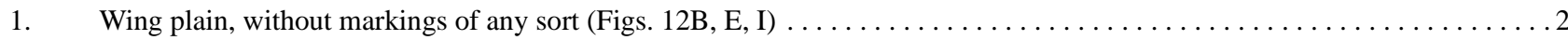

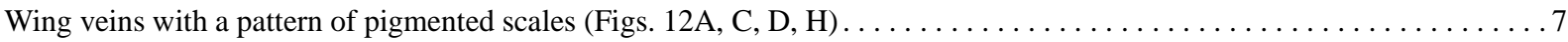

2 (1). Scutum more lightly pigmented than at least portions of pleura (Fig. 9B, 10A); tergites and sternites uniformly pigmented or 
with at least tergites $2-5$ with either darker anterolateral light brown pigmentation or with posterior margin lighter than ante-

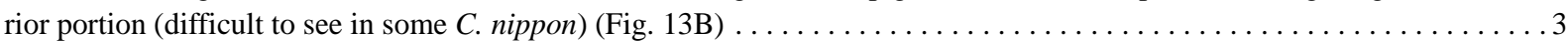
Thorax uniformly yellow to dark brown or with the scutum (or a portion of the scutum) darker than pleura (Figs. 4E, 10D);

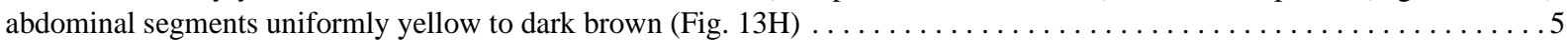

3 (2). Flagellomeres 1-4 elongate (Fig. 8F); cerci as dark brown as segments 8 and 9 (Fig. 13E) . . . . . . . . . . . mitra

(Brunei, Malaysia (Sarawak, Sabah))

Flagellomeres 1-4 short (Fig. 8B); cerci pale or light brown, contrasting with dark segments 8 and 9 (Fig. 13B) $\ldots \ldots \ldots 4$

4 (3). Midfemur relatively thick (Fig. 9B); flagellomeres 11 and 12 each with two sensilla coeloconica (sometimes with two on

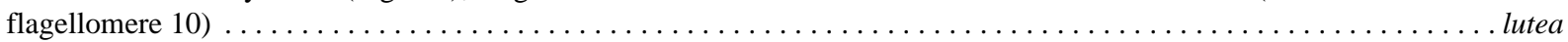

(Brunei, Malaysia (Sarawak))

Midfemur relatively slender (Borkent, 2008: fig. 39A); flagellomeres 10-12 each with one sensilla coeloconicum... nippon (Japan)

5 (2). Wing veins with slender setae (as in Borkent, 2008: fig. 73C), although a few apical macrotrichia are somewhat thicker .....

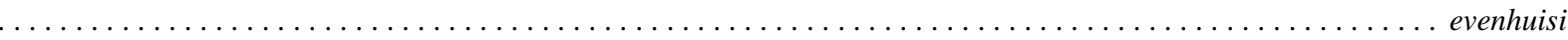

(Papua New Guinea)

Wing veins with definite but narrow scales along their lengths (as in Borkent, 2008: fig. 73E) $\ldots \ldots \ldots \ldots \ldots$

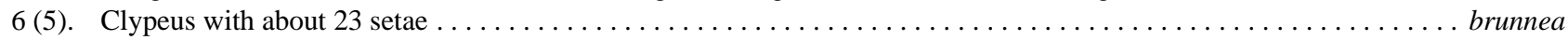

(Malaysia (Sarawak))

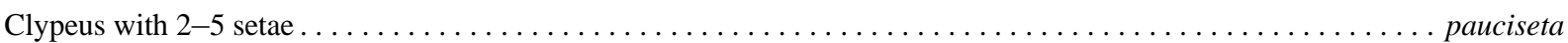

((Brunei, Malaysia (Sarawak), Papua New Guinea)

7 (1). With at least abdominal tergites $2-6$ and/ or sternites $3-5$ each with an anterior darker band (Figs. 13A, C, D) . . . . . . 8 Abdominal tergites 2-6 and sternites 3-5 uniformly pigmented (tergites and sternites may not be equal) (Figs. 13F, G, I, J). 12

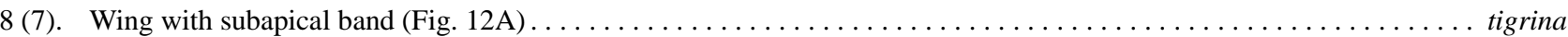

(Brunei, Malaysia (Sarawak))

Wing without subapical band (at most with $\mathrm{R}_{4+5}$ with dark scales at apex) $\ldots \ldots \ldots \ldots \ldots \ldots \ldots \ldots \ldots \ldots \ldots$

9 (8). Midfemur, midtibia, hind femur and hind tibiae each with narrow discrete apical band of dark pigmentation (as in Fig. 9A)...

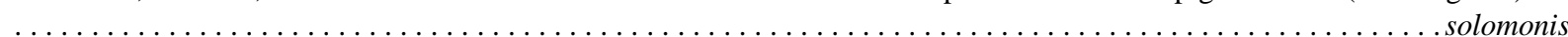

(Solomon Islands)

Midfemur with, at most, non-discrete darker pigmentation on basal 0.7 , midtibia uniformly pigmented, hind femur with, at most, non-discrete darker pigmentation on basal 0.5, hind tibia with, at most, a discrete basal band of dark pigmentation (Figs.

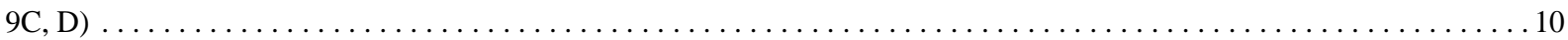

10 (9). Hind tibia with discrete basal band of dark pigmentation; palpal segments 1 and 2 paler than dark brown segments $3-5 \ldots \ldots$

(Solomon Islands)

Hind tibia with, at most, very slightly, non-discrete basal and apical pigmentation (Figs. 9C, D); palpal segments 1 and 2 dark brown, contrasting with pale segments 3 and 4, with segment 5 grading from pale to medium brown (Figs. 6C, D) ......11

11 (10).Flagellomeres $1-4$ short, each notably shorter than flagellomere 5 (Fig. 8C) . . . . . . . . . . . . .nanoantennalis

(Brunei, Malaysia (Sarawak))

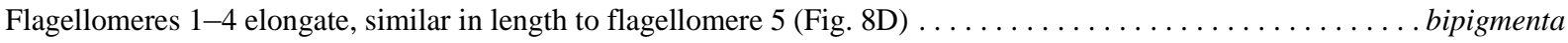

(Brunei)

12 (7). Midtibia and midfemur brown but with the femur lighter basally towadensis (Japan)

Midtibia and midfemur both uniformly pigmented or pigmented otherwise than above (not discretely so) $\ldots \ldots \ldots \ldots 13$

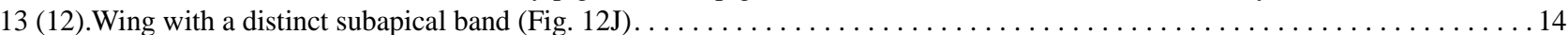
Wing with single midlength band represented by at least dark pigmentation on anterior margin of wing (Figs. 12G, H, K); with,

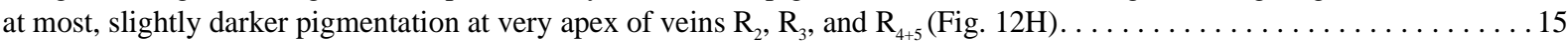

14 (13).Hind tibia with broad dark brown pigmentation at both its base and apex (Fig. 11A); antenna with flagellomeres 10-13 each with two sensilla coeloconica.

(Brunei, Malaysia (Sarawak)) Hind tibia uniformly pigmented except for poorly defined, somewhat darker pigmentation at its base; antenna with flagellomeres $10-13$ each with one sensilla coeloconicum $\ldots \ldots \ldots \ldots \ldots \ldots \ldots \ldots \ldots \ldots \ldots \ldots \ldots \ldots \ldots \ldots \ldots \ldots \ldots \ldots \ldots \ldots$

(Papua New Guinea)

15 (13).Palpus pale or very light brown, contrasting with dark brown clypeus (Fig. 7A); midfemur with well-developed scales (Fig.

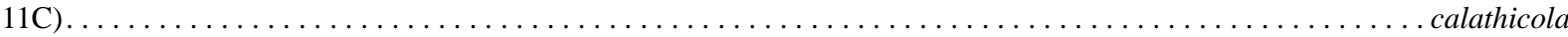

(Singapore, Malaysia (Pahang, Sarawak), Indonesia (East Kalimantan), Brunei) Palpus and clypeus equally dark brown (Figs. 6F, 7D); midfemur without scales or, at most, very slightly expanded scales ...

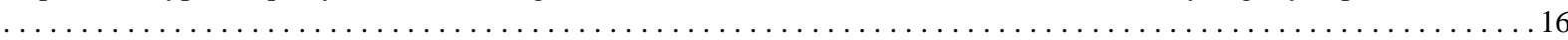

16 (15).Hind tibia with broad dark brown pigmentation at both its base and apex. . . . . . . . . . . . . . . . urumense

(Japan)

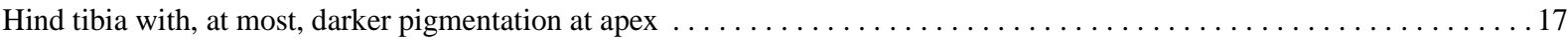


17 (16).Hind tibia with, at most, somewhat darker pigmentation at apex (Fig. 11B); antenna with flagellomeres 10-13 each with one

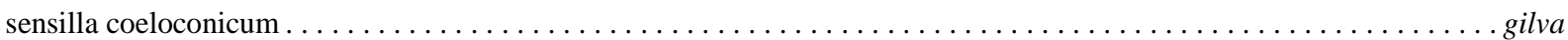

(Brunei)

Hind tibia with distinct dark pigmentation at apex (Figs. 10B); antenna with flagellomeres 11-13 each with two sensilla coelo-

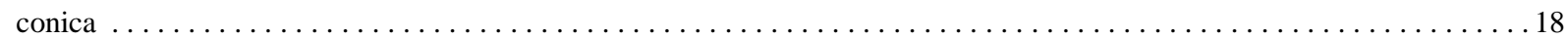

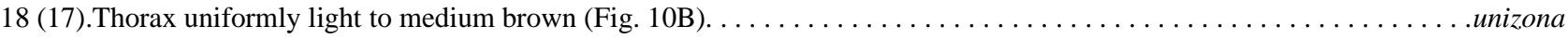

(Brunei, Malaysia (Sarawak))

Thorax light brown with anterior portion of scutum, anepisternum, katepisternum, posterior portion of mediotergite more

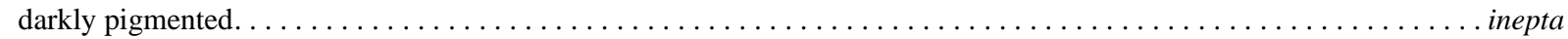

(Sri Lanka)

\section{Descriptions}

Corethrella (Corethrella) tigrina Borkent \& Grafe, new species

(Figs. 2A, 4A, 6A, 7E, G, 8A, L, M, 9A, 12A, 13A, 14B)

DIAGNOSIS: Male and female adults: Only extant species of Corethrella in the Palaearctic, Oriental, Oceanian and northern Australasian Regions with the combination of a wing with a subapical band (Fig. 12A) and with abdominal tergites 2-6 each with anterior dark pigmentation and lighter posteriorly (Fig. 13A). Only extant species in Borneo with the combination of a wing with a subapical band (Fig. 12A) and all femora and tibiae each with darker pigmentation at both base and apex (Fig. 9A).

DESCRIPTION: Male adult. Head: Outline in anterior view somewhat circular (as in Fig. 6A). Two large setae on frons between ventromedial area of ommatidia. Antenna with flagellomere 1 dark brown, remainder pale; pedicel without distinctive elongate, stout setae; flagellomeres as in Fig. 8L; sensilla coeloconica on flagellomeres 1, 9-13, only flagellomere 1 with more than one; flagellomere 13 with well-developed apical bifurcation. Palpus brown; segment 3 of nearly constant width. Thorax (as in Fig. 9A): Light brown with following medium to dark brown: paratergite, margin of scutum posterior to paratergite, dorsal portion of mediotergite, posterodorsal portion of anterior anepisternum, posterior anepisternum, dorsal and ventral portion of anepimeron (pale at midheight), most of katepisternum (pale area at about midheight on posterior margin), dorsal portion of metanepisternum. Posterior portion of dorsocentral row with 2 elongate setae situated somewhat lateral to one another. Prescutal suture elongate, thick, uninterrupted, extending to near dorsocentral row of setae. Anterior anepisternum divided diagonally by sinuous suture, dorsal portion about equal to ventral portion. Ventral portion of posterior anepisternum triangular, uniformly brown, with anterodorsal margin not thick. Wing (as in Fig. 12A but slightly lighter): Length $=0.95 \mathrm{~mm}$. Apex of $\mathrm{R}_{2}$ slightly distal to apex of $\mathrm{M}_{1}$. Anterior margin with differently, discretely pigmented scales (indicating anterior margin of midlength, subapical bands), with midlength, subapical bands, with dark scales on $\mathrm{R}_{4+5}$ and $\mathrm{M}$ connecting the two bands; veins (other than costa and wing margin) with well-developed scales. Halter pale. Legs (as in Fig. 9A): Light brown with forefemur with basal and apical darker pigmentation, each of following with discrete basal and apical dark pigmentation: foretibia, midfemur, midtibia, hind femur, hind tibia, fore-, mid-, hind leg tarsomeres 1 each with two bands, fore-, mid-, hind leg tarsomeres 2-4 with basal banding. With only slender setae, lacking scales. Midleg with thick, subapical setae on each of at least tarsomeres 1-3. Apices of fore-, midleg fifth tarsomeres undivided, with claws slightly subapical. Foreleg with tarsomeres $3 /$ $4=1.42$. Claws of fore-, midleg equal in length, longer than those of hind leg. Each claw without inner tooth. Anterior claws of each leg without basal prong. Foreleg claws unequal. Midleg claws unequal. Foreleg tarsomere 3 longer than tarsomere 4. Empodia slender. Abdomen: Pale except as follows: tergites 1-7, sternites 3-6 each with anterior band of brown pigmentation, segments 8-9 light brown. Genitalia (Fig. 8M): Gonocoxite uniformly pale, gently tapering; anteromedial area with spicules similar in length to those elsewhere on gonocoxite; with well-defined dorsal row of setae, with anterior setae of similar thickness as some other setae on gonocoxite, more posterior setae thicker, with row curving posteromedially with posteriormost seta of row positioned dorsomedially. With one dorsomedial stout seta, tapering near apex. Gonostylus (in retracted position) with slight concavity along posterior margin, curved subapically, thick, of more or less equal thickness for entire length, tapered apically; one elongate, thick subbasal seta, situated ventrally; with thick, blunt apical peg. Aedeagus slender, elongate, tapering gradually to apex, pointed apically, with lateral margins separate apically. Dorsomedial seta from base of gonocoxite/ length of gonocoxite $=0.39$. Subbasal seta from base of gonostylus/ length of gonostylus $=0.37$. 
Female adult. Descriptive statistics: See Tables 1-5. As for male, with following differences. Head: Antenna light brown, with flagellomere 1, apical portion of flagellomeres 4-10, all of flagellomeres 11-13 medium brown. Antennal flagellomeres as in Fig. 8A; sensilla coeloconica on flagellomeres 1, 9-13, only flagellomere 1 with more than one. Coronal suture elongate, extending ventrally past ommatidia. Clypeus (Fig. 6A) somewhat wider than long, triangular in outline. Mandible with very small, pointed teeth. Palpus as in Fig. 6A. Wing (Fig. 12A): As for male but some with some darker pigmentation in subbasal area. Halter medium brown, somewhat paler or as dark as scutellum. Legs: Claws of each leg equal to those of others; equal on each leg, simple (without inner teeth). Abdomen (Fig. 13A): Pale or very light brown with anterior margin of each of tergites 1-7 and anterior portion of sternites 3-6 medium brown, segments 8-9 medium brown. Cercus medium brown.

Immature stages. Unknown.

DISTRIBUTION AND BIONOMICS: Corethrella tigrina is known from Brunei and two localities in Sarawak, Malaysia at elevations of 30-220 m (Fig. 14B). Habitats include lowland peat swamps (including standing water and very slow moving streams) and steep terrain in mature mixed dipterocarp forest (Figs. 1A, F). The sexes were associated on the basis of a male and two females collected with a frog-call trap at $15 \mathrm{~km} \mathrm{~S}$. of Liang, Brunei on 7-VI-2007. This is the only instance we know of in which a male Corethrella has been collected with a frog-call trap and provides very limited additional evidence supporting the tentative suggestion by Borkent (2008) that males may be attracted to the vicinity of frog calls to mate.

This species is a member of the drakensbergensis species group (Fig. 19) and morphologically very similar to C. solomonis Belkin. The latter species has been collected as larvae from the leaf axil of a Pandanaceae (possibly Sararanga) (Borkent, 2008), suggesting that $C$. tigrina immatures may occur in a similar habitat. However, as indicated in our conclusions, intense sampling from phytotelmata in Borneo has failed to find any immature Corethrella (other than C. calathicola in species of Nepenthes).

Adult female $C$. tigrina have been collected with frog-call traps and from calling males of two species of frogs (Table 7).

TAXONOMIC DISCUSSION: There is puzzling variation in the size of the female adult flagellomeres $1-3$, a feature which otherwise provides consistent evidence of differences between species of Corethrella. In specimens from Brunei each of these flagellomeres is short (Fig. 7E) and for most of those from Lanjak Entimau, Sarawak, each is relatively elongate (Fig. 7G). However, one specimen from Lanjak Entimau has flagellomeres that are somewhat intermediate in size; otherwise it is indistinguishable from three others collected at the same place and time with more elongate flagellomeres. We could find no other consistent differences between any of these specimens that would support considering them as separate species. Lim (2007) sequenced specimens from both Brunei and Lanjak Entimau and considered them the same, confirming the conclusion here that the differences in flagellomere lengths are intraspecific variation.

Corethrella tigrina is morphologically very similar to C. solomonis, a species known as adult females, pupae and larvae from the Solomon Islands but the latter is more setose and does not have a subapical wing band. The discovery of this new species, and especially the discovery of the male, provides phylogenetic information regarding its position within the genus. The presence of unequal midleg claws on the male indicates that $C$. tigrina and C. mckeeveri Colless form an unresolved clade with the remainder of the drakensbergensis species group (Borkent, 2008). Because of the striking similarity between the females of $C$. tigrina and C. solomonis, we have placed the latter species in this species group, considering it likely that the male of $C$. solomonis, once discovered will also have unequal midleg claws. These modified relationships are depicted in Fig. 19.

The male genitalia of $C$. tigrina is very similar to that of $C$. mckeeveri but differs in having the parameres tapering more abruptly near its apex. In addition, the apex of the gonostylus tapers more gradually than that of $C$. mckeeveri.

Corethrella tigrina has a subapical band on the wing that was considered a synapomorphy of the Neotropical quadrivittata species group by Borkent (2008). Here it is clearly an instance of homoplasy (i.e. C. tigrina is a member of the drakensbergensis species group and lacks the series of synapomorphies leading to the quadrivittata species group).

Males and females of $C$. tigrina have a small pale area posterior to the prescutal suture, somewhat similar to the derived condition described in character 28 (Borkent, 2008). It is either a precursor or a partially homoplastic expression of the derived condition. Because we did not reexamine material of many of the early lineages of Corethrella, we cannot confidently interpret this observation.

TYPES: Holotype, male adult on microscope slide, labeled "HOLOTYPE Corethrella tigrina Borkent and Grafe", "15 km S. Liang, Brunei, 7-VI-2007; frog-call trap with synthetic tone; U. Grafe; 075-5" (CNCI). 
Allotype, female adult on microscope slide, labeled as for holotype but "75-5/1". Paratypes on microscope slides: 1 from type locality (UBD); 3 q, $12 \mathrm{~km} \mathrm{~S}$. Liang, Brunei, $30 \mathrm{~m}, 8-\mathrm{VI}-2007,11-\mathrm{VI}-2007,23-\mathrm{V}-2007$, respectively (2, CNCI; 1 UBD); 1 \% , Lanjak Entimau $\left(112^{\circ} 4^{\prime} \mathrm{E}, 1^{\circ} 28^{\prime} \mathrm{N}\right)$, Sarawak, Malaysia, $80 \mathrm{~m}, 18-\mathrm{VI}-2008$ (CNCI); 4 + , from previous locality but 22-VI-2008 (CNCI); 1 , from previous locality but 19-VI-2008 (CNCI). Paratypes on pins: 4 + , $12.5 \mathrm{~km} \mathrm{~S}$. Liang, Brunei, $33 \mathrm{~m}, 30-\mathrm{I}-2009$ (CNCI); 1 + , from previous locality but 21-II2009 (CNCI); 1 + , from previous locality but 23-III-2009 (UBD); 1 + , 12 km S. Liang, Brunei, 30 m, 15-V-2011 (CNCI); 1 ㅇ, from previous locality but 10-I-2009 (CNCI); 4 , , KBFSC-walkway, Ulu Temburong NP, Brunei, 23-VII-2008 (CNCI); 6 \%, Sungai Mata Ikan, Ulu Temburong NP, Brunei, 110 m, 10-VII-2008 (5, CNCI; 1 UBD); 3 ㅇ, from previous locality but 12-VII-2008 (CNCI); 4 ㅇ, Sungai Baki, Ulu Temburong NP, Brunei, $120 \mathrm{~m}, 18-$ VII-2008 (CNCI); 1 \&, lower Sungai Apan Ulu Temburong NP, Brunei, 110 m, 13-VII-2008 (CNCI); 1 \%, from previous locality but 8-VII-2008 (CNCI); 2 \%, Belalong Münd (estuary), Ulu Temburong NP, Brunei, 4-VII-2008 (CNCI); 12 , 0.5 km S. Kuala Belalong Field Studies Centre, along Sungai Esu, Brunei, 60 m, 12-XI-2010 (CNCI); 1 , Ashton Trail in the Ulu Temburong NP, Brunei, $220 \mathrm{~m}, 24-\mathrm{V}-2010$ (CNCI); 1 \%, from previous locality but 15-VI-2010 (CNCI); 2 \%, Gunung Mulu NP, Sarawak, Malaysia, 30 m, 7-VII-2008 (CNCI); 12 q, Lanjak Entimau, $\left(112^{\circ} 4^{\prime} \mathrm{E}, 1^{\circ} 28^{\prime} \mathrm{N}\right)$, Sarawak, Malaysia, $80 \mathrm{~m}, 22-\mathrm{VI}-2008(\mathrm{CNCI}) ; 1 \stackrel{+}{\circ}$, from previous locality but 25-VI-2008 (CNCI); 1 , from previous locality but 24-VI-2008 (CNCI); 2 , from previous locality but 21VI-2008 (CNCI).

DERIVATION OF SPECIFIC EPITHET: The name tigrina (tiger) refers to the patterned thorax and legs of females of this species.

\section{Corethrella (Corethrella) lutea Borkent \& Grafe, new species}

(Figs. 2B, 4B, 6B, 8B, 9B, 12B, 13B, 15A)

DIAGNOSIS: Male adult. Unknown. Female adult. Only extant species of Corethrella in the Palaearctic, Oriental, Oceanian and northern Australasian Regions with the combination of a plain wing (Fig. 12B), flagellomeres 1-4 relatively short (Fig. 8B), scutum a lighter brown, contrasting with darker, mottled, pleura (Fig. 9B) and midfemur relatively thick (Fig. 9B) (compared to that of C. nippon Miyagi). Only extant species in Borneo with the combination of a plain wing (Fig. 12B) and a thorax with patterned pigmentation (especially the pleura) (Fig. 9B).

DESCRIPTION: Male adult. Unknown. Female adult. Descriptive statistics: See Tables 1-5. Head: Outline in anterior view somewhat circular (Fig. 6B). Coronal suture elongate, extending ventrally past ommatidia. Two large setae on frons between ventromedial area of ommatidia. Antenna uniformly medium brown; pedicel without distinctive elongate, stout setae. Antennal flagellomeres as in Fig. 8B; sensilla coeloconica on flagellomeres 1-2, 9-13, flagellomeres 1 with several, (10), 11-12 with 2 sensilla; flagellomere 13 with well-developed apical bifurcation. Clypeus (Fig. 6B) somewhat square. Mandible with moderately sized, pointed teeth. Palpus (Fig. 6B) brown; segment 3 swollen apically. Thorax (Fig. 9B): Scutum mostly light to medium brown, contrasting with darker brown pleura; scutellum, mediotergite, most of pleura dark brown, katepisternum with pale area at midheight, posterior portion of anepimeron paler, pale sclerites around base of wing. Posterior portion of dorsocentral row with 2 elongate setae situated somewhat lateral to one another. Prescutal suture elongate, thick, uninterrupted, extending to near dorsocentral row of setae. Anterior anepisternum divided diagonally by sinuous suture, dorsal portion about equal to ventral portion. Ventral portion of posterior anepisternum triangular, uniformly brown, with anterodorsal margin not thick. Wing (Fig. 12B): Apex of $\mathrm{R}_{2}$ slightly distal to apex of $\mathrm{M}_{1}$. Plain, without pattern of pigmented veins and/or scales; veins (other than costa and wing margin) with slender scales. Halter light to medium brown, equal to or somewhat lighter than scutellum. Legs (Fig. 9B): Light brown, forecoxa lighter than mid- , hind coxae, with about basal 0.4 of hind femur dark brown. With only slender setae, lacking scales. Midleg with thick, subapical setae on each of at least tarsomeres 1-3. Claws of each leg equal to those of others; equal on each leg, simple (without inner teeth). Empodia thick. Abdomen (Fig. 13B): Pale or light yellow, tergites 2-6 with anterolateral light brown pigmentation, sternites medium brown, 3-5 somewhat darker anteriorly, segment 7 light to dark brown, segments $8-9$ dark brown. Cercus light brown or pale.

Immature stages. Unknown (but see below).

DISTRIBUTION AND BIONOMICS: Corethrella lutea is known from Brunei and Sarawak, Malaysia from 30-200 m (Fig. 15A). Habitats include lowland peat swamps (including standing water and very slow moving streams) and steep terrain in mature mixed dipterocarp forest (Figs. 1A, D, E). They are relatively common in 
frog-call traps in Brunei (Grafe et al. 2008, as morphotype 2) and have been collected feeding on calling males of three species of frogs (Table 7).

TAXONOMIC DISCUSSION: The seven females noted by Borkent (2008) in the taxonomic discussion of $C$. nippon, collected from a tributary of Sungai Belalong, Temburong district, Brunei, are paratypes of $C$. lutea here.

Six females collected from the headquarters of Gunung Mulu National Park, Sarawak, Malaysia $\left(113^{\circ} 55^{\prime} \mathrm{E}, 4^{\circ}\right.$ $23^{\prime} \mathrm{N}$ ) on 14-XI-2009 with a frog-call trap differed from other $C$. lutea in having only a single sensilla coeloconicum on each of flagellomeres 10-12 and relatively shorter flagellomeres 2-3 (only one slide-mounted). For the present we consider these as variants of $C$. lutea.

The females of $C$. lutea are very similar to those of $C$. nippon but the latter have relatively thicker midfemora. Although the male of $C$. lutea is unknown, and therefore we do not know if this species shares the only synapomorphy for the group (unequal male midclaws), we consider it a member of the drakensbergensis species group (Fig. 19). It has synapomorphy 25 but lacks 26 and 27 (hence, an unresolved lineage along with $C$. nippon and C. harrisoni Freeman (Borkent, 2008)).

TYPES: Holotype, female adult on microscope slide, labeled "HOLOTYPE Corethrella lutea Borkent and Grafe", "12 km S. Liang, Brunei, 30 m, 10-V-2007; on Hylarana glandulosa; U. Grafe; 18-2/3", "18-2/3 261107" (CNCI). Paratypes on microscope slides: 1 labeled as for holotype but 18-2/2, 231007 (CNCI); 3 from type locality but 21-IV-2007, 30-IV-2007, 15-V-2007 (CNCI); 1 \&, 15 km S. Liang, Brunei, 40 m, 9-V-2007 (CNCI); 1 , $17 \mathrm{~km} \mathrm{~N}$. Labi, Brunei, $40 \mathrm{~m}, 6-\mathrm{IV}-2009$ (UBD); 1 क , from previous locality but 8-IV-2009 (CNCI); 7 , tributary of Sungai Belalong, Temburong district, Brunei, $110 \mathrm{~m}, 115^{\circ} 09^{\prime} \mathrm{E}, 4^{\circ} 33^{\prime} \mathrm{N}, 50 \mathrm{~m}, 7-\mathrm{VIII}-2006$ (6 CNCI; 1 UBD); 1 , Gunung Mulu NP, Sarawak, Malaysia, 30 m, 14-XI-2008 (CNCI); 5 q, Matang, Sarawak, Malaysia, 200 m, 4-IX-2008 (CNCI). Paratypes on pins: 1 , , Kuala Belalong Field Studies Centre, Brunei, 50 m, 17-XI-2010 (CNCI); 1 + , Belalong Münd (estuary), Ulu Temburong NP, Brunei, 4-VII-2008 (CNCI); 1 , lower Sungai Apan, Ulu Temburong NP, Brunei, $110 \mathrm{~m}, 8$-VII-2008 (CNCI); 1 \%, from previous locality but 13-VII-2008 (CNCI); 8 , $12.5 \mathrm{~km}$ S. Liang, Brunei, 33 m, 28-I-2011 (6, CNCI; 2 UBD); 12 + , from previous locality but 2-IV-2009 (CNCI); 6 ㅇ, 20 km N. Labi, Luagan Lalak Forestry Rec. Site, Brunei, 6-XI-2010 (CNCI); 2 ㅇ, Sungai Ingei, 8.2 km S. Melilas, Brunei, $50 \mathrm{~m}, 9-\mathrm{VII}-2010$ (CNCI); 11 q, from previous locality but12-VII-2010 (CNCI); 4 q, from previous locality but VII-2010 (CNCI); 2 क , from previous locality but 10-VII-2010 (CNCI); 5 \&, Gunung Mulu NP, Sarawak, Malaysia, 30 m,14-XI-2008 (CNCI); 3 \%, from previous locality but 26-XI-2009 (CNCI).

DERIVATION OF SPECIFIC EPITHET: The name lutea (yellow) refers to the overall yellowish appearance of the females of this species.

\section{Corethrella (Corethrella) nanoantennalis Borkent \& Grafe, new species}

(Figs. 3A, 4C, 6C, 8C, 9C, 12C, 13C, 14A)

DIAGNOSIS: Male adult. Unknown. Female adult. Only extant species of Corethrella in the Palaearctic, Oriental, Oceanian and northern Australasian Regions with the combination of no pigmentation distal to a single distinct midlength wing band (no subapical band) (Fig. 12C), flagellomeres 1-4 short, each notably shorter than flagellomere 5 (Fig. 8C), with non-discrete darker pigmentation on the basal 0.5 of the midfemur and basal 0.3-0.4 of the hind femur, uniformly yellow or light brown hind tibia, and abdominal tergites each with an anterior darker band (Fig. 9C). Only extant species in Borneo with the combination of flagellomeres 1-4 short (Fig. 8C) and palpal segments 1-2 dark brown and contrasting with pale segments 3-4 (5 grading from pale to medium brown) (Fig. 6C).

DESCRIPTION: Male adult. Unknown. Female adult. Descriptive statistics: See Tables 1-5. Head: Outline in anterior view somewhat circular (Fig. 6C). Coronal suture elongate, extending ventrally past ommatidia. Two large setae on frons between ventromedial area of ommatidia. Antenna uniformly medium brown; pedicel without distinctive elongate, stout setae. Antennal flagellomeres as in Fig. 8C; sensilla coeloconica on flagellomeres 1-2, 9-13, only flagellomere 1 with more than one; flagellomere 13 with well-developed apical bifurcation. Clypeus (Fig. 6C) somewhat square. Mandible with very small, pointed teeth. Palpus (Fig. 6C) with segments 1-2 dark brown, very base of segment 3 dark brown or pale, most or all of segment 3, segments 4 light brown, segment 5 grading from light to medium brown apically; segment 3 swollen apically. Thorax (Fig. 9C): Scutum, scutellum mostly light to medium brown, contrasting with darker brown pleura; pale sclerites around base of wing. Posterior portion of dorsocentral row with 2 elongate setae situated somewhat lateral to one another. Prescutal suture elongate, thick, uninterrupted, extending to near dorsocentral row of setae. Anterior anepisternum divided 
diagonally by sinuous suture, dorsal portion about equal to ventral portion. Ventral portion of posterior anepisternum triangular, uniformly brown, with anterodorsal margin not thick. Wing (Fig. 12C): Apex of $\mathrm{R}_{2}$ slightly distal to apex of $\mathrm{M}_{1}$. Anterior margin with differently, discretely pigmented scales (indicating anterior margin of midlength band), with midlength band, with darker more basal scales restricted to vein $\mathrm{C}$, Sc, slightly in more posterior veins, with basal scales on posterior margin of wing dark; veins (other than costa and wing margin) with well-developed scales. Halter medium brown, equal to scutellum. Legs (Fig. 9C): Light brown, with about basal 0.5 of forefemur slightly darker, about basal 0.5 of midfemur darker, about basal $0.2-0.3$ of hind femur darker; with darker pigmentation not discrete. With only slender setae, lacking scales. Midleg with thick, subapical setae on each of at least tarsomeres 1-3. Claws of each leg equal to those of others; equal on each leg, simple (without inner teeth). Empodia thick. Abdomen (Fig. 13C): Tergites 2-7 pale with anterolateral corners more darkly pigmented, sternites light brown with sternites 2-6 with posterior margin pale. Segments 8-9 medium brown. Cercus pale.

Immature stages. Unknown.

DISTRIBUTION AND BIONOMICS: Corethrella nanoantennalis is known from female specimens collected in Ulu Temburong National Park in Brunei at $110 \mathrm{~m}$ and Lanjak Entimau, Sarawak, Malaysia at $80 \mathrm{~m}$ (Fig. 14A). Habitats are found in steep terrain in mature mixed dipterocarp forest (as in Fig. 1F). One female was collected with a frog-call trap broadcasting $4 \mathrm{kHz}$, the maximum frequency $(\mathrm{Hz})$ attractive to any Corethrella species (Grafe et al. unpublished). The others were collected feeding on calling males of two species of frogs (Table 7).

TAXONOMIC DISCUSSION: We have placed C. nanoantennalis in the drakensbergensis species group based on the presence of synapomorphies 21-23 and its plesiomorphic complete prescutal suture (character 28) (Fig. 19). It could equally form an earlier lineage anywhere between the nodes defined by Borkent (2008: fig. 141) by "21-23" and "26, 28-30". Discovery of the male will help resolve its phylogenetic position.

TYPES: Holotype, female adult on microscope slide, labeled "HOLOTYPE Corethrella nanoantennalis Borkent and Grafe", "Sungai Mata Ikan, Ulu Temburong National Park, Brunei, 10-VII-2008; on M. nasuta, U. Grafe; 11n1", "11n1 050109" (CNCI). Paratypes on microscope slides: 4 , Lanjak Entimau, Sarawak, Malaysia, $112^{\circ} 4^{\prime} \mathrm{E}, 1^{\circ} 28^{\prime} \mathrm{N}, 80 \mathrm{~m}, 24-\mathrm{VI}-2008$ (CNCI); 1 , from previous locality but 18-VI-2008 (UBD). Paratypes on pins: 11 , Lanjak Entimau, Sarawak, Malaysia, $112^{\circ} 4^{\prime} \mathrm{E}, 1^{\circ} 28^{\prime} \mathrm{N}, 80 \mathrm{~m}, 24-\mathrm{VI}-2008$ (9, CNCI; 2 UBD); 1 ㅇ, from previous locality but $18-\mathrm{VI}-2008$ (CNCI).

DERIVATION OF SPECIFIC EPITHET: The name nanoantennalis (small, antenna) refers to the relatively short flagellomeres $1-3$ of females of this species.

\section{Corethrella (Corethrella) bipigmenta Borkent \& Grafe, new species}

(Figs. 2C, 4D, 6D, 8D, 9D, 12D, 13D, 15B)

DIAGNOSIS: Male adult. Unknown. Female adult. Only extant species of Corethrella in the Palaearctic, Oriental, Oceanian and northern Australasian Regions with the combination of no pigmentation distal to the single distinct midlength wing band (no subapical band) (Fig. 12D), flagellomeres 1-4 elongate, each similar in length to flagellomere 5 (Fig. 8D), with non-discrete darker pigmentation on the basal 0.5 of the midfemur and basal $0.3-0.4$ of the hind femur, uniformly yellow or light brown hind tibia (Fig. 9D), and abdominal tergites each with anterolateral darker pigmentation (Fig. 13D). Only extant species in Borneo with the combination of flagellomeres 1-4 elongate, each similar in length to flagellomere 5 (Fig. 8D) and palpal segments 1 and 2 dark brown and contrasting with pale segments 3 and 4 (5 grading from pale to medium brown) (Fig. 6D).

DESCRIPTION: Male adult. Unknown. Female adult. Descriptive statistics: See Tables 1-5. Head: Outline in anterior view somewhat circular (Fig. 6D). Coronal suture elongate, extending ventrally past ommatidia. Two large setae on frons between ventromedial area of ommatidia (as in Fig. 16B). Antenna uniformly medium brown; pedicel with distinctive elongate, stout setae. Antennal flagellomeres as in Fig. 8D; sensilla coeloconica on flagellomeres 1-2, 9-13, only flagellomere 1 with more than one; flagellomere 13 with well-developed apical bifurcation. Clypeus somewhat square. Mandible with moderately small, pointed teeth. Palpus (Fig. 6D) with segments 1-2 dark brown, segments 3-5 light brown, segment 5 darker apically; segment 3 swollen apically. Thorax (Fig. 9D): Scutum, scutellum mostly light to medium brown, contrasting with darker brown pleura; pale sclerites around base of wing. Posterior portion of dorsocentral row with 2 elongate setae situated somewhat lateral to one another. Prescutal suture elongate, thick, uninterrupted, extending to near dorsocentral row of setae. 
Anterior anepisternum divided diagonally by sinuous suture, dorsal portion about equal to ventral portion. Ventral portion of posterior anepisternum triangular, uniformly brown, with anterodorsal margin not thick. Wing (Fig. 12D): Apex of $R_{2}$ slightly distal to apex of $M_{1}$. Anterior margin with differently, discretely pigmented scales (indicating anterior margin of midlength band), with midlength band, with darker more basal scales restricted to vein $\mathrm{C}$, Sc, slightly in more posterior veins, with basal scales on posterior margin of wing dark; veins (other than costa and wing margin) with well-developed scales. Halter medium brown, equal to or slightly lighter than scutellum. Legs (Fig. 9D): Light brown, with about basal 0.5 of forefemur slightly darker, about basal 0.5 of midfemur darker, about basal $0.3-0.4$ of hind femur darker; with darker pigmentation not discrete. With only slender setae, lacking scales. Midleg with thick, subapical setae on each of at least tarsomeres 1-3. Claws of each leg equal to those of others; equal on each leg, simple (without inner teeth). Empodia thick. Abdomen (Fig. 13D): Tergites 2-7 pale or light brown with anterolateral corners more darkly pigmented, tergite 8 pale or light brown, sternites light brown with sternites $2-6$ with anterior portions medium brown, posterior margins pale, sternites 7-8 medium brown. Cercus medium light brown.

Immature stages. Unknown.

DISTRIBUTION AND BIONOMICS: Corethrella bipigmenta is known only from steep terrain in the mature mixed dipterocarp forest (Figs. 1E, F) of Ulu Temburong National Park, Brunei, at elevations of 50-120 meters (Fig. 15B). Three females in the type series were collected on 22-VII-2006 from a calling male Megophrys nasuta (Schlegel) at 8:30 PM (Fig. 2C). A photograph by the second author (Fig. 2C) shows numerous identical looking female Corethrella on and surrounding the frog: seven were on the legs, two were on the back, and at least 10 were on nearby substrate. Further specimens were collected from other M. nasuta and one other frog species (Table 7). This species has not yet been collected with a frog-call trap.

TAXONOMIC DISCUSSION: The three type specimens of C. bipigmenta were noted by Borkent (2008) in the taxonomic discussion of $C$. nippon (but mistakenly stated as coming from Sungai Belalong). This species is very similar to $C$. nanoantennalis but differs in the relative lengths of flagellomeres 1-4.

Corethrella bipigmenta is placed in the drakensbergensis species group for the same reason that $C$. nanoantennalis was placed there, along with the same caveats (Fig. 19). However, it appears that this species has synapomorphy 40 (pedicel with strong setae), which would place it elsewhere in the phylogeny of the Corethrellidae. We are inclined however, to question the validity of this synapomorphy - it is often difficult to interpret consistently in specimens and its distribution may have been misrepresented by Borkent (2008).

TYPES: Holotype, female adult on microscope slide, labeled "HOLOTYPE Corethrella bipigmenta Borkent and Grafe", "Tributary of Sungai Temburong in Temburong district of Brunei Darussalam, $115^{\circ} 09^{\prime} \mathrm{E}, 4^{\circ} 333^{\prime} \mathrm{N}$, 22-VIII-2006, U. Grafe, CD2069" (CNCI). Paratypes on microscope slides: 2 q, labeled as for holotype (1, CNCI; 1 UBD). Paratypes on pins: 2 9, from Kuala Belalong, Ulu Temburong NP, Brunei, 50 m, 23-VII-2007 (CNCI); 4 , from Sungai Esu, Ulu Temburong NP, Brunei, 60 m, 11-VII-2008 (CNCI); 2 , from Sungai Baki, Ulu Temburong NP, Brunei, 120 m, 18-VII-2008 (1 CNCI; 1 UBD); 1 \%, Sungai Mata Ikan, Ulu Temburong NP, Brunei, 110 m, 10-VII-2008, (UBD).

DERIVATION OF SPECIFIC EPITHET: The name bipigmenta (two, pigment) refers to differently pigmented palpal segments 1-2 (dark) and segments 3-5 (lightly pigmented) of females of this species.

\section{Corethrella (Corethrella) brunnea Borkent}

(Figs. 4E, 12E, 14B)

Corethrella brunnea Borkent 2008:56. Type locality: $1^{\text {st }}$ Div., Semongoh Forest Reserve, $1^{\circ} 25^{\prime}$ N $110^{\circ} 17^{\prime} E$, Sarawak, Malaysia. Holotype $q(\mathrm{BMNH})$.

DIAGNOSIS: Male adult. Unknown. Female adult. Only extant species of Corethrella in the Palaearctic, Oriental, Oceanian and northern Australasian Regions with the combination of about 23 setae on the clypeus, a plain wing (no pattern) (Fig. 12E), wing with well-developed scales on all the wing veins, and an entirely dark brown thorax. Only extant species in Borneo with the combination of about 23 setae on the clypeus, a plain wing (no pattern) (Fig. 12E), and an entirely dark brown thorax (Fig. 4E).

DESCRIPTION AND TAXONOMIC DISCUSSION: This species, known only from the female adult holotype from Sarawak, Malaysia (Fig. 14B), was described and interpreted by Borkent (2008). It is a member of the drakensbergensis species group (Fig. 19). The type locality is in lowland mixed dipterocarp forest. 
DIAGNOSIS: Male adult. Unknown. Female adult. Only extant species of Corethrella in the Palaearctic, Oriental, Oceanian and northern Australasian Regions with the combination of a plain wing (Fig. 12F), flagellomeres 1-4 elongate (Fig. 8F) and the scutum a lighter brown, contrasting with darker pleura (Fig. 10A). Only extant species in Borneo with the combination of a plain wing (Fig. 12F) and the scutum a lighter brown, contrasting with a uniformly darker pleura (Fig. 10A).

DESCRIPTION: Male adult. Unknown. Female adult. Descriptive statistics: See Tables 1-5. Head: Outline in anterior view somewhat circular (Fig. 6E). Coronal suture elongate, extending ventrally past ommatidia. Two large setae on frons between ventromedial area of ommatidia. Antenna uniformly medium brown; pedicel without distinctive elongate, stout setae. Antennal flagellomeres as in Fig. 8F; sensilla coeloconica on flagellomeres 1-2 (3), 7-13, only flagellomere 1 with more than one; flagellomere 13 with well-developed apical bifurcation. Clypeus (Fig. 6E) somewhat square. Mandible with moderately small, pointed teeth. Palpus (Fig. 6E) brown; segment 3 swollen apically. Thorax (Fig. 10A): Scutum mostly light to medium brown, contrasting with darker brown pleura; scutellum, mediotergite, most of pleura dark brown, pale sclerites around base of wing. Posterior portion of dorsocentral row with 2 elongate setae situated somewhat lateral to one another. Prescutal suture elongate, thick, uninterrupted, extending to near dorsocentral row of setae. Anterior anepisternum divided diagonally by sinuous suture, dorsal portion about equal to ventral portion. Ventral portion of posterior anepisternum triangular, uniformly brown, with anterodorsal margin not thick. Wing (Fig. 12F): Apex of $R_{2}$ slightly distal to apex of $\mathrm{M}_{1}$. Plain, without pattern of pigmented veins and/or scales; veins (other than costa and wing margin) with slender scales. Halter dark brown, equal to scutellum. Legs (Fig. 10A): Light brown, with about basal 0.5 hind femur slightly darker. With only slender setae, lacking scales. Midleg with thick, subapical setae on each of at least tarsomeres 1-3. Claws of each leg equal to those of others; equal on each leg, simple (without inner teeth). Empodia thick. Abdomen (Fig. 13E): Medium brown, with tergites and sternites uniformly medium brown or at least tergites 2-5 with posterior margins pale, sternites medium brown, segments 8-9 medium brown. Cercus medium brown.

Immature stages. Unknown.

DISTRIBUTION AND BIONOMICS: Corethrella mitra is known from female specimens collected in Ulu Temburong National Park in Brunei and the Malaysian states of Sabah and Sarawak 60-340 m (Fig. 16B). Habitats are in steep terrain in mature mixed dipterocarp forest (Fig. 1E, F). They were collected feeding on calling males of three species of frogs and have not yet been collected with a frog-call trap (Table 7).

TAXONOMIC DISCUSSION: Female adults have variably pigmented abdomens with some from Kuala Belalong Field Study Centre or nearby Sungai Esu in Ulu Temburong NP, Brunei having uniformly pigmented abdomens and others, like $C$. mitra from elsewhere, with at least tergites 2-5 brown anteriorly and pale posteriorly. We initially thought these two forms represented two species (the feature separates other species) but could find no other differences. The two forms were collected together on a single evening at Sungai Esu and we presently consider this to be intraspecific variation.

Corethrella mitra is placed in the drakensbergensis species group for the same reasons and with the same limitations as indicated for C. nanoantennalis (Fig. 19). The uniform wing of C. mitra (synapomorphy 25) indicates that it belongs further within the group (Fig. 19). This uniform wing, however, is susceptible to homoplasy and is, at best, a weak indicator of relationship. Overall, C. mitra is otherwise quite similar to $C$. nanoantennalis and C. bipigmenta.

TYPES: Holotype, female adult on microscope slide, labeled "HOLOTYPE Corethrella mitra Borkent and Grafe", "lower Sungai Apan, Ulu Temburong National Park, Brunei, 4-vii-2008; on L. leporinus, U. Grafe; 6" (CNCI). Paratypes on microscope slides: 2 q, labeled as for holotype but 1-vii-2008 (1, CNCI; 1 UBD). Paratypes on pins: 2 , $0.5 \mathrm{~km}$ S. Kuala Belalong Field Studies Centre, along Sungai Esu, Brunei, 60 m, 12-XI-2010 (CNCI); 2 , Kuala Belalong Field Studies Centre, Brunei, 50 m,16-17-XI-2010 (CNCI); 1 q, lower Sungai Apan, Ulu Temburong National Park, Brunei, 110 m, 19-VII-2008 (CNCI); 2 q, from previous locality but 1-VII-2008 (CNCI; UBD); 2 \%, from previous locality but 8-VII-2008 (CNCI; UBD); 1 +, SMI, Belalong, Ulu Temburong NP, Brunei, 26-VI-2010 (CNCI); 1 q, 34 km NE Kalabakan, Sabah, Malaysia, 340 m, 26-VIII-2011 (CNCI); 4 \%, 30 km NE Kalabakan, Sabah, Malaysia, 300 m, 17-V-2011 (CNCI); 1 \%, Lanjak Entimau, $\left(112^{\circ} 4^{\prime} \mathrm{E}, 1^{\circ} 28^{\prime} \mathrm{N}\right)$, Sarawak, Malaysia, 80 m, 25-VI-2008 (CNCI). 
DERIVATION OF SPECIFIC EPITHET: The name mitra (crown) refers to the relatively paler scutum compared to the darker pleura of females of this species.

\section{Corethrella (Corethrella) unizona Borkent, Grafe \& Miyagi, new species}

(Figs. 5A, 6F, 8G, 10B, 12G, 13F, 14A)

DIAGNOSIS: Male adult. Unknown. Female adult. Only extant species of Corethrella in the Palaearctic, Oriental, Oceanian and northern Australasian Regions with the combination of the palpus and clypeus equally dark brown (Fig. 6F), a single, midlength wing band (Fig. 12G), tergites 2-6 uniformly brown (Fig. 13F), midfemur either uniformly brown or lighter apically (non-discrete), and hind tibia with dark pigmentation at apex (in some very light pigmentation basally) (Fig. 10B). Only extant species in Borneo with the combination of the palpus and clypeus equally dark brown, a single, midlength wing band, hind tibia with dark pigmentation at apex (in some very light pigmentation basally), and with tergites 2-6 uniformly brown.

DESCRIPTION: Male adult. Unknown. Female adult. Descriptive statistics: See Tables 1-5. Head: Outline in anterior view somewhat circular (Fig. 6F). Coronal suture elongate, extending ventrally past ommatidia. Two large setae on frons between ventromedial area of ommatidia. Antenna uniformly medium brown; pedicel with distinctive elongate, stout setae. Antennal flagellomeres as in Fig. 8G; sensilla coeloconica on flagellomeres 1, 9-13, flagellomeres 1 with several, (9), 10-12 with 2 sensilla; flagellomere 13 with well-developed apical bifurcation. Clypeus (Fig. 6F) wide. Mandible with very small, pointed teeth. Palpus (Fig. 6F) medium brown; segment 3 swollen apically. Thorax (Fig. 10B): Uniformly medium brown. Posterior portion of dorsocentral row with 2 elongate setae situated somewhat lateral to one another. Prescutal suture elongate, thick, interrupted by area of pale cuticle, extending nearly to dorsocentral row of setae. Anterior anepisternum divided diagonally by sinuous suture, dorsal portion about equal to ventral portion. Ventral portion of posterior anepisternum triangular, uniformly brown, with anterodorsal margin thick. Wing (Fig. 12G): Apex of $R_{2}$ slightly distal to apex of $M_{1}$. Anterior margin with differently, discretely pigmented scales (indicating anterior margin of basal, midlength bands), with basal, midlength bands; veins (other than costa and wing margin) with well-developed scales. Halter medium brown, equal to scutellum. Legs (Fig. 10B): Medium brown, with poorly defined paler areas on apex of fore-, midfemur and base of fore-, midtibia in some, with paler area on apical about 0.4-0.7 of hind femur, hind tibia in some with narrow basal band of darker pigmentation, very apex of hind tibia with dark pigmentation. With only slender setae, lacking scales. Midleg with thick, subapical setae on each of at least tarsomeres 1-3. Claws of each leg equal to those of others; equal on each leg, simple (without inner teeth). Empodia slender. Abdomen (Fig. 13F): Uniformly medium brown, with segments 8-9. Cercus darker brown.

Immature stages. Unknown.

DISTRIBUTION AND BIONOMICS: Corethrella unizona is known from female specimens from one locality in Brunei and two closely approximated sites in Sarawak 30-1083 m (Fig. 14A). Habitats include lowland peat swamp and mid-elevation peat swamp or a nearby river (Fig. 1G). Specimens were collected with frog-call traps, always in very low numbers on a given evening and have not been observed feeding on frogs (Table 7).

TAXONOMIC DISCUSSION: Corethrella unizona belongs to the clade defined by synapomorphies 39-44 (Borkent 2008: fig. 141) (Fig. 19). It has all these features except for 44 which could not be scored because it depends on knowledge of the male (unknown for C. unizona). There were no further features which would allow for further placement phylogenetically.

TYPES: Holotype, female adult on microscope slide, labeled "HOLOTYPE Corethrella unizona Borkent, Grafe and Miyagi", "15 km S. Liang, Brunei, 7-VI-2007; frog-call trap with synthetic tone + 200, U. Grafe; 76-4/1 DNA extracted", "076-4/1 080108" (CNCI). Paratypes on microscope slides: 1 + , labeled as for holotype but 22V-2007, 49-3/1, 49-3/1 301107 (UBD); 15 क, Bario, Sarawak, Malaysia, 1060 m, on several dates: 29-VIII-2008, 2, 5, 6-IX-2007, 5,10-IX-2009 (14, CNCI; 1, UBD). Paratype on pin: 1 , Pa Umor, 5 km E. Bario, Sarawak, Malaysia, $1083 \mathrm{~m}, 25-\mathrm{XI}-2010$ (CNCI).

DERIVATION OF SPECIFIC EPITHET: The name unizona (single belt) refers to the single wing band of females of this species. 
Corethrella (Corethrella) calathicola Edwards

(Figs. 5B, 7A, F, H, 8H, 10C, 11C, 12H, 13G, 18)

Corethrella calathicola Edwards 1930:529. Type locality: Singapore, Malaysia. Lectotype male (BMNH). Mogi and Yong 1992:180; Borkent 2008:145.

DIAGNOSIS: Male and female adults: Only extant species of Corethrella in the Oriental, Australasian, and Oceanic Regions with the combination of a pale or light brown palpus (contrasting with dark brown clypeus) (Fig. 7A), patterned wing (with a midlength band, darker where $\mathrm{R}_{1}$ joins the costa) (Fig. 12H), uniformly dark brown midfemur, hind tibia with dark pigmentation at base and apex (Fig. 10C), and with abdominal tergites 2-6 uniformly brown (Fig. 13G). Only extant species in Borneo with the combination of well-developed scales on midfemur (Fig. 11C); also only species with palpus entirely pale and contrasting with a dark clypeus (Fig. 7A) and with distinct dark pigmentation at both base and apex of hind tibia (Fig. 10C).

DESCRIPTION: This species was redescribed by Borkent (2008), but see Taxonomic Discussion below.

DISTRIBUTION AND BIONOMICS: Corethrella calathicola is known from Singapore, Malaysia, Indonesia and Brunei (Fig. 18) at altitudes ranging from 1-1083 m. In Borneo, it has been recorded only from Brunei, Sarawak, Malaysia and eastern Kalimantan, Indonesia. This is the only species of Corethrella recorded from and restricted to species of Nepenthes. Its biology has been summarized by Borkent (2008). Habitats include lowland and mid-elevation peat swamp in Brunei (Fig. 1A). Previously recorded from N. ampullaria (Jack), there were earlier records of an unnamed Corethrella species from $N$. bicalcarata (Hook). Here we confirm that $C$. calathicola occurs in N. bicalcarata in Brunei as well as in N. veitchii (Hook) in the Bario highlands of Sarawak. We have found it commonly in N. ampullaria in Brunei as well (Fig. 1B). Immatures of C. calathicola were found in these three species of Nepenthes only when they were on or near the ground (both authors, pers. obs.; Miyagi pers. comm.).

We reared nine males and five females from 14 larvae collected from N. ampullaria and N. bicalcarata. Aside from rearings, we examined female adults collected with frog-call traps in Brunei and Lanjak Entimau, Sarawak, as well as feeding on a calling male of one species of frog (Table 7). We examined the specimens reared from $N$. ampullaria at Matang, Sarawak, Malaysia noted by Miyagi et al. (2009).

TAXONOMIC DISCUSSION: Borkent (2008) described the pigmentation of the male abdomen as having "segments 1-7, 9 light to medium brown, segment 8 pale". Some of our fresh slide-mounted material matches this description but at least some fresh material in alcohol or pinned (from Brunei, some from Bario, Sarawak) had tergites 2-7 pale and contrasting with a dark tergite 1 and darker sternites. Upon treatment with $\mathrm{KOH}$, some specimens with lighter tergites had tergites and sternites appeared uniformly medium brown but in others, the lighter tergites were discernible. We are puzzled as to why there was this difference between alcohol and slidemounted material when this is not the case with other Corethrella specimens studied by Borkent (2008). The abdomens of all females were entirely medium to dark brown, so that there is a clear sexual dimorphism in pigmentation of the abdomen in at least some members of C. calathicola. More study and specimens are needed to further interpret this variation.

There was significant variation in the relative sizes of flagellomeres 1-3 in the female C. calathicola we examined. In specimens from Brunei they were relatively short (Fig. 7F), compared to those from Matang, Sarawak (Fig. 7H) and other sites recorded and illustrated by Borkent (2008, fig. 30H).

Borkent (2008) designated the lectotype for $C$. calathicola and listed the paralectotypes known to him. There are an additional two larvae that should be considered paralectotype specimens on separate slides in the BMNH. Both are from Singapore and taken from a "pitcher plant" (Zoe Adams, pers. comm.).

Corethrella calathicola belongs to the appendiculata species group, a group that otherwise includes only New World species occupying treeholes and is the sister species of the Neotropical C. melanica Lane and Aitken (Borkent 2008).

MATERIAL EXAMINED: In addition to the material listed by Borkent (2008), we examined the following on microscope slides: $1 \hat{\jmath}, 12 \mathrm{~km}$ S. Liang, Brunei, $30 \mathrm{~m}$, 9-VIII-2009, from Nepenthes ampullaria (CNCI); 1 , from previous locality but 18-V-2007 (CNCI); 2 ㅇ, 15 km S. Liang, Brunei, 40 m, 12-V-2007 (1, CNCI; 1, UBD); 2 ㅇ, from previous locality but 5-VI-2207 (CNCI); 3 f from previous locality but 22-V-2207 (CNCI); 2 o , $17 \mathrm{~km} \mathrm{S.}$ Liang, Brunei, 40 m, 6-IV-2009 (1, CNCI; 1, UBD); 2 $َ$, Bario, Sarawak, Malaysia, 1060 m,6-IX-2009, reared from Nepenthes veitchii (CNCI); $1 \hat{\jmath}$, from previous locality but 17-IX-2006 (CNCI); $1 \hat{\jmath}$, Pa Umor, 5 km E. 
Bario, $03^{\circ} 44.118^{\prime} \mathrm{N} 115^{\circ} 30.404^{\prime} \mathrm{E}, 1083 \mathrm{~m}$, Sarawak, Malaysia, 17-IX-2006, reared from 'pitcher plant' (CNCI); 2

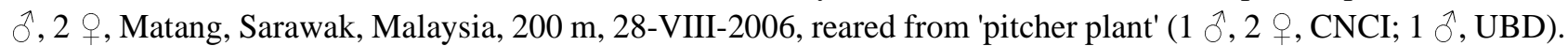
Pinned specimens: 1 + , 12.5 km S. Liang, Brunei, 33 m, 10-I-2009 (CNCI); 2 O, 12 km S. Liang, Brunei, 30 m, 9VIII-2009 (CNCI); $1 \hat{\jmath}, 2$, previous locality but 23-VII-2009 (2 $\odot$, CNCI; $1 \hat{\jmath}$, UBD); $1 \hat{\jmath}, 1$, previous

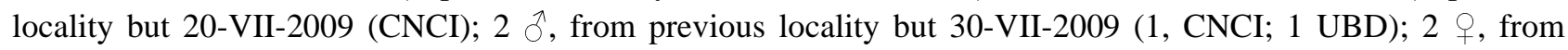

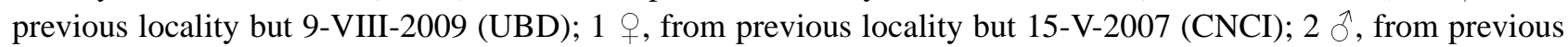
locality but 25-VII-2009 (CNCI); 4 +, 15 km S. Liang, Brunei, 40 m, 22-V-2007 (CNCI); 1 \%, 17 km S. Liang, Brunei, 40 m, 17-V-2007 (CNCI); 1 + , Lanjak Entimau, Sarawak, Malaysia, 80 m, 28-II-2011 (SMKM).

\section{Corethrella (Corethrella) pauciseta Borkent}

(Figs. 5C, 7B, 8I, 10D, 12I, 13H, 17)

Corethrella pauciseta Borkent, 2008:191. Type locality: Hospital Ck., Wau, NE New Guinea. Holotype female (BPBM).

DIAGNOSIS: Male adult. Unknown. Female adult. Only extant species of Corethrella in the Palaearctic, Oriental, Oceanian and northern Australasian Regions with the combination of a clypeus with 2-5 setae, plain wing (Fig. 12I), veins (other than along the wing margin) with definite but slender scales, and uniformly medium to dark brown thorax (Fig. 10D). Only extant species in Borneo with the combination of a plain wing (Fig. 12I), uniformly dark brown thorax (Fig. 10D), and clypeus with 2-5 setae.

DESCRIPTION: Male adult. Unknown. Female adult. As described by Borkent (2008), with the following modifications based on Brunei material. Descriptive statistics: See Tables 1-5. Head: (as in Fig. 7B). Pedicel with distinctive elongate, stout setae. Antennal flagellomeres medium brown; flagellomeres as in Fig. 8I; sensilla coeloconica on flagellomeres 1, 8-13, only flagellomere 1 with more than one; flagellomere 13 with welldeveloped apical bifurcation. Clypeus (Fig. 7B) wider than long. Palpus (Fig. 7B) medium brown; segment 3 somewhat thicker at midlength. Thorax (Fig. 10D): Posterior portion of dorsocentral row with 2 elongate setae situated somewhat lateral to one another. Wing (Fig. 12I). Legs (Fig. 10D): Medium brown, but slightly lighter in some on apex of hind femur, bases of fore-, mid-, hind tibiae. Abdomen (Fig. 13H): Uniformly medium to dark brown.

\section{Immature stages. Unknown.}

DISTRIBUTION AND BIONOMICS: Corethrella pauciseta is known from a single specimen (holotype) from Papua New Guinea at an altitude of $1250 \mathrm{~m}$ and from numerous specimens from Brunei and Sarawak, Malaysia (Fig. 17) at altitudes of 30-120 m. Habitats include lowland peat swamps (including standing water and very slow moving streams) and steep terrain in mature mixed dipterocarp forest (Fig. 1A). It is uncertain how the holotype female was collected. Female adult $C$. pauciseta are the most common species collected with frog-call traps in the area south of Liang, Brunei (= Labi Road of Grafe et al. 2008; as morphotype 1). Females have been found feeding on calling males of four species of frogs in Brunei and Sarawak (Table 7).

Sixteen female $C$. pauciseta were collected $12.5 \mathrm{~km} \mathrm{~S}$. Liang, Brunei $\left(04^{\circ} 34.935^{\prime} \mathrm{N} 114^{\circ} 30.300^{\prime} \mathrm{E}, 20 \mathrm{~m}\right)$ on 8 XI-2010 from vegetation hanging about 1-2 meters above a shallow pool (about 3X6 meters in size) at mid afternoon. Females did not have mature eggs and larvae, pupae and pupal exuviae were absent from the pool, suggesting that these were not recently emerged adults. One possibility is that they were waiting to feed on calling frogs later that night but we have no evidence this was so.

TAXONOMIC DISCUSSION: Borkent (2008) indicated that a female from Brunei was similar to $C$. pauciseta (known only from the female holotype) but likely was an undescribed species. Here, in spite of significant size differences between the Papua New Guinea holotype (wing length $=1.63 \mathrm{~mm}$ ) and the specimens from Brunei (wing length $=0.98-1.06 \mathrm{~mm}$ ), we consider them conspecific. Now that more material is available from Brunei, we no longer consider the difference in number of clypeal setae to be significant (5 in the holotype, 2-3 in specimens from Brunei), especially considering the size differences. In addition, the holotype has one anepimeral seta compared to 2-5 setae in material from Brunei. Further material, especially from Papua New Guinea would be helpful in resolving these small meristic differences.

Borkent (2008) stated that $C$. pauciseta did not have distinctive elongate pedicel setae but fresh material from Brunei shows that they actually do. The habitus of the holotype from Papua New Guinea was poor. 
Specimens from Ulu Temburong National Park in eastern Brunei appeared lighter in overall pigmentation compared to those from the Liang - Labi area in western Brunei. We presently consider this intraspecific variation.

The phylogenetic position of $C$. pauciseta is uncertain (Borkent, 2008) and even though character 40 (from Borkent, 2008) is now known to be apomorphic for this species (it is a homoplastic feature), it does not shed further light on its position. There remains a conflict of character states, with $C$. pauciseta having the derived condition of characters $1-7,21,23,25,26,40,41$, and 62 but the plesiomorphic state for characters $28,35,39,42,43,46$, and 47. The male and pupa of this species are needed for further interpretation.

MATERIAL EXAMINED: Holotype (as recorded in Borkent, 2008) (CNCI); slide-mounted: 5 q, $12 \mathrm{~km}$. S. Liang, Brunei, 30 m, various dates: 24-IV-2007, 4-V-2007, 15-V-2007, 28-V-2007 (CNCI); 1 \% 15 km. S. Liang, Brunei, 40 m, 22-IV-2007 (CNCI); 4 + 17 km. S. Liang, Brunei, 40 m, 6-IV-2007 (3 CNCI; 1 UBD); 1 + lower Sungai Apan, 0.6 km E. headquarters, Ulu Temburong National Park, Brunei, 110 m, 9-II-2010 (UBD); 1 , tributary of Sungai Belalong in the Temburong district, Brunei, $110 \mathrm{~m}, 115^{\circ} 09^{\prime} \mathrm{E}, 4^{\circ} 33^{\prime} \mathrm{N}, 50 \mathrm{~m}, 7-\mathrm{VIII}-2006$ (CNCI). Pinned specimens: 1 , lower Sungai Apan, Ulu Temburong NP, Brunei, 110 m, 9-II-2010 (CNCI); 10 , 12 km S. Liang, Brunei, 30 m, 4-III-2011 (8, CNCI; 2 UBD); 9 \%, from previous locality but 4-XI-2010 (CNCI); 1 , Sungai Baki, Ulu Temburong NP, Brunei, 120 m, 18-VII-2008 (CNCI); 8 \%, Sungai Ingei, $8.2 \mathrm{~km} \mathrm{S.} \mathrm{Melilas,}$ Brunei, $50 \mathrm{~m}$, VII-2010 (CNCI); 7 , from previous locality but 10-VII-2010 (CNCI); 2 , Lanjak Entimau, Sarawak, Malaysia, 80 m, 21-VI-2008 (CNCI, SMKM); 4 †, Gunung Mulu NP, Sarawak, Malaysia, Headquarters, $30 \mathrm{~m}, 26-\mathrm{XI}-2009$ (CNCI), 2 , from previous locality but 14-XI-2009 (CNCI); 1 +, from previous locality but 23XI-2009 (CNCI).

\section{Corethrella (Corethrella) bicincta Borkent, Grafe \& Miyagi, new species}

(Figs. 5D, 7C, 8J, 11A, 12J, 13I, 15B)

DIAGNOSIS: Male adult. Unknown. Female adult. Only extant species of Corethrella in the Palaearctic, Oriental, Oceanian and northern Australasian Regions with the combination of a subapical band on the wing (Fig. 12J), a uniformly brown abdomen (Fig. 13I), and with the hind tibia with darker pigmentation at base and apex (Fig. 11A). Only extant species in Borneo with the combination of a subapical band on the wing (Fig. 12J) and a uniformly brown abdomen (Fig. 13I).

DESCRIPTION: Male adult. Unknown. Female adult. Descriptive statistics: See Tables 6-11. Head: Outline in anterior view laterally somewhat elongate (Fig. 7C). Coronal suture elongate, extending to midheight to ventrally past ommatidia. Two large setae on frons between ventromedial area of ommatidia. Antenna uniformly medium brown; pedicel with distinctive, more elongate, stout, dorsal or dorsolateral setae; flagellomeres as in Fig. $8 \mathrm{~J}$; sensilla coeloconica on flagellomeres $1,(8), 9-13$, flagellomeres 1 with several, 9-13 with 2 sensilla; flagellomere 13 with well-developed apical bifurcation. Clypeus (Fig. 7C) wide. Mandible with moderately small, pointed teeth. Palpus (Fig. 7C) brown; segment 3 swollen subapically. Thorax (Fig. 11A): Uniformly medium to dark brown but scutum with anterolateral darker patch of darker pigmentation, pale sclerites around base of wing. Posterior portion of dorsocentral row with 2 elongate setae situated somewhat lateral to one another. Prescutal suture elongate, thick, interrupted by area of pale cuticle, extending nearly to dorsocentral row of setae. Anterior anepisternum divided diagonally by sinuous suture, dorsal portion about equal to ventral portion. Ventral portion of posterior anepisternum triangular, uniformly brown, with anterodorsal margin thick. Wing (Fig. 12J): Apex of $\mathrm{R}_{2}$ equal to apex of $\mathrm{M}_{1}$. Anterior margin with differently, discretely pigmented scales (indicating anterior margin of wing bands), basal band with dark scales on $\mathrm{C}, \mathrm{Sc}, \mathrm{R}$, subbasal band with dark scales on $\mathrm{R}, \mathrm{M}, \mathrm{A}_{1}$, midlength band entire, subapical band with dark scales but $\mathrm{R}_{4+5}$ pale; veins (other than costa and wing margin) with well-developed scales. Halter as dark as scutellum. Legs (Fig. 11A): Uniformly pigmented dark brown, except for poorly defined lighter pigmentation on apex of forefemur, base of foretibiae in some, in all apical 0.3 of hind femur pale, hind tibiae pale but with basal and apical bands of dark pigmentation. With only slender setae, lacking scales. Midleg with thick, subapical setae on each of at least tarsomeres 1-3. Claws of each leg equal to those of others; equal on each leg, simple (without inner teeth). Empodia slender. Abdomen (Fig. 13I): Uniformly medium brown, with segments 8-9. Cercus darker brown.

Immature stages. Unknown. 
DISTRIBUTION AND BIONOMICS: Corethrella bicincta is known from Brunei and eastern Sarawak, Malaysia (Fig. 15B) at elevations of 30-1083 m. Habitats include mid-elevation peat swamps or a nearby river (Fig. 1G) and steep terrain in lowland mature mixed dipterocarp forest. They were collected with frog-call traps and on a calling male of one species of frog (Table 7).

TAXONOMIC DISCUSSION: The specimens from Brunei and Gunung Mulu National Park (low elevations) were smaller (wing length less than $1.3 \mathrm{~mm}$ ) than those from the Bario highlands (wing length more than $1.4 \mathrm{~mm}$ ). Corethrella bicincta may be the first Old World species of the quadrivittatus species group. It has all the synapomorphies of the lineage identified by characters 39-44 (Borkent 2008: fig. 141) although character 44 could not be scored (present only in the currently unknown male). Corethrella bicincta lacks, however, both the apomorphic state of characters 33 and 68 and must be considered as unplaced until other life stages and character states become available.

TYPES: Holotype, female adult on microscope slide, labeled "HOLOTYPE Corethrella bicincta Borkent, Grafe and Miyagi", "Gunung Mulu National Park, Sarawak, Malaysia, Headquarters, 14-XI-2009; on Hylarana glandulosa, U. Grafe;" (CNCI). Paratypes on microscope slides: 1 , labeled as for holotype (CNCI); 10 \%, Bario, Sarawak, Malaysia, 1060 m, on several dates: 2-VIII-2007, 6,7-IX-2007, 29-VIII-2008 (9, CNCI; 1, UBD). Paratypes on pins: 1 , Pa Umor, 5 km E. Bario, Sarawak, Malaysia, 1083 m, 25-XI-2010 (CNCI); 1 , , 0.5 km E Pa Umor, 034' N 115³0'E, Sarawak, Malaysia, 1083 m, 27-XI-2010 (CNCI); 11 q, Sungai Ingei, $8.2 \mathrm{~km} \mathrm{S.}$ Melilas, Brunei, 50 m, VII-2010 (10, CNCI; 1 UBD); 12 \%, from previous locality but 10-VII-2010 (11, CNCI; 1 UBD); 5 \%, Gunung Mulu National Park, Sarawak, Malaysia, Headquarters, 30 m, 14-XI-2009 (CNCI).

DERIVATION OF SPECIFIC EPITHET: The name bicincta (two belts) refers to the presence of both a midlength and subapical band on the wing of females of this species.

\section{Corethrella (Corethrella) gilva Borkent \& Grafe, new species}

(Figs. 5E, 7D, 8K, 11B, 12K, 13J, 16A)

DIAGNOSIS: Male adult. Unknown. Female adult. Only extant species of Corethrella in the Palaearctic, Oriental, Oceanian and northern Australasian Regions with the combination of the palpus and clypeus equally dark brown (Fig. 7D), a single, midlength wing band (Fig. 12K), tergites 2-6 uniformly brown (Fig. 13J), midfemur either uniformly brown or lighter apically (non-discrete), and hind tibia with, at most, very light pigmentation at apex (Fig. 11B). Only extant species in Borneo with the combination of the palpus and clypeus equally dark brown (Fig. 7D), a single, midlength wing band (Fig. 12K), hind tibia with, at most, very light pigmentation at apex (Fig. 11B), and tergites 2-6 uniformly brown (Fig. 13J).

DESCRIPTION: Male adult. Unknown. Female adult. Descriptive statistics: See Tables 1-5. Head: Outline in anterior view somewhat circular (Fig. 7D). Coronal suture elongate, extending ventrally nearly past ommatidia. Two large setae on frons between ventromedial area of ommatidia. Antenna uniformly medium brown; pedicel with distinctive elongate, stout setae. Antennal flagellomeres as in Fig. 8K; sensilla coeloconica on flagellomeres $1-2,8-13$, only flagellomere 1 with more than one; flagellomere 13 with well-developed apical bifurcation. Clypeus (Fig. 7D) somewhat square. Mandible with very small, pointed teeth. Palpus (Fig. 7D) medium brown; segment 3 swollen near midlength. Thorax (Fig. 11B): Scutum, scutellum mostly light to medium brown, contrasting with darker brown pleura; pale sclerites around base of wing. Posterior portion of dorsocentral row with 2 elongate setae situated somewhat lateral to one another. Prescutal suture elongate, thick, uninterrupted, extending to near dorsocentral row of setae. Anterior anepisternum divided diagonally by sinuous suture, dorsal portion about equal to ventral portion. Ventral portion of posterior anepisternum triangular, uniformly brown, with anterodorsal margin not thick. Wing (Fig. 12K): Apex of $\mathrm{R}_{2}$ equal or slightly distal to apex of $\mathrm{M}_{1}$. Anterior margin with differently, discretely pigmented scales (indicating anterior margin of midlength band), with midlength band, with poorly defined basal band; veins (other than costa and wing margin) with well-developed scales. Halter medium brown, equal to scutellum. Legs (Fig. 11B): Medium brown, with about apical 0.3 of midfemur, basal 0.5 of midtibia, apical 0.5 of hind femur, all of hind tibia pale other than slightly darker pigmentation on apical 0.2 of hind tibia; with darker pigmentation not discrete. With only slender setae, lacking scales. Midleg with thick, subapical setae on each of at least tarsomeres 1-3. Claws of each leg equal to those of others; equal on each leg, simple (without inner teeth). Empodia thick. Abdomen (Fig. 13J): Tergites 1-6 pale, sternites 1-6 light brown, segments 7-9 medium brown. Cercus medium brown. 
Immature stages. Unknown.

DISTRIBUTION AND BIONOMICS: Corethrella gilva is known from Brunei at 30-110 m (Fig. 16A). Habitats include lowland peat swamps (including standing water and very slow moving streams) and steep terrain in mature mixed dipterocarp forest (Fig. 1A, as in Fig. 1F). Females have been collected with frog-call traps and on calling males of three species of frogs (Table 7).

TAXONOMIC DISCUSSION: Borkent (2008: 237) noted three species attracted to the taped call of Hyla gratiosa (LeConte) in Brunei and C. gilva was one of them (included as a paratype here).

We are uncertain of the phylogenetic placement of $C$. gilva because it is known only as female adults and there were few synapomorphies present to interpret. Corethrella gilva has synapomorphies 21-23 and lacks synapomorphy 28. It has a banded wing but plain brown abdomen. It may belong to the drakensbergensis group but, as presently understood, the loss of wing pigmentation occurred before loss of abdominal pigmentation pattern, which would conflict with what is present in C. gilva. In addition, C. gilva has synapomorphy 40 (pedicel with strong setae), which would place it higher up in the phylogeny of the Corethrellidae. The discovery of the male of this species would help in its placement.

TYPES: Holotype, female adult on microscope slide, labeled "HOLOTYPE Corethrella gilva Borkent and Grafe", "12 km S. Liang, Brunei, 15-V-2007; on Hylarana glandulosa; U. Grafe; 34-1/1, DNA extracted", "34-1/1 231007" (CNCI). Paratypes on microscope slides: 1 \% , from type locality, but 10-V-2007 (CNCI); 1 , from type locality but 15-V-2007 (CNCI); 1 , from type locality but 23-V-2007 (CNCI); 1 \%, from type locality but 9-VI2007 (UBD); 7 , from type locality but 11-XII-2007; 1 , from type locality but 28-V-2007 (UBD); 1 + $15 \mathrm{~km} \mathrm{S.}$ Liang, Brunei, 40 m, 9-V-2007 (CNCI); 1 \%, from previous locality but 22-V-2007 (CNCI); 1 \%, lower Sungai Apan, 0.9 km E. headquarters, Ulu Temburong National Park, Brunei, 110 m, 9-II-2010 (CNCI); 1 q, tributary of Sungai Belalong, Temburong, Brunei, $110 \mathrm{~m}, 115^{\circ} 09^{\prime} \mathrm{E}, 4^{\circ} 33^{\prime} \mathrm{N}, 7-\mathrm{VIII}-2006$ (CNCI). Paratypes on pins: 3 , lower Sungai Apan, Ulu Temburong NP, Brunei, 110 m, 5-II-2010 (2 CNCI; 1 UBD); 1 , from previous locality but 13-VII-2008 (CNCI); 2 †, Temburong, Ulu Temburong NP, Brunei, 7-VII-2008 (CNCI); 1 \%, $12 \mathrm{~km} \mathrm{S.} \mathrm{Liang,}$

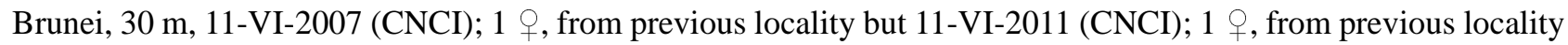
but 28-V-2007 (CNCI); 2 , from previous locality but 4-VI-2007 (CNCI; UBD); 1 , from previous locality but 23-V-2007 (CNCI); 1 ㅇ, from previous locality but 9-VI-2007 (CNCI); 4 + , from previous locality but 15-V-2007 (CNCI); 1 ㅇ, from previous locality but 4-XI-2010 (CNCI); 1 ㅇ, 12.5 km S. Liang, Brunei, 33 m, 21-II-2009 (CNCI); 1 \%, from previous locality but 3-I-2009 (CNCI); 1 9, 15 km S. Liang, Brunei, 40 m, 5-VI-2007 (CNCI); 2 \%, from previous locality but 12-V-2007 (CNCI); 1 q, from previous locality but 22-V-2007 (CNCI); 1 q, $17 \mathrm{~km}$ N. Labi, Brunei, 40 m, 14-V-2007 (CNCI); 1 9, Sungai Ingei, $8.2 \mathrm{~km} \mathrm{~S}$. Melilas, Brunei, $50 \mathrm{~m}$, VII-2010 (CNCI); $1+$, from previous locality but $10-\mathrm{VII}-2010$ (CNCI).

DERIVATION OF SPECIFIC EPITHET: The name gilva (yellow) refers to the lightly pigmented hind tibiae of females of this species.

\section{CONCLUSIONS}

When Borkent (2008) produced his monograph on the Corethrellidae of the world, there were numerous questions remaining concerning the diversification of the group. In particular, it was striking that the only intensely studied tropical region, Costa Rica in Central America, with only three previously known species, now had 38 (with 25 as these as newly described). An important question concerned the diversity in the Old World - how many species might we expect in the Afrotropical and Oriental Regions? The six Afrotropical and 12 species from the Oriental, southern Japanese islands, and northern Australasian Regions described or redescribed by Borkent (2008) were based on very few specimens and this suggested that species richness would be significantly higher with further sampling. An initial survey of species from Brunei indicated the presence of further species (Borkent 2008; Grafe et al. 2008).

Our study of the Corethrella of Borneo is the first concerted effort to study Corethrella in the Old World and shows that 11 species are present, even though only a few areas were adequately sampled. The most intensely area surveyed was Brunei Darussalam and we discovered 10 of the species to be present in this small country of 5770 $\mathrm{km}^{2}$ (Figs. 14-18), with only $C$. brunnea from western Sarawak not recorded from Brunei. Two species, $C$. bipigmenta and C. gilva, are restricted to Brunei and the remaining eight of the Bruneian species are more broadly distributed in Borneo. Two (C. unizona, C. bicincta) were found in nearby localities in eastern Sarawak 
(Malaysia), but six (C. tigrina, C. lutea, C. nanoantennalis, C. mitra, C. calathicola, C. pauciseta) are also present in western Sarawak, near Kuching or in Lanjak Entimau, 400-500 km SW of Brunei, showing that these, at least, have a broader distribution in Borneo. Of these six species, C. mitra is also found in Sabah (Fig. 16B). Corethrella calathicola, present as immatures in species of Nepenthes, is also more broadly distributed in Borneo, peninsula Malaysia, and Singapore (Fig. 18). Corethrella pauciseta is present in Borneo and Papua New Guinea (Fig. 17) but there is some question as to whether specimens from the two islands are conspecific. What does this suggest regarding expectations of further species of Corethrella from Borneo? Borkent (2008:236-237, table 17) compared the results of sampling various lowland tropical sites in Costa Rica, a country nearly 10 times the size of Brunei. In general, his survey indicated a significant difference in species composition between even nearby sites, showing that further sampling would surely uncover further undescribed species. Our more limited samples from Borneo show that six Bruneian species of Corethrella were also present in western Sarawak, Malaysia. All five species present at Lanjak Entimau (Fig. 14A) were also present in Brunei and this pattern suggests limited diversity in at least this northern portion of Borneo. Only two species from Brunei are endemic, namely C. gilva and C. bipigmenta.

Within Brunei, we compare the two most intensely sampled areas, that in the region south of Liang (Labi Road area) with its large peat swamps, and Ulu Temburong National Park with its precipitous terrain, mixed dipterocarp forest, and rapidly running streams and rivers (Fig. 14A). The two are separated by about $70 \mathrm{~km}$. Six species are present in the area south of Liang and seven in Ulu Temburong National Park. Of these, four are shared between the two areas. Only one species, C. bipigmenta from Ulu Temburong National Park, is endemic. This pattern also suggests that diversity in northern Borneo, although showing a substantial increase in diversity, will be more limited than that found in a comparable area in the Neotropical Region. Having written this, it is important to keep in mind that sampling on Borneo has been so limited that the southern majority of the island, in Indonesia, is entirely uncollected. In addition, collecting in Costa Rica was more prolonged and included collecting with Malaise traps, producing further sampling bias.

Another clue providing evidence of levels of diversity is to compare different sampling methods of material in Borneo. This study is the first to systematically survey calling frogs of different species for the presence of female Corethrella. In conjunction with the use of frog-call traps, we can compare for the first time the results of these two different collecting techniques. Table 7 records the method by which each species was collected. Corethrella brunnea, known from a single specimen collected with a Malaise trap, is not considered further. It is striking that eight of the ten remaining species were collected with a frog-call trap and nine of the ten were sampled directly from calling male frogs. The nearly complete overlap in species of Corethrella sampled also suggests that not many more species will be discovered in Brunei.

Borkent's (2008) survey of the fauna of Costa Rica showed that frog-call traps retrieved less than $50 \%$ of those discovered in that country (17 out of 38 reported). In our sampling in Brunei, frog-call traps recovered eight of the ten species. It is uncertain what these differences mean, if anything. Sampling in Brunei was significantly more intense than in Costa Rica, which may indicate that more consistent use of a frog-call trap in Costa Rica would retrieve more of the described species. Alternately, the relatively lower number of species collected with frog-call traps in Brunei may indicate that there is yet a significant number of species of Corethrella to be discovered using other methods (although the overlap of species collected directly from frogs would argue against this). If there are many more species of Corethrella biting other species of frogs in Brunei and elsewhere in Borneo, it would be puzzling as to why the frog-call traps did not sample at least some of them.

It is important to realize that we sampled Corethrella females from only 11 species of frogs, but Brunei has a total anuran fauna of 81 species (Grafe \& Das in press). A preliminary view of the data suggests that host specificity might be high. A more rigorous analysis, however, is necessary to reach any firm conclusions (Grafe, Ahmad \& Borkent, in prep.).

Grafe et al. (2008) identified morphotypes from an area of peat swamps in Brunei by number and brief title. To allow for further interpretation of that paper (see below), we here identify those morphotypes, based on examination of their reference collection and DNA sequenced material (Table 6). These authors used the number of morphotypes to suggest the likelihood of further diversity. However, their list of morphotypes included only six species of Corethrella, with other morphotypes belonging to other families of Diptera.

The first author has significant experience collecting Corethrella in Costa Rica and first-hand experience by both authors in Brunei indicate differences in the relative abundances of species of Corethrella between the two areas. Frog-call traps in the lowlands of Costa Rica often bring in hundreds of individuals in less than an hour of 
trapping (Borkent 2008:20). McKeever \& Hartberg (1980) collected 566 adults in 30 minutes of collecting in Georgia, USA. Trapping in peat swamp habitat in Brunei rarely brought in more than 50 in an hour (on average 37 Corethrella were collected per hour) and trapping in lowland rainforest brought in only five Corethrella in nine hours of trapping (Grafe et al., 2008). Part of the difference may be logically thought of as being due to larger numbers of species present in most catches in Costa Rica. However, only two or three species dominated catches there, followed by small percentages of others, similar to the situation in Brunei (Grafe et al. 2008). What might be the reason for the difference? Because workers on Culicidae collect from a wide array of aquatic habitats and sometimes record the presence of Corethrella, we often have records of the presence of their immature stages. For example, Borkent (2008:252) used the surveys by Belkin and his colleagues to interpret the diversification of larval habitats within the genus (Belkin \& Heinemann 1973, 1975a, 1975b, 1976a, 1976b, 1976c; Heinemann \& Belkin 1977a, 1977b, 1977c, 1978a, 1978b, 1978c, 1979; Belkin et al. 1970; Heinemann et al. 1980). The New World has numerous species of Corethrella in phytotelmata and others that are in ground pools. Aside from C. calathicola in species of Nepenthes, a species otherwise related to New World species also living in phytotelmata, we were unable to find any immature Corethrella in any phytotelmata in Brunei. It is unlikely that this is due to rarity. Ichiro Miyagi has worked extensively in Southeast Asia and reports (pers. comm.) that he has examined many thousands of phytotelmata, including tree holes, bamboo cuts, leaf axils of many kinds of taro plants, screw pines (Pandanus Parkinson), wild banana, ginger (Boesenbergia Mansfeld spp.) Phrynium Willdenow spp., Scaphochlamys Baker spp., inflorescences of Hornstedtia Retzius spp., Zingiber spectabile (Griffith) and many species of Nepenthes, but has found only a few Corethrella larvae in N. ampullaria and N. veitchii in Sulawesi (likely C. calathicola), and leaf axils of Donax Loureiro sp. in Irian Jaya (Miyagi \& Toma 1997). In Gombak in Peninsular Malaysia, he found immatures of Corethrella in the leaf axils of a Phrynium species. He has collected or examined over 3,750 collections from Borneo without a single record of Corethrella (other than in Nepenthes). Kitching $(1987,1990)$ studied phytotelmata in Sulawesi and Papua New Guinea, also without encountering immature Corethrella and Kitching \& Orr (1996) failed to find them in Ulu Temburong National Park in Brunei. This is strong evidence that species of Corethrella have not invaded and diversified in phytotelmata in Southeast Asia to any significant degree, as they have in the Neotropical Region (Borkent 2008). We also attempted sampling from a variety of ground pools and swamps without success but our efforts were perhaps too limited. At Kuala Belalong Field Studies Centre in Ulu Temburong National Park, Brunei, five artificial basins each holding at least 5 liters of rainwater and left standing for many months were carefully sifted and studied for the presence of immatures of Corethrella without success. In Ulu Temburong National Park standing ground water is virtually non-existent in this high relief area. Ichiro Miyagi (pers. comm.) has also made considerable efforts to collect Corethrella from ground waters in Borneo without success. Considering that the Corethrella are not in phytotelmata, the only other aquatic habitats are small or moderately sized creeks and larger rivers, which vary considerably in their flow (e.g. the creek in Fig. $1 \mathrm{~F}$ rose over a meter in less than 30 minutes on November 14, 2010). Borkent (2008: figs. 141, 142) summarized the known aquatic habitats of all species of Corethrella worldwide. Early lineages are very poorly represented, with C. marksae Colless (in the marksae species group, Fig. 19) from a "small, pebbly back-water of a flowing river" in Australia (Colless 1986) and C. solomonis from leaf axils of palms on the Solomon Islands (Belkin 1962). The rotunda species group (Fig. 19) is restricted to the New World and although none have been confidently reared out, it is likely that at least one species occurs in the hyporheic (Borkent, 2008). We conclude that the most likely habitat for most species of Corethrella in Borneo will be the hyporheic or some other protected microhabitat associated with streams. Borkent (2008) also pointed out that with substantial efforts by mosquito workers in Costa Rica, only 16 of the 38 Costa Rican species have been reared and only 11 of these from Costa Rica itself (five Costa Rican species were reared from elsewhere). This too strongly suggests that the immatures of a significant number of species are living in a secluded and presently elusive aquatic habitat. Regardless, the failure to find immature Corethrella in phytotelmata and obvious ground waters (peat swamps) suggests the relatively low numbers of adults in frog-call traps in Borneo is due to limited larval habitats. In addition, numbers of female Corethrella in frog-call traps were far fewer in the steep terrain of Ulu Temburong National Park than in the area south of Liang with its abundant peat swamps (Grafe et al. 2008), suggesting that larval habitat is even more limited in the former. Miyagi (pers. comm.) also found adult Corethrella to be rare in frog-call traps in the steep terrain of Lanjak Entimau.

Further clues regarding potential larval habitats for Bornean species are present. The female adults of $C$. lutea from Borneo are structurally very similar to those of $C$. nippon (from Japan), which have been discovered as immatures in crab holes (Miyagi, pers. comm.). Corethrella tigrina is morphologically very similar to $C$. 
solomonis and, in spite of what is written above, the immatures are perhaps in leaf axils of Pandanaceae, as are those of $C$. solomonis. Belkin (1962) reported unreared larvae as purported $C$. solomonis from the base of fronds of two species of palms on Bougainville Island (Papua New Guinea).

We attempted to induce egg laying in females of $C$. pauciseta and $C$. lutea by collecting live females of both these species (10 females from $12 \mathrm{~km} \mathrm{~S}$. Liang, Brunei, 04³ $35.194^{\prime} \mathrm{N} 114^{\circ} 30.418^{\prime} \mathrm{E}, 18 \mathrm{~m}, 4-\mathrm{XI}-2010$ and 3 females from 20 N. Labi, Luagan Lalak Forestry Rec. Site, Brunei, 04³0.950' N 114²28.401'E, 28 m, 6-XI-2010, respectively). Each female was placed in a separate covered petri dish with a layer of freshwater (so the female stood either on the water surface or on side of the dish or on its cover). All died within about 4 days and subsequent examination showed that all had slender abdomens and no egg development. This suggests that female C. pauciseta and $C$. lutea are either anautogenous or were not previously fertilized (although many biting nematocerous flies mate before seeking a blood-meal). This technique resulted in egg laying in several autogenous species of Corethrella in Costa Rica (Borkent, 2008). It would be valuable to capture live females after they have blood fed to see if they will lay eggs in the laboratory. Aside from the potential of additional character states to interpret, study of laboratory-reared immatures may provide clues as to the natural habitat of the species.

Grafe et al. (2008) reported that two species, their morphotypes 1 and 2, were by far the most abundant in their frog-call traps, followed by significantly smaller numbers of morphotypes $3,4,5$ and 9 . Other morphotypes were misidentified to family (Table 6). They discovered that there were no significant differences in numbers collected with a frog-call trap using either natural calls of two species of Hylarana Tschudi or synthetic calls. Corethrella pauciseta (as morphotype 1) dominated the samples, making up 73\% of samples from frog-call traps using natural frog calls and $80 \%$ using synthetic frog calls. Corethrella lutea (as morphotype 2) made up 23\% and 14\% respectively. The remaining four species, sometimes misidentified to morphotype, made up $3 \%$ and $6 \%$ respectively.

Both morphotypes 6 and 7 were Culicoides maculatus (Shiraki), a broadly distributed Oriental ceratopogonid species, previously recorded from China and Japan, south to Indonesia and the Philippines (Wirth and Hubert 1989). It is newly reported here from Borneo. The species is a known biting pest of humans (Tokunaga 1937) and its occurrence in frog-call traps in Brunei is almost certainly incidental.

Borkent (2008:245-246) discussed the interspecific variation in mouthpart structures and antennal sensilla within Corethrella, structures that are otherwise known to influence specific biting behaviour in other groups of biting flies. Such variation between species suggests some level of host specificity and site selection on the host's body. One of the Bornean species, C. mitra, is distinctive in biting frogs right around the nares (Fig. 3B). Corethrella tigrina bites on the head (Fig. 2A) but does not seem focused on the nares area. Other species of Bornean Corethrella feed on the general body of frogs (Table 7). Of the species we studied from Borneo, C. mitra has a distinctively large number of antennal flagellomeres with sensilla coeloconica, with these present on flagellomeres $1-2,7-13$, and sometimes on flagellomere 3 . In addition, of the species studied here, $C$. mitra has the largest number of capitate sensilla on palpal segment 3. These are the sensilla that detect $\mathrm{CO}_{2}$ in other biting flies and this suggests that $C$. mitra is using them to detect $\mathrm{CO}_{2}$ to determine its final biting position around the nares of its host frog. Silva et al. (2010) indicated that unidentified species of Corethrella in Panama preferred feeding around the nares of Engystomops pustulosus (Cope) because the skin of the frog is thin and the underlying tissue heavily vascularized in that area.

The phylogenetic position of Bornean species is informative (Fig. 19). Six of the 11 known species are members of the drakensbergensis species group, one of the earliest lineages within the genus. Corethrella unizona also belongs to a relatively early lineage as the sister group of a large number of Old and New World species. Although cladistic resolution is poor within the group (and characters 25-27 are weak) it is clear that diversification among these early lineages generally took place in the Southern Hemisphere and are likely Gondwanan (Borkent, 2008). Corethrella buettikeri from Saudi Arabia, is located in the southwestern corner of that country, a region considered to be part of the Afrotropical Region. Corethrella nippon, a Japanese species known as far south as the Ryukyu Islands, is likely a northern extension of a more southern lineage (of which $C$. lutea is a member). It would be productive to revisit all members of the drakensbergensis species group, especially once more males are known for more of the species (as well as discovering further undescribed species).

Three species are unplaced phylogenetically and provide evidence of some conflicting character states (as discussed under those species: C. pauciseta, C. bicincta, C. gilva). The males of these species, once discovered, will help in their placement and may challenge some of the synapomorphies proposed by Borkent (2008). 
The eleventh species, C. calathicola, belongs to the appendiculata species group (Borkent, 2008), an otherwise Neotropical group, and within this group, is the sister species of $C$. melanica, a Central American and northern South American species. All members of the appendiculata group live in phytotelmata and it seems most likely that $C$. calathicola is an example of a lineage which dispersed to the Old World from the Neotropical Region. It probably lives in the distinctive phytotelmata created by Nepenthes leaves because these are common and easily available phytotelmata in southeastern Asia. Nepenthes is likely more similar to treeholes than are other common phytotelmata in Borneo.

\section{Acknowledgment}

The first author thanks his wife Annette Borkent for joining him on a six week expedition to Borneo to study Corethrella and other flies. She supports all his studies of flies with finances, love and a willingness to scramble down waterfalls, slog through wet terrain and up steep trails in the pursuit of biodiversity.

We express our appreciation to the following for the loan of specimens: Jeff M. Cumming and Scott Brooks (CNCI), Zoe Adams (BMNH), Neal Evenhuis (BPBM), Richard Wilkerson and Jim Pecor (USNM), David Yeates and Chris Manchester (ANIC), and Ichiro Miyagi, (Laboratory of Mosquito Systematics of Southeast Asia and South Pacific, Okinawa, Japan).

Ichiro Miyagi made special efforts to collect material from Borneo and provided much appreciated advice and comparative observations of his collecting efforts. Annia Picado (INBio) made nearly all of the slides with her usual skill and care and we thank her for her efforts.

The second author thanks Hanyrol Ahmadsah, Hjh Siti Nadzrinah Haji Abd Ahmit, Anne Jendrusiak, Matthias Dahmen, Anissa binti Junaidi, Nikolai Knapp, Oliver Konopik, and Gwynne Lim for helping collect Corethrella in the field under difficult conditions. Hanyrol Ahmadsah and Norhayati Ahmad wrote the Malay abstract.

Logistic support was provided by the Kuala Belalong Field Studies Centre with assistance from Hjh Kamariah Abu Salim, Hjh Masnah Mirasan, Siti Rafhiah Abdul Kahar, Rodzay Abdul and Md. Salleh Abdul Bat, Brian and Sue Clark at Gunung Mulu NP, the SAFE Project Scientific Coordinator Edgar Turner, Anna Wong at the Universiti of Malaysia Sabah, the staff of the LEWS Expedition headed by Hj Mohamed Abdul Majid, and the Sungai Ingei expedition leaders Joseph Charles, Ang Bee Biaw, and Samhan Nyawa. Permits were issued by the Forestry Department of Brunei Darussalam, the Brunei Museums Department, the Forest Department of Sarawak, Yayasan Sabah, Sabah Parks, and the Economic Planning Unit, Prime Minister's Department, Putra Jaya Malaysia. This work was funded, in part, by the Sungai Ingei Faunal Expedition (2010-2012) sponsored by the Standard Chartered Bank and supported by the Ministry of Industry \& Primary Resources, Universiti Brunei Darussalam and World Wide Fund for Nature (WWF) as well as a grant from the Brunei Darussalam National Development Plan with a grant to the Universiti Brunei Darussalam (S\&T 13).

Material collected by Ichiro Miyagi was with the permission of Dr. Leh Moi Ung, Charles, Curator of Natural History, Sarawak Museum, Kuching and Mr. Haji Ali Bin Yusop, Controller of Wildlife of National Parks and Nature Reserves, Forest Department, Sarawak.

The authors thank Bradley J. Sinclair (CNCI) and an anonymous reviewer for much appreciated reviews of the manuscript.

\section{References}

Belkin, J.N. (1962) The Mosquitoes of the South Pacific (Diptera, Culicidae). Volume 1. University of California Press, Berkeley and Los Angeles, xii +608 pp.

Belkin, J.N. \& Heinemann, S.J. (1973) Collection records of the project "Mosquitoes of Middle America" 1. Introduction; Dominican Republic (RDO). Mosquito Systematics, 5, 201-220.

Belkin, J.N. \& Heinemann, S.J. (1975a) Collection records of the project "Mosquitoes of Middle America" 2. Puerto Rico (PR, PRA, PRX) and Virgin Is. (VI, VIA). Mosquito Systematics, 7, 269-296.

Belkin, J.N. \& Heinemann, S.J. (1975b) Collection records of the project "Mosquitoes of Middle America" 3. Bahama Is. (BAH), Cayman Is. (CAY), Cuba (CUB), Haiti (HAC, HAR, HAT) and Lesser Antilles (LAR). Mosquito Systematics, 7 , 367-393.

Belkin, J.N. \& Heinemann, S.J. (1976a) Collection records of the project "Mosquitoes of Middle America" 4. Leeward Islands: 
Anguilla (ANG), Antigua (ANT), Barbuda (BAB), Montserrat (MNT), Nevis (NVS), St. Kitts (KIT). Mosquito Systematics, 8, 123-162.

Belkin, J.N. \& Heinemann, S.J. (1976b) Collection records of the project "Mosquitoes of Middle America" 5. French West Indies: Guadeloupe (FWI) and Martinique (FWIM, MAR). Mosquito Systematics, 8, 163-193.

Belkin, J.N. \& Heinemann, S.J. (1976c) Collection records of the project "Mosquitoes of Middle America" 6. Southern Lesser Antilles: Barbados (BAR), Dominica (DOM), Grenada (GR, GRR), St. Lucia (LU), St. Vincent (VT). Mosquito Systematics, 8, 237-297.

Belkin, J.N., Heinemann, S.J. \& Page, W.A. (1970) The Culicidae of Jamaica (Mosquito Studies. XXI). Contribution of the American Entomological Institute, 6(1), 1-458.

Borkent, A. (2008) The Frog-Biting Midges of the World (Corethrellidae: Diptera). Zootaxa, 1804,1-456.

Borkent, A. \& Spinelli, G.R. (2007) Neotropical Ceratopogonidae (Diptera: Insecta). In: Adis, J., J.R. Arias, G. RuedaDelgado, and K.M. Wnatzen (Eds.): Aquatic Biodiversity in Latin America (ABLA). Vol. 4. Pensoft, Sofia-Moscow, 198 pp.

Colless, D.H. (1986) The Australian Chaoboridae (Diptera). Australian Journal of Zoology Supplementary Series, 124, 1-66.

Cumming, J.M. \& Wood, D.M. (2009) Adult morphology and terminology. pp. 9-50. In Brown, B.V., Borkent, A., Cumming, J.M., Wood, D.M., Woodley, N.E., \& Zumbado, M.A. (Eds). Manual of Central American Diptera: Volume 1. NRC Research Press, Ottawa, Ontario, Canada, pp. 9-50.

Edwards, F.W. (1930) Notes on exotic Chaoborinae, with descriptions of new species (Diptera, Culicidae). Annals and Magazine of Natural History, 10, 528-540.

Grafe, T.U. \& Das, I. (in press). Conservation Status of Amphibians of Brunei Darussalam. In: Amphibian Biology, Volume 11: Status of Decline of Amphibians: Eastern Hemisphere (Ed. Heatwole, H.) Surrey Beatty \& Sons.

Grafe, T. U., Saat, H.B.M., Hagen, N., Kaluza, B., Berudin, Z.B.H. \& Wahab, M.A.B.A. (2008) Acoustic localisation of frog hosts by blood-sucking flies Corethrella Coquillet (Diptera: Corethrellidae) in Borneo. Australian Journal of Entomology 47,350-354.

Heinemann, S.J. \& Belkin, J.N. (1977a) Collection records of the project "Mosquitoes of Middle America" 7. Costa Rica (CR). Mosquito Systematics, 9, 237-287.

Heinemann, S.J. \& Belkin, J.N. (1977b) Collection records of the project "Mosquitoes of Middle America" 8. Central America: Belize (BH), Guatemala (GUA), El Salvador (SAL), Honduras (HON), Nicaragua (NI, NIC). Mosquito Systematics, 9, 403-454.

Heinemann, S.J. \& Belkin, J.N. (1977c) Collection records of the project "Mosquitoes of Middle America" 9. Mexico (MEX, MF, MT, MX). Mosquito Systematics, 9, 483-535.

Heinemann, S.J. \& Belkin, J.N. (1978a) Collection records of the project "Mosquitoes of Middle America" 10. Panama, including Canal Zone (PA, GG). Mosquito Systematics, 10, 119-196.

Heinemann, S.J. \& Belkin, J.N. (1978b) Collection records of the project "Mosquitoes of Middle America" 11. Venezuela (VZ); Guianas: French Guiana (FG, FGC), Guyana (GUY), Surinam (SUR). Mosquito Systematics, 10, 365-459.

Heinemann, S.J. \& Belkin, J.N. (1978c) Collection records of the project "Mosquitoes of Middle America" 12. Colombia (COA, COB, COL, COM). Mosquito Systematics, 10, 493-539.

Heinemann, S.J. \& Belkin, J.N. (1979) Collection records of the project "Mosquitoes of Middle America" 13. South America: Brazil (BRA, BRAP, BRB), Ecuador (ECU), Peru (PER), Chile (CH). Mosquito Systematics, 11, 61-118.

Heinemann, S.J., Aitken, T.H.G. \& Belkin, J.N. (1980) Collection Records of the Project "Mosquitoes of Middle America" 14. Trinidad and Tobago (TR, TRM, TOB). Mosquito Systematics, 12, 179-284.

Kitching, R.L. 1987. A preliminary account of the metazoan food webs in phytotelmata in northern Sulawesi. Malayan Nature Journal, 41, 1-12.

Kitching, R.L. (1990) Foodwebs from phytotelmata in Madang, Papua New Guinea. Entomologist, 109,153-164.

Kitching, R.L. \& Orr, A.G. (1996) The foodweb from water-filled treeholes in Kuala Belalong, Brunei. Raffles Bulletin of Zoology, 44, 405-413.

Lim, G.S. (2007) Can DNA sequences help with sorting biodiversity samples? Masters thesis, National University of Singapore, xii + $148 \mathrm{pp}$.

McKeever, S. \& Hartberg, W.K. (1980) An effective method for trapping adult female Corethrella (Diptera: Chaoboridae). Mosquito News, 40, 111112.

Miyagi, I. and T. Toma (1997) Description of Topomyia irianensis n. sp. and new records of To. papuensis from Maluku and Irian Jaya, Indonesia (Diptera: Culicidae). Journal of the American Mosquito Control Association 13, 134-139.

Miyagi, I., Okazawa, T., Toma, T., Higa, Y. \& Leh, M.U. (2009) Culicidae and Corethrellidae (Diptera) collected in Sarawak, Malaysia from 2005 to 2008. The Sarawak Museum Journal, 66, 313-331.

Mogi, M. \& Yong, H.S. (1992) Aquatic arthropod communities in Nepenthese pitchers: the role of niche differentation, aggregation, predation and competition in community organization. Oecologia, 90, 172-184.

Silva, P. de, Jaramillo, C. \& Bernal, X.E. (2010) Selection of biting sites on anuran hosts by frog-biting midges (Corethrella spp.). Abstracts of the 7th International Congress of Dipterology, 8-13 August 2010, San José, Costa Rica, pg. 223.

Tokunaga, M. (1937) Sand flies (Ceratopogonidae, Diptera) from Japan. Tenthredo, 1, 233-338.

Wirth, W.W. \& Hubert, A.A. (1989) The Culicoides of Southeast Asia (Diptera: Ceratopogonidae). Memoirs of the American Entomological Institute 44, i-iv, 1-508. 


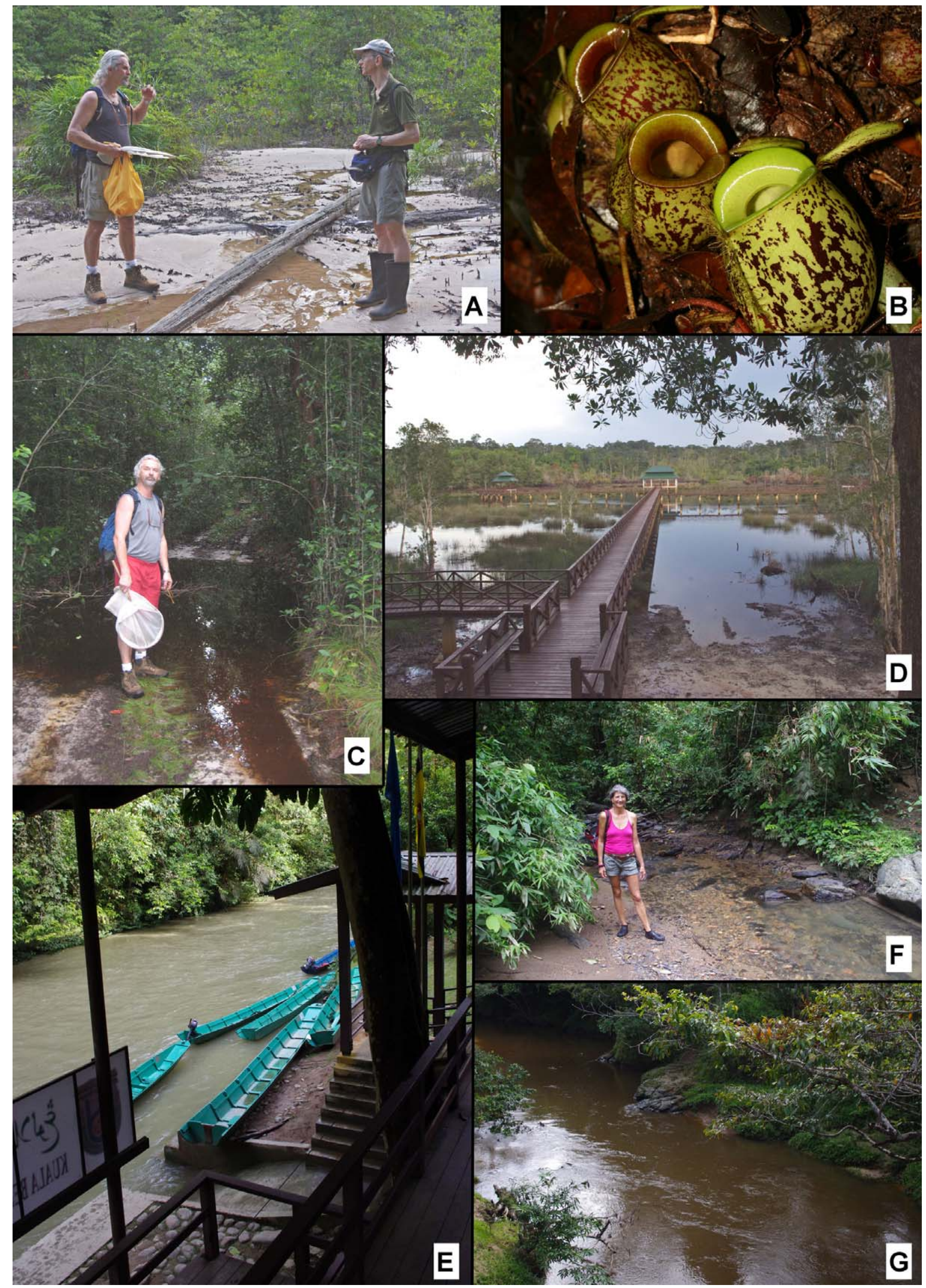

FIGURE 1. Habitats from which Corethrella adults were collected with a frog-call trap in Brunei (species collected given in parentheses). A. $12 \mathrm{~km} \mathrm{~S}$. Liang, Brunei (C. tigrina, C. lutea, C. calathicola, C. pauciseta, C. gilva) (authors, for scale). B. Nepenthes ampullaria, $12 \mathrm{~km} \mathrm{~S}$. Liang, Brunei (C. calathicola). C. $12.5 \mathrm{~km} \mathrm{S.} \mathrm{Liang,} \mathrm{Brunei} \mathrm{(same} \mathrm{species} \mathrm{as} \mathrm{for} \mathrm{A)} \mathrm{(first}$ author, for scale). D. $20 \mathrm{~km}$ N. Labi, Luagan Lalak Forestry Rec. Site, Brunei (C. lutea). E. Belalong River, Kuala Belalong Field Studies Centre, Brunei $(C$. lutea, $C$. bipigmenta, $C$. mitra). F. Sungai Esu, Ulu Temburong NP, Brunei $(C$. tigrina, $C$. bipigmenta, C. mitra) (first author's wife Annette, for scale). G. Pa Umor, $5 \mathrm{~km}$ E. Bario (C. bicincta, C. unizona). 

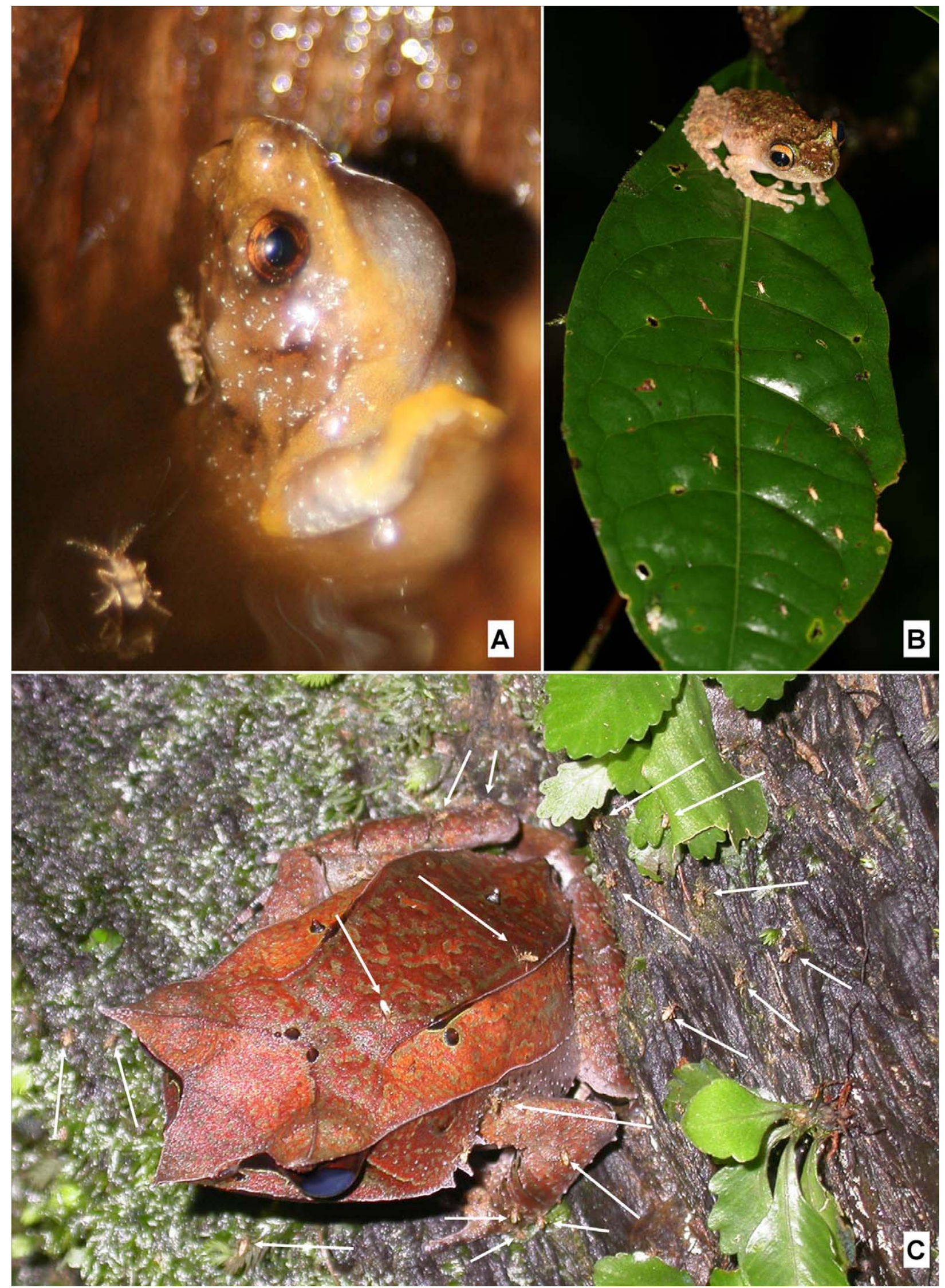

FIGURE 2. Female adult Corethrella feeding on calling male frogs in Borneo. A. C. tigrina on Metaphrynella sundana (Peters) (Ashton Trail in the Ulu Temburong National Park, Brunei Darussalam). B. C. lutea resting on somewhat drooping leaf after feeding on Rhacophorus appendiculatus (Günther) (Sungai Ingei Conservation Forest, $8.2 \mathrm{~km} \mathrm{S.} \mathrm{Melilas,} \mathrm{Brunei} \mathrm{Darussalam).} \mathrm{C.}$ C. bipigmenta on Megophrys nasuta (Ulu Temburong National Park, Brunei). All photographs by second author. 


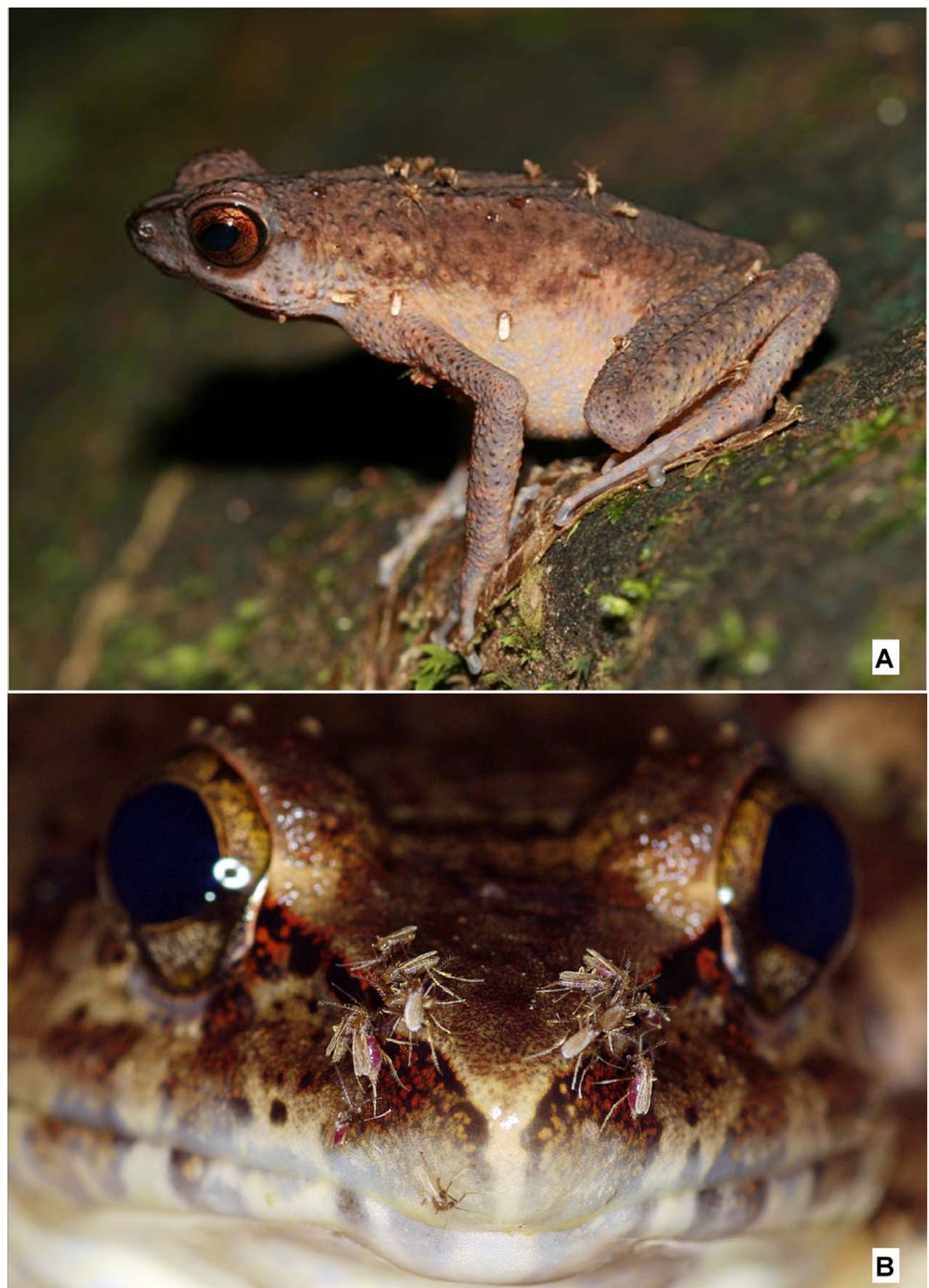

FIGURE 3. Female adult Corethrella feeding on calling male frogs in Borneo. A. C. nanoantennalis on thorax and legs of Ansonia longidigita (Inger) (Lanjak Entimau, Sarawak, Malaysia; photograph by second author). B. C. mitra on area surrounding nares of Limnonectes leporinus (Andersson) (30 km NE Kalabakan, Sabah, Malaysia; photograph by Oliver Konopik; note reddish abdomens of engorged females). 


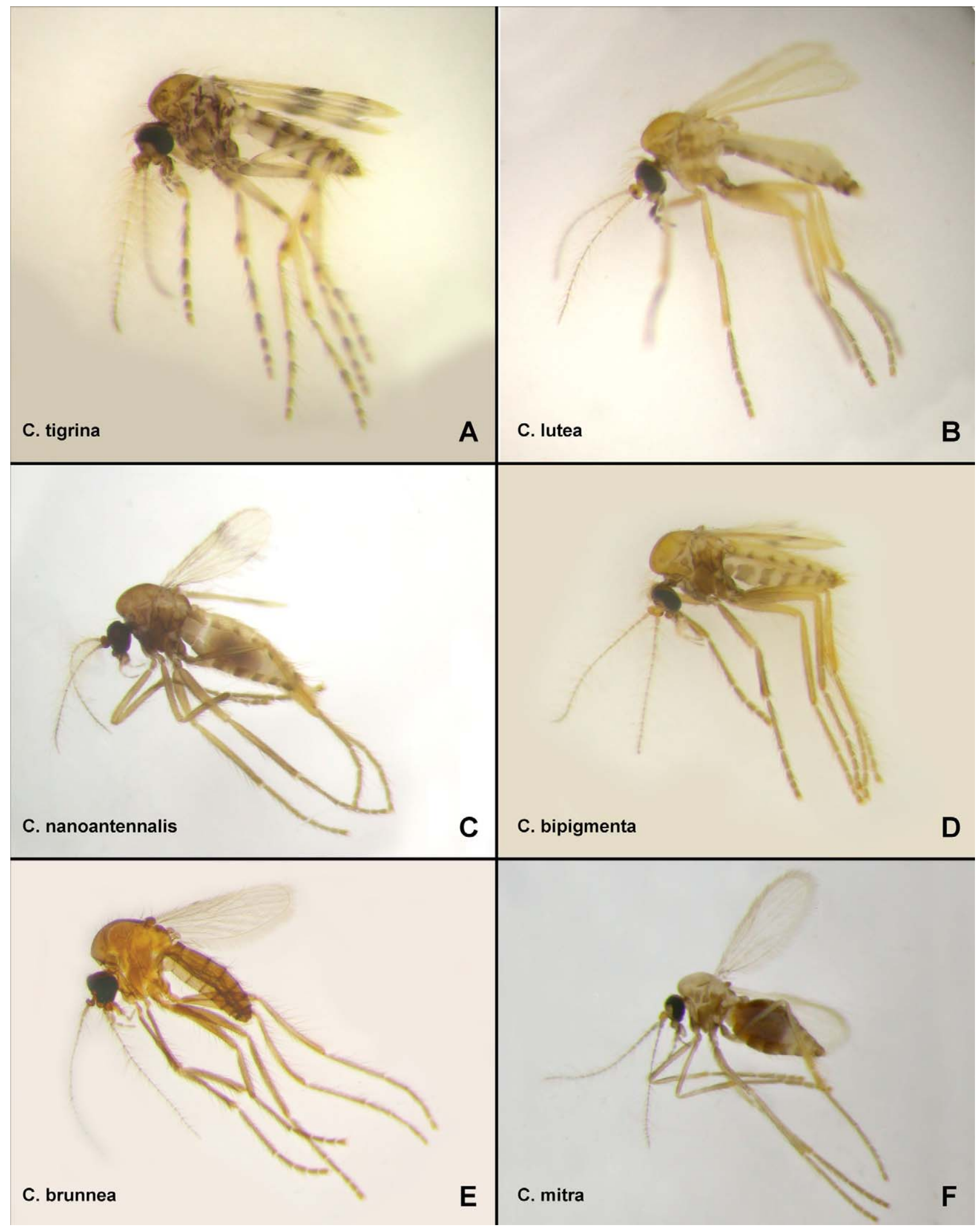

FIGURE 4. Habitus of adult female Corethrella, in lateral view, A-D, F in alcohol, E on microscope slide. C, F, with blood meal apparent in abdomen. 


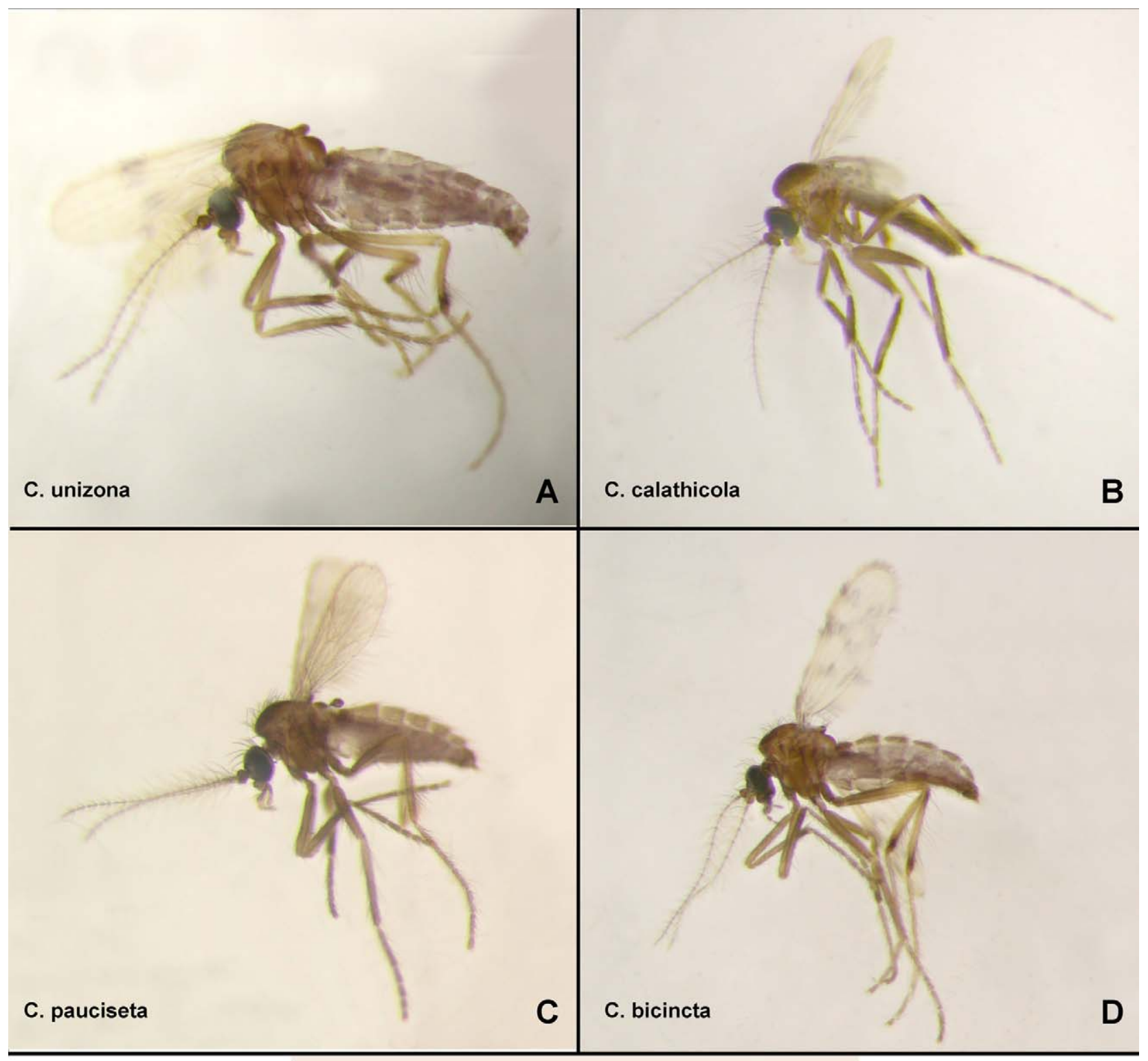

C. gilva

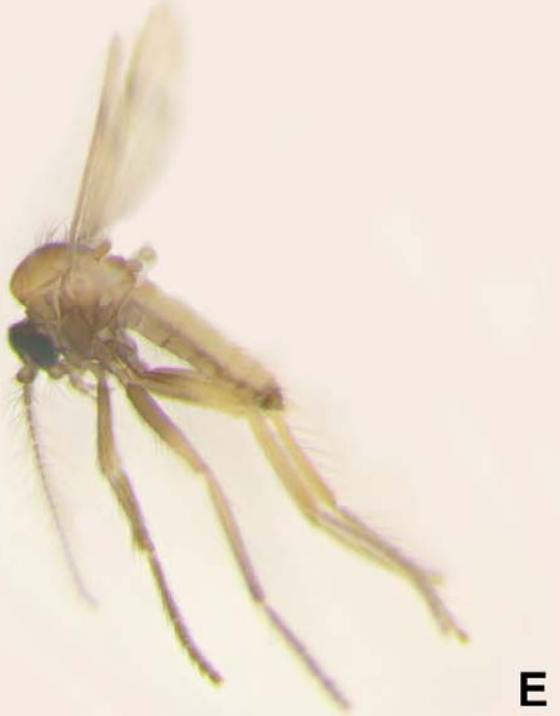

FIGURE 5. Habitus of adult female Corethrella, in lateral view, all in alcohol. 


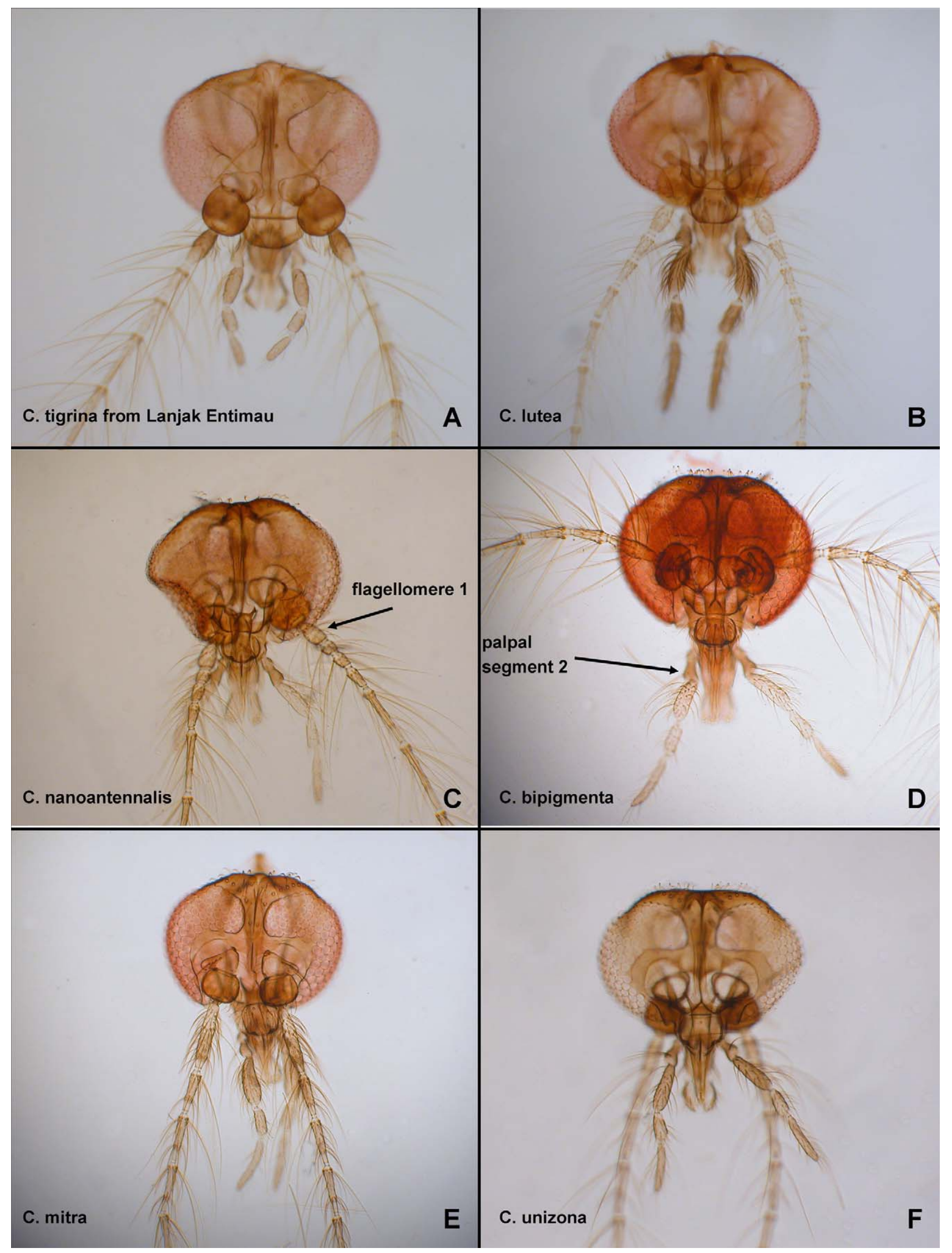

FIGURE 6. Head capsules of female Corethrella, anterior view. 


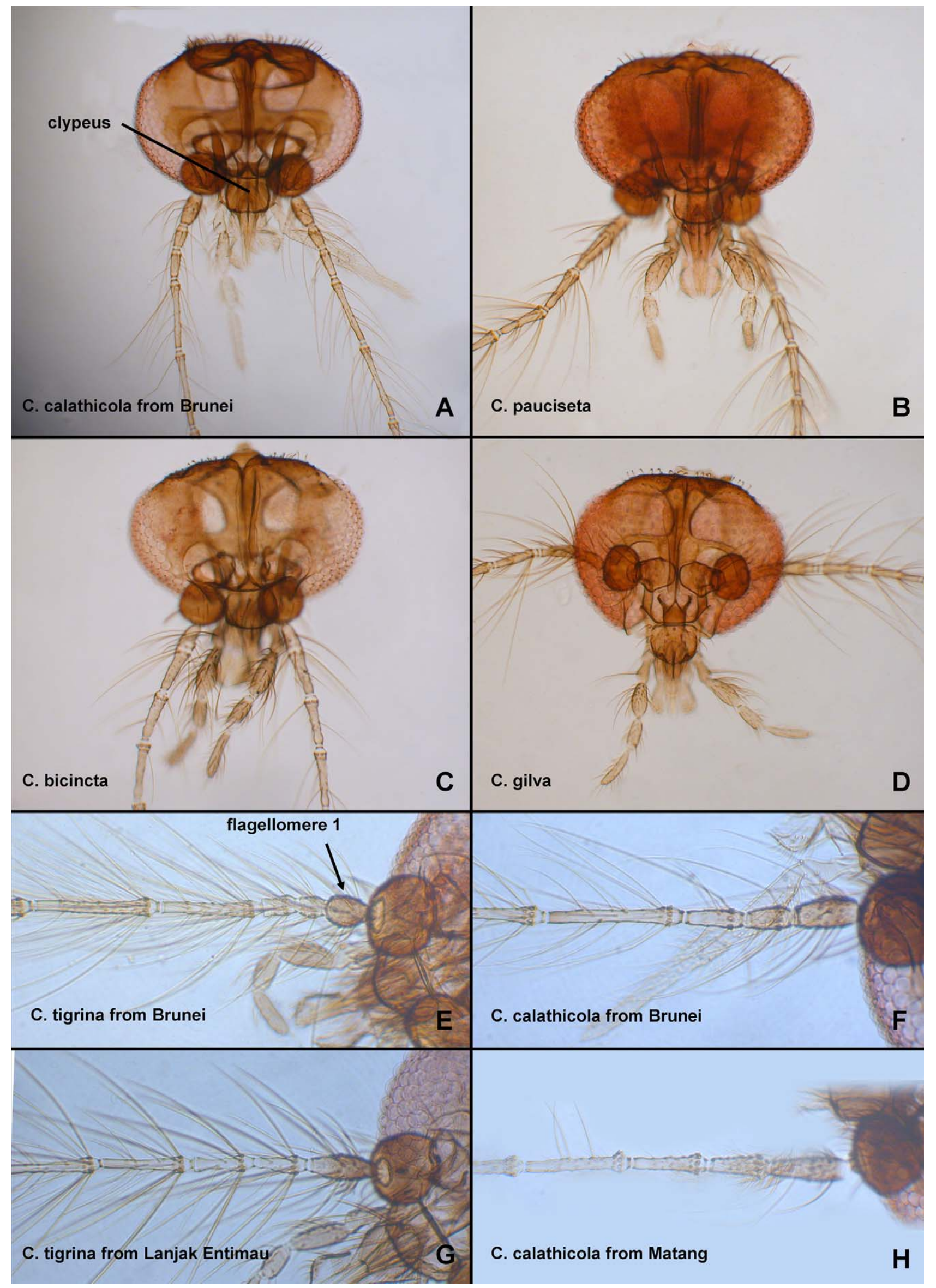

FIGURE 7. A-D. Head capsules of female Corethrella, anterior view. E-H. Antennal flagellomeres 1-4 of female. 


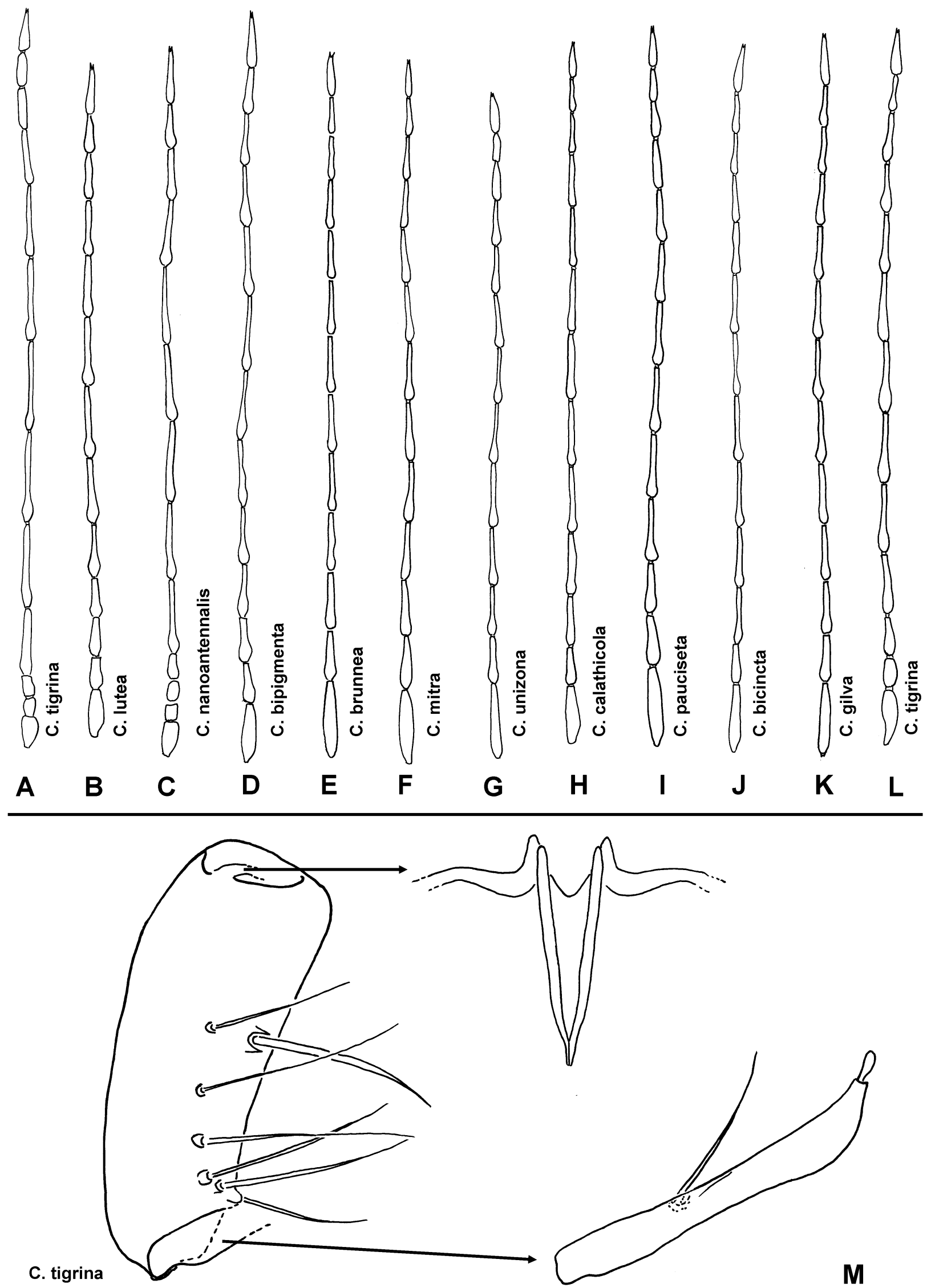

FIGURE 8. Antennae and male genitalia of Corethrella. A-K. Antennae of female Corethrella. L. Antenna of male $C$. tigrina. M. Male genitalia of C. tigrina, dorsal view; parts drawn in proportion to each other. 


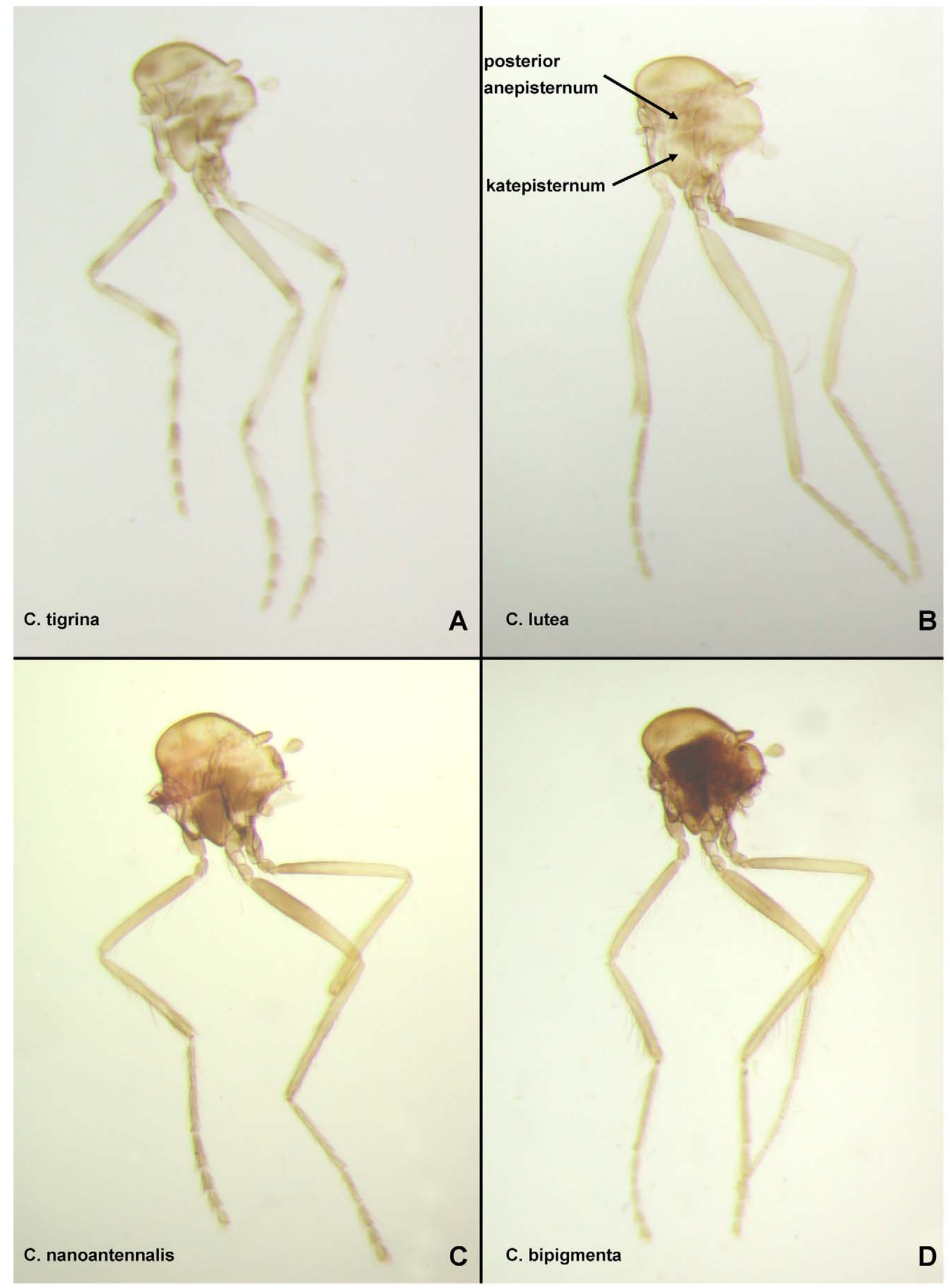

FIGURE 9. A-D. Thoraces and legs of female Corethrella, lateral view; slide-mounted. 


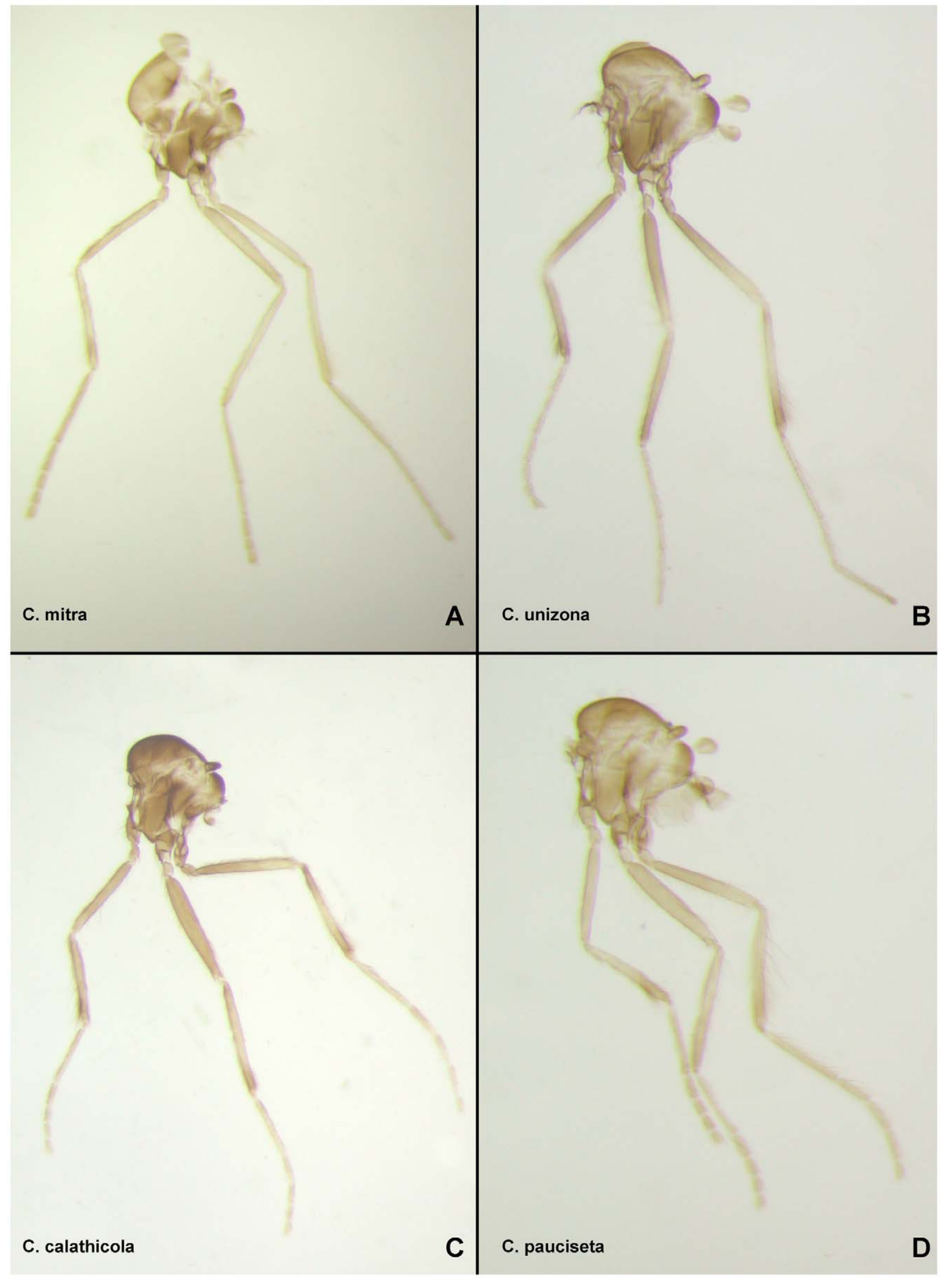

FIGURE 10. A-D. Thoraces and legs of female Corethrella, lateral view; slide-mounted. 


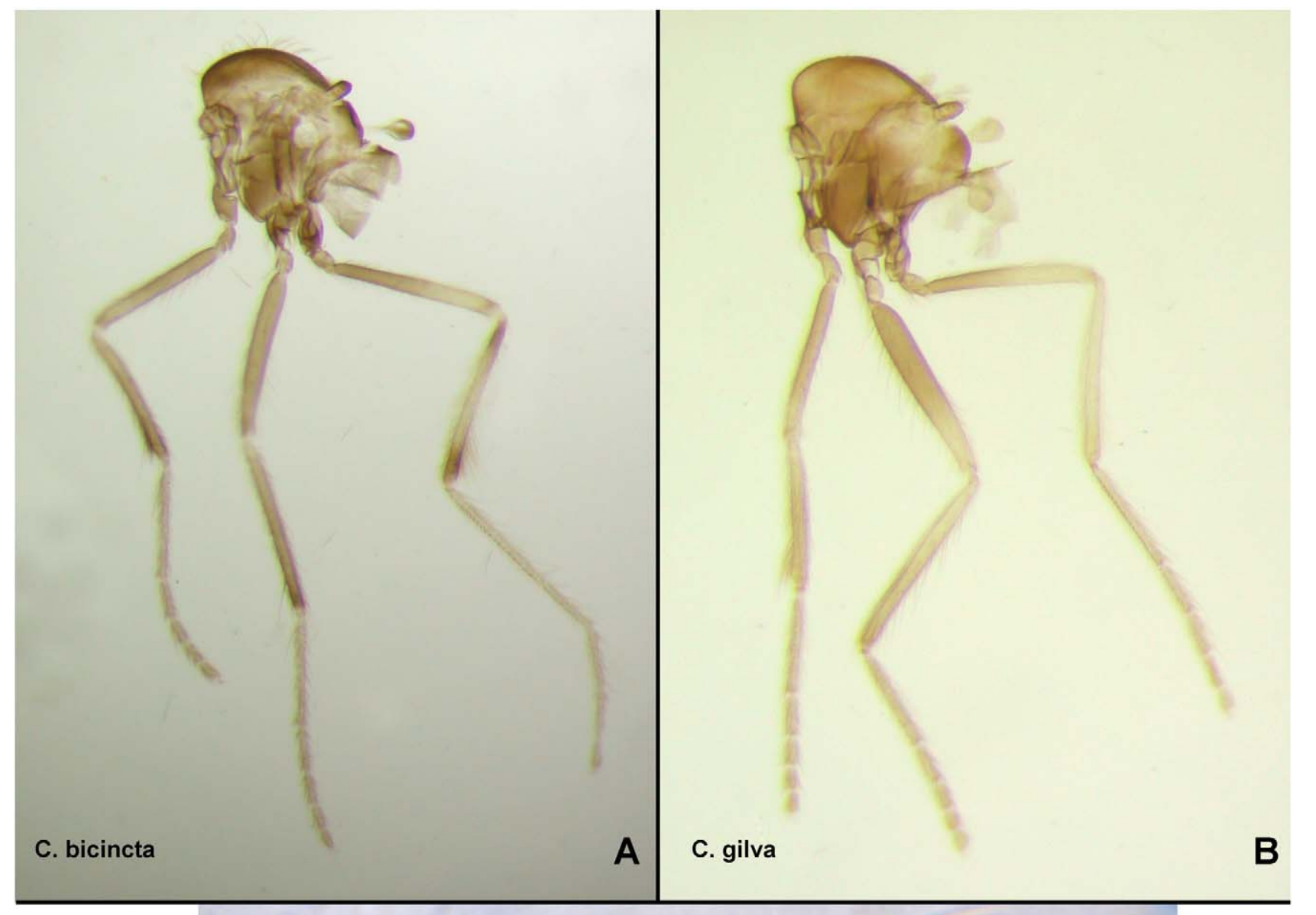

\section{C. calathicola}

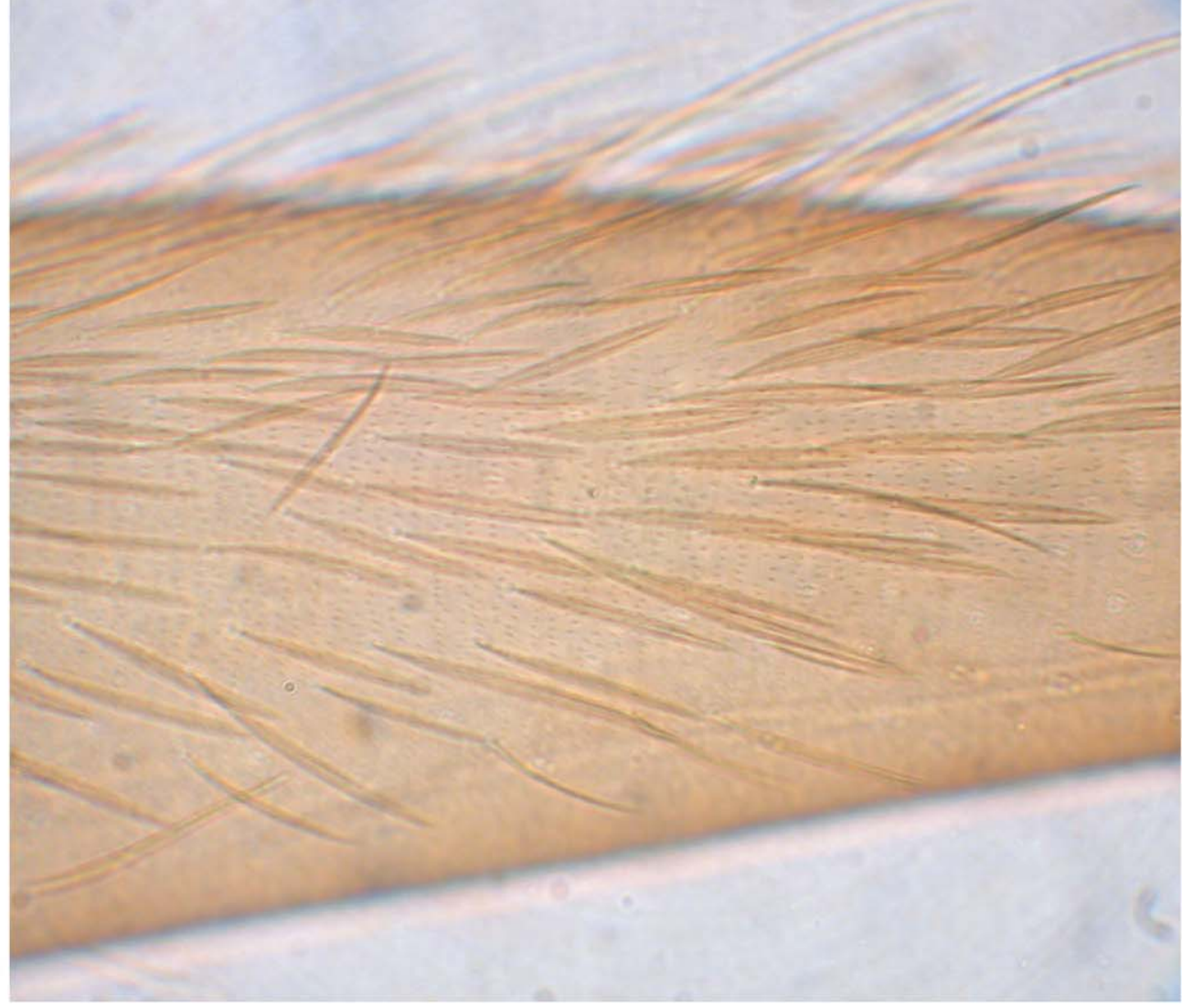

C

FIGURE 11. A-B. Thoraces and legs of female Corethrella, lateral view; slide-mounted. C. Portion of midfemur of female $C$. calathicola, at about distal third of femur, showing scales, dorsal view (with leg extended laterally from body). 


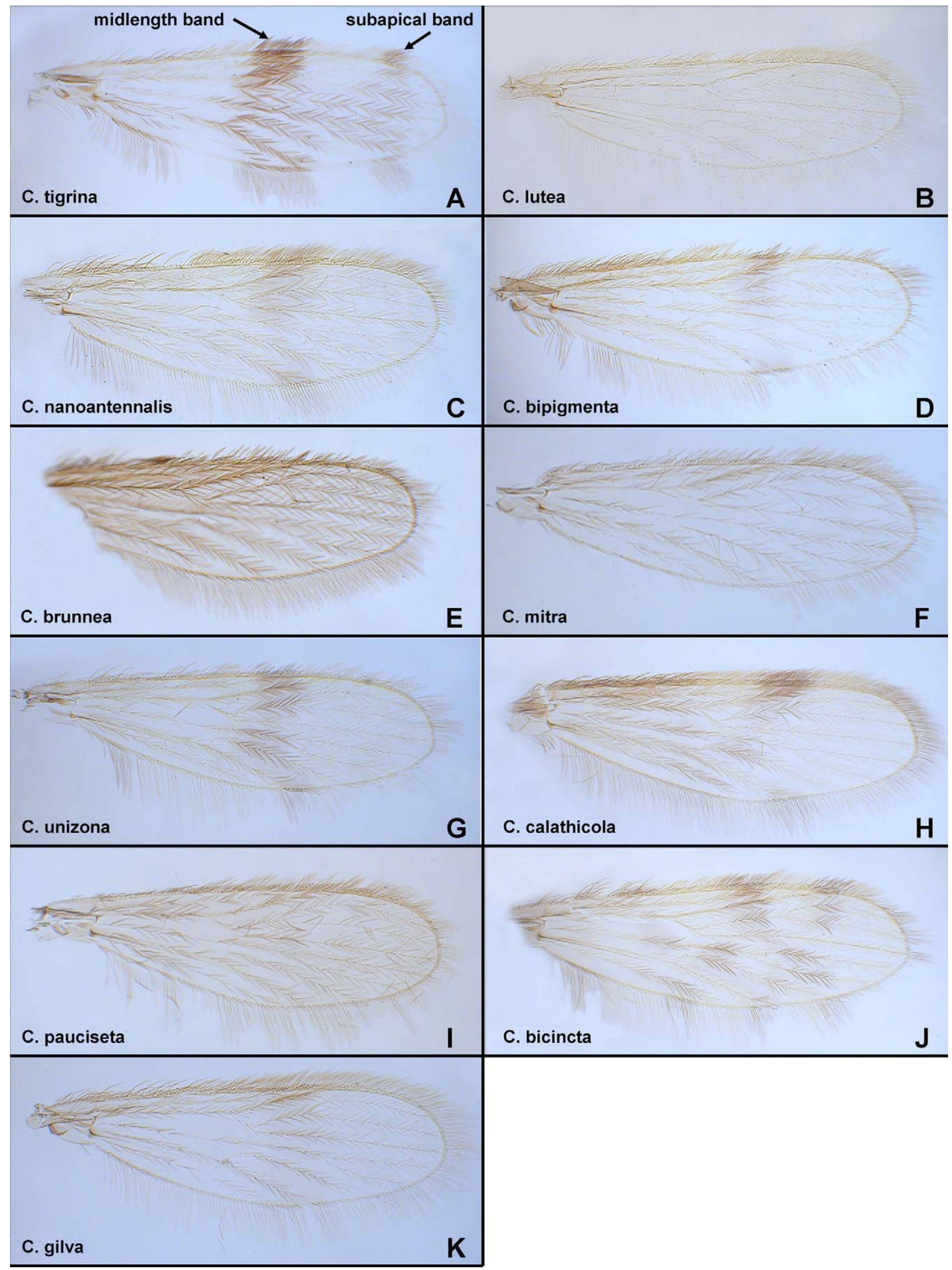

FIGURE 12. A-K. Wings of female Corethrella. 


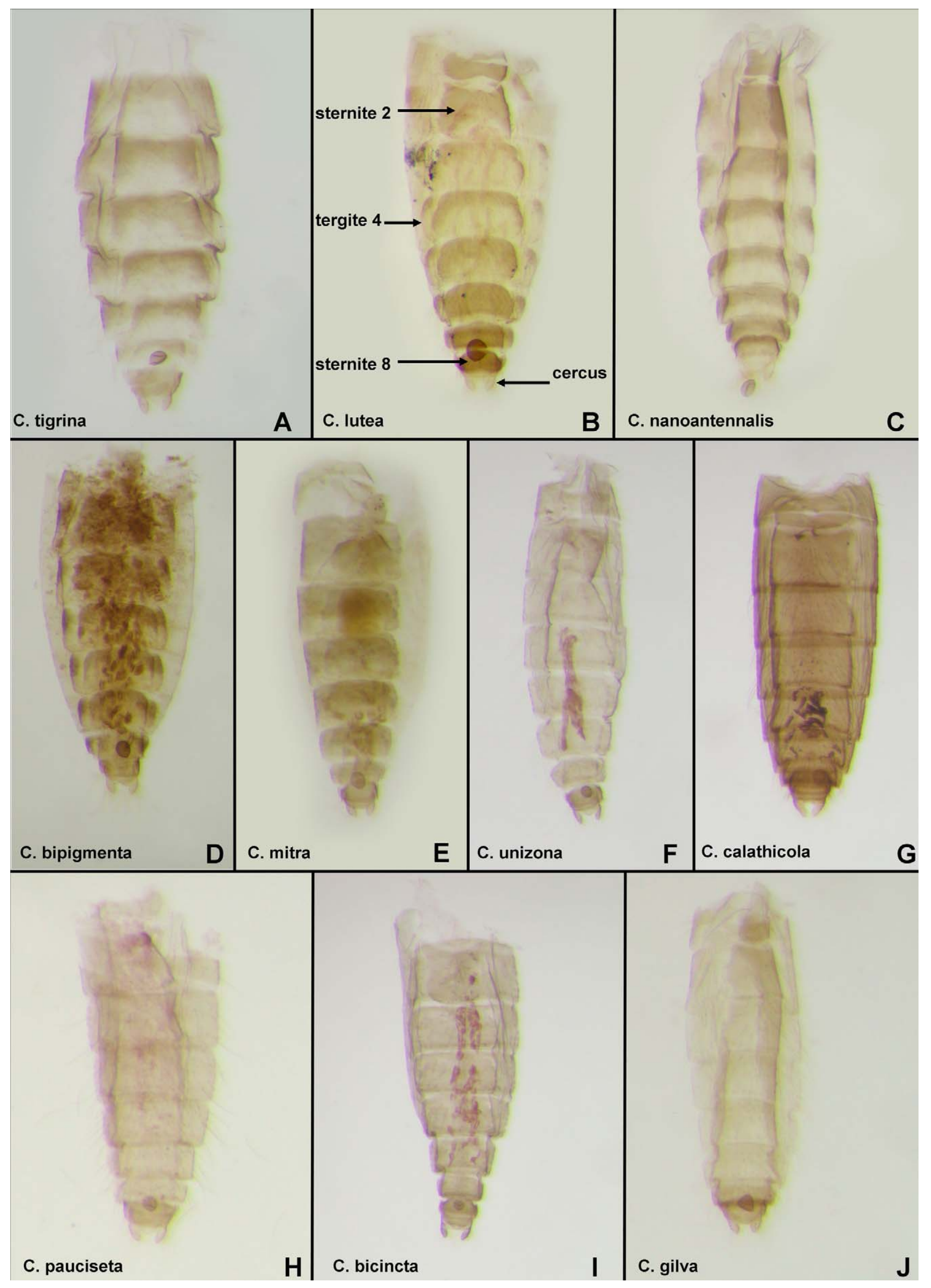

FIGURE 13. A-J. Abdomens of female Corethrella, ventral view. 
- C. nanoantennalis

- C. unizona

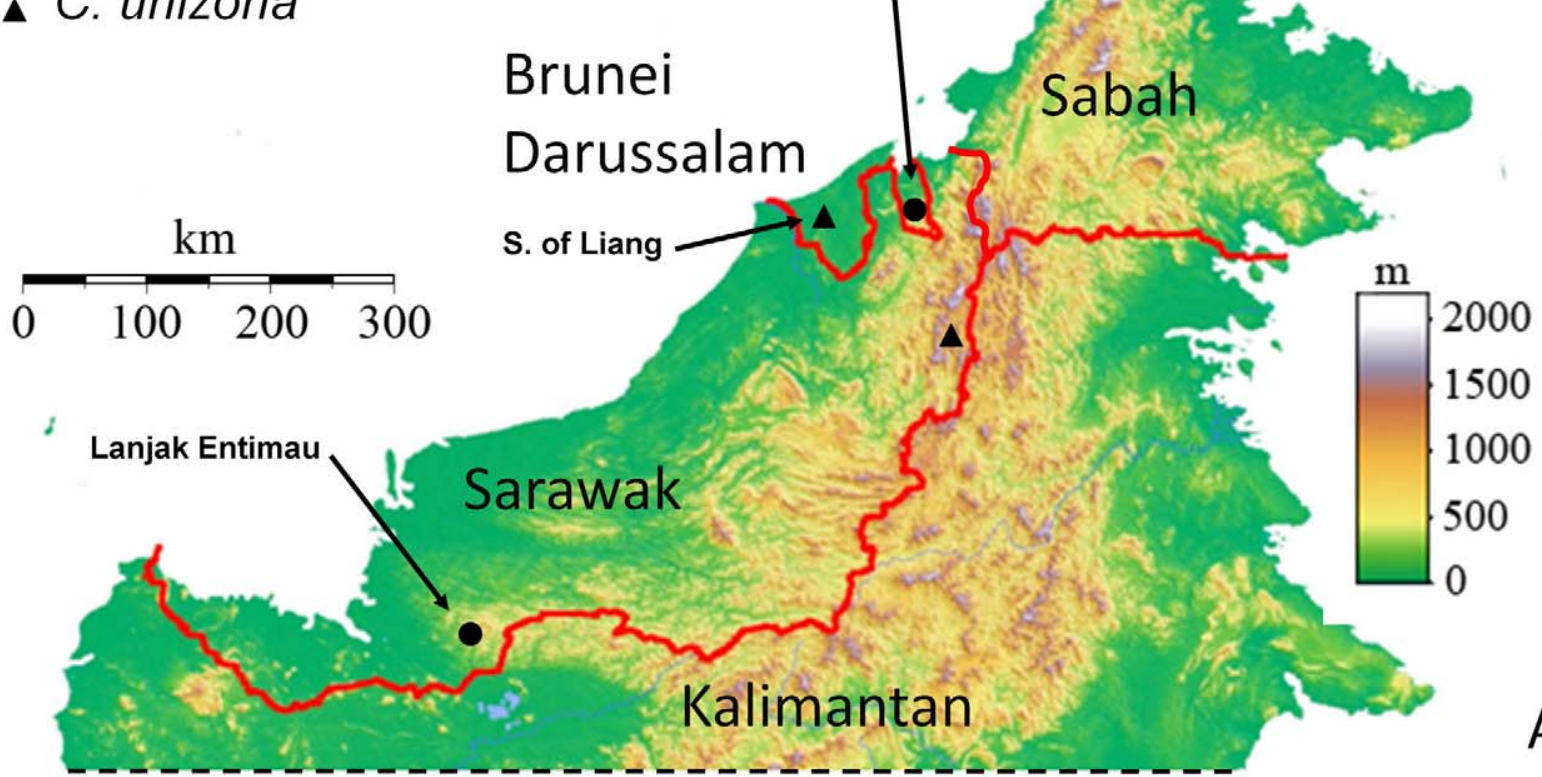

- C. tigrina

- C. brunnea

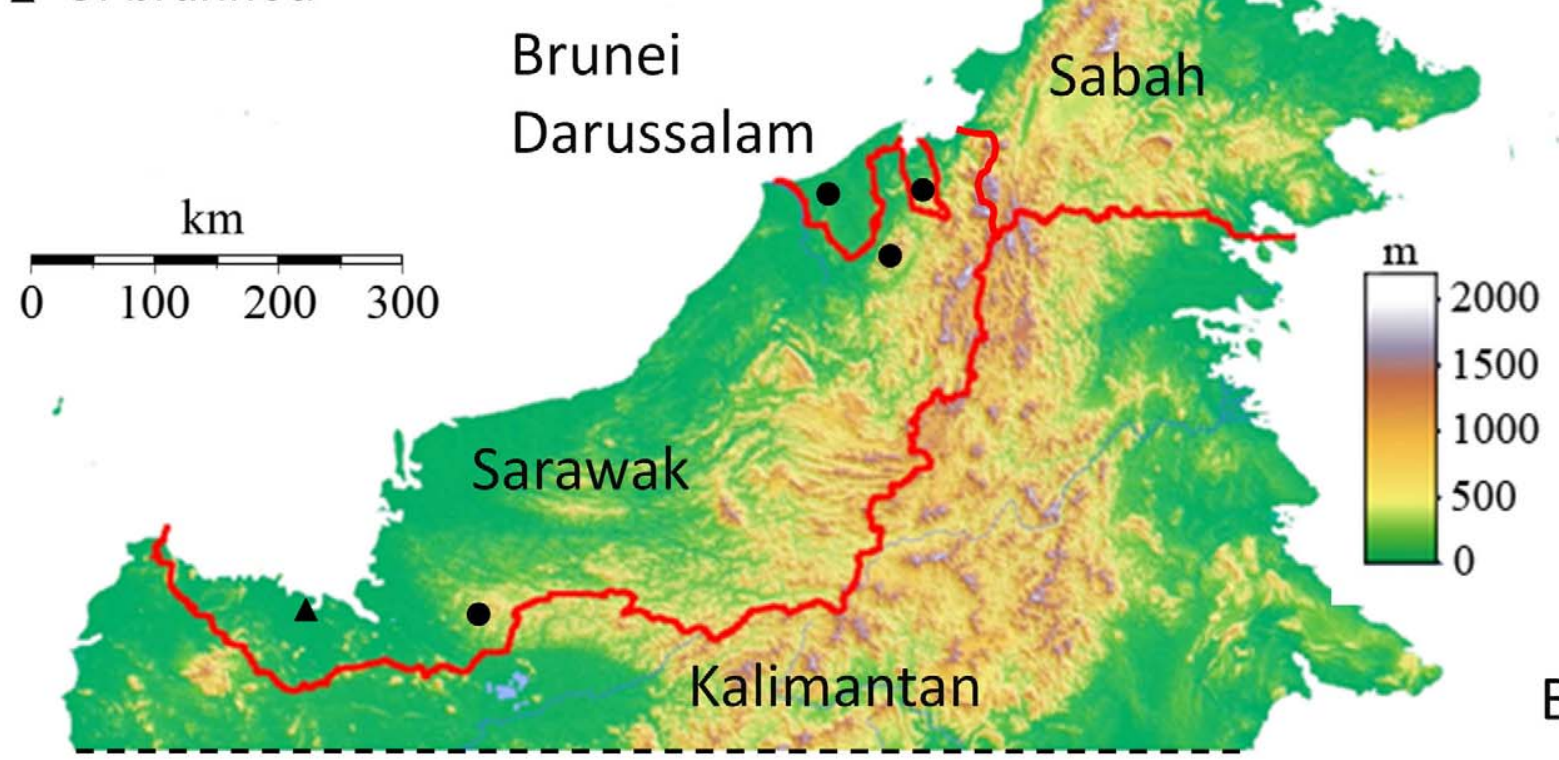

FIGURE 14. A-B. Distributions of species of Corethrella from Borneo. 
- C. lutea

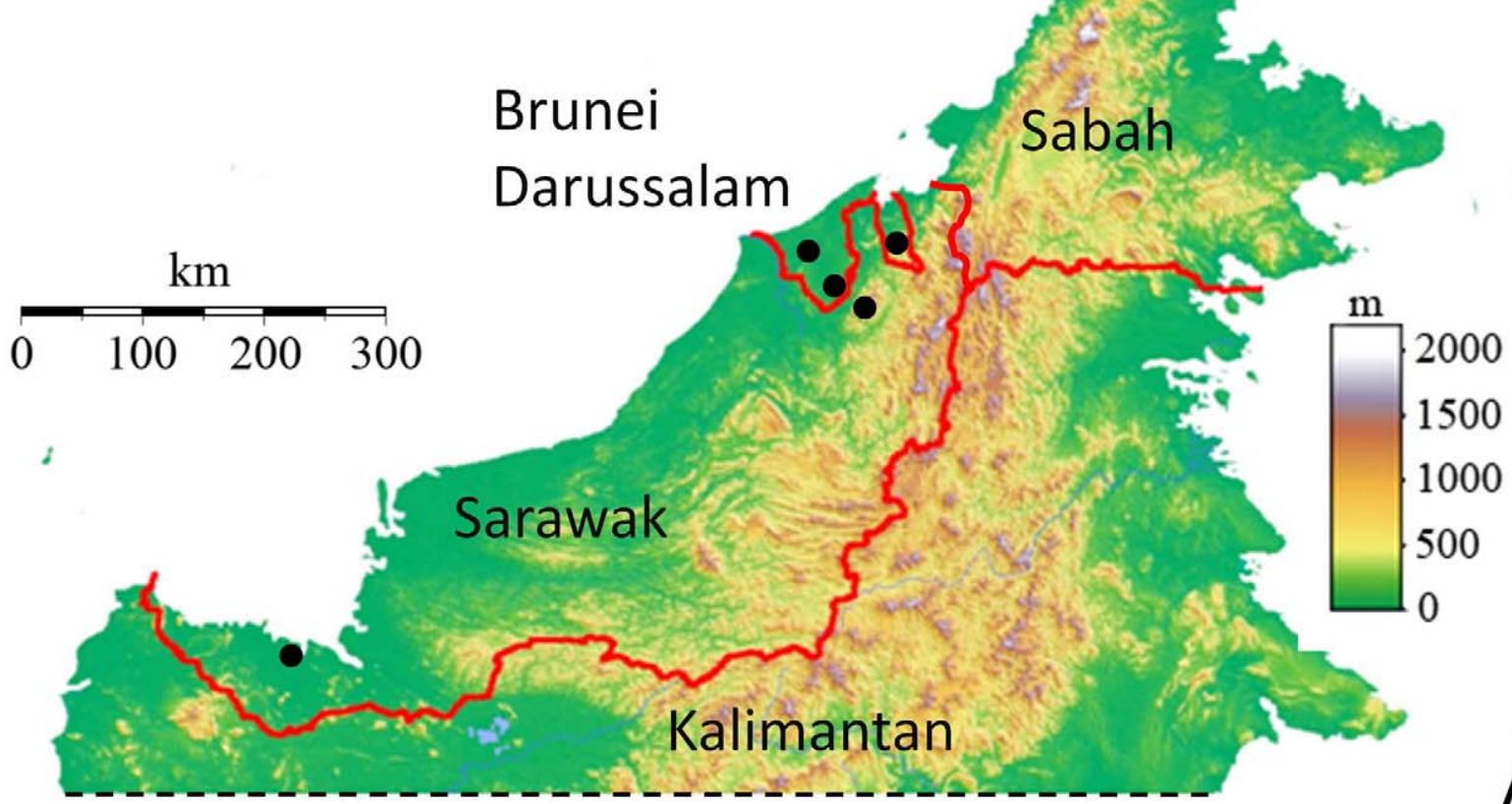

- C. bicincta

- C. bipigmenta

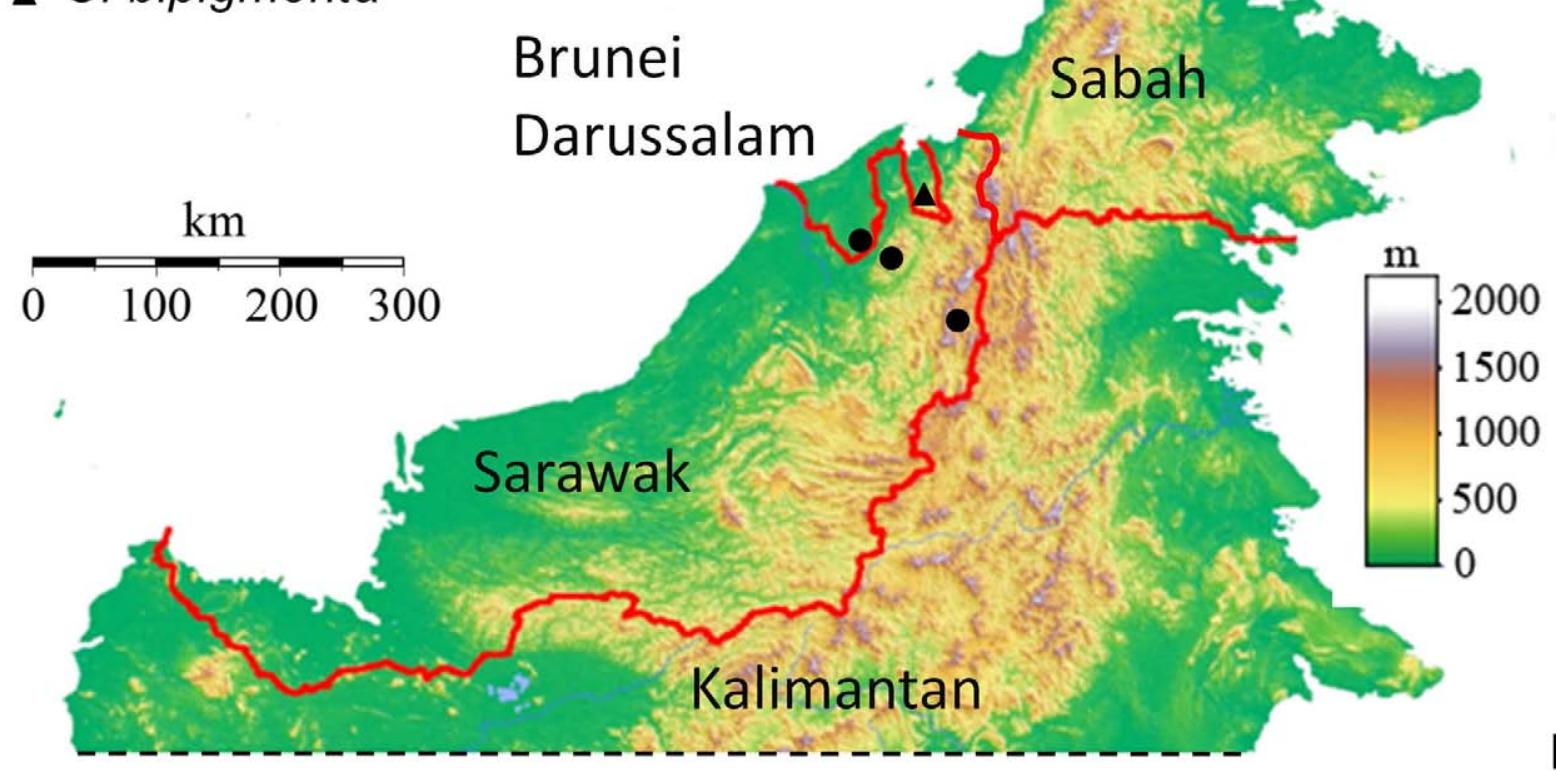

FIGURE 15. A-B. Distributions of species of Corethrella from Borneo. 
- C. gilva

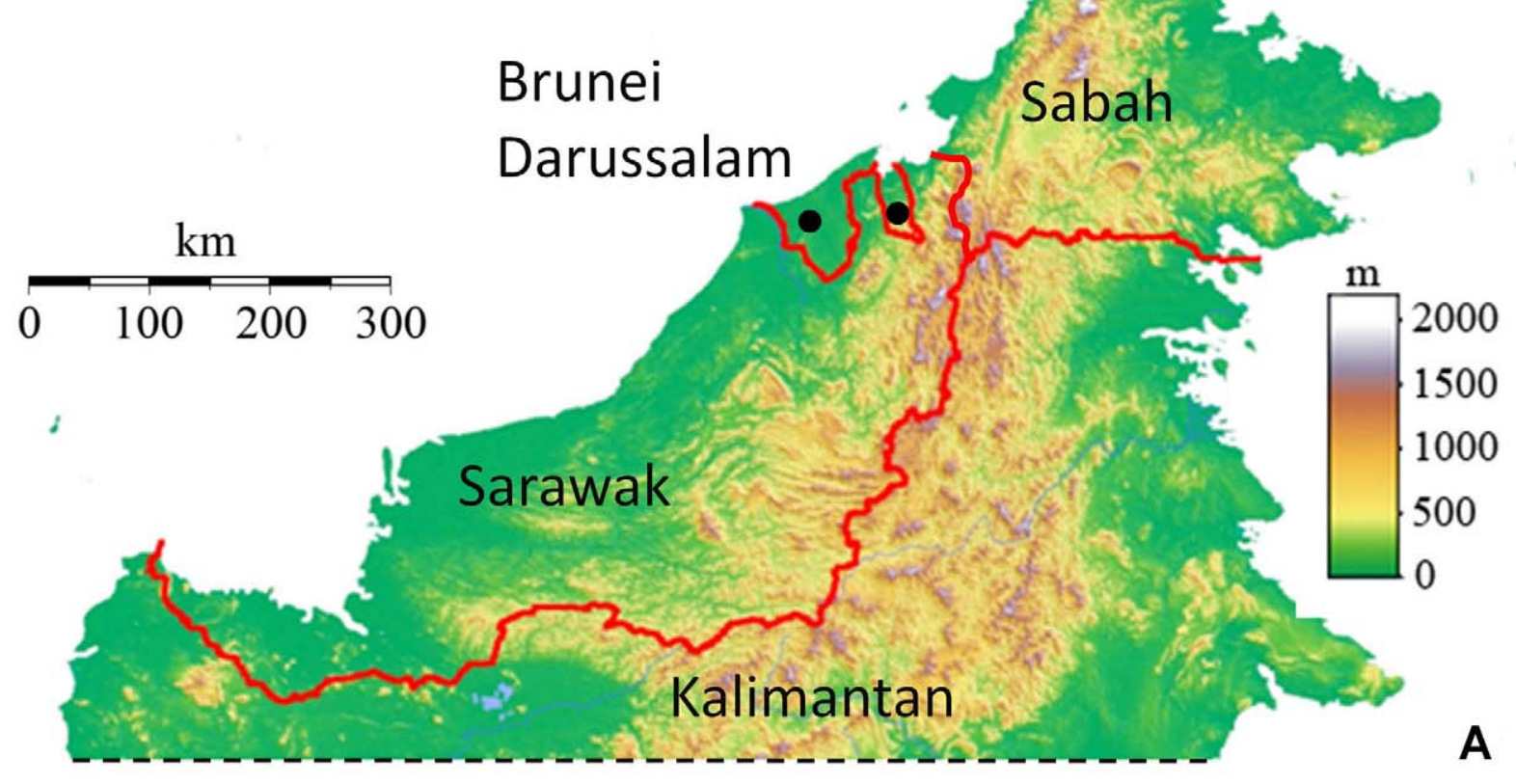

- C. mitra

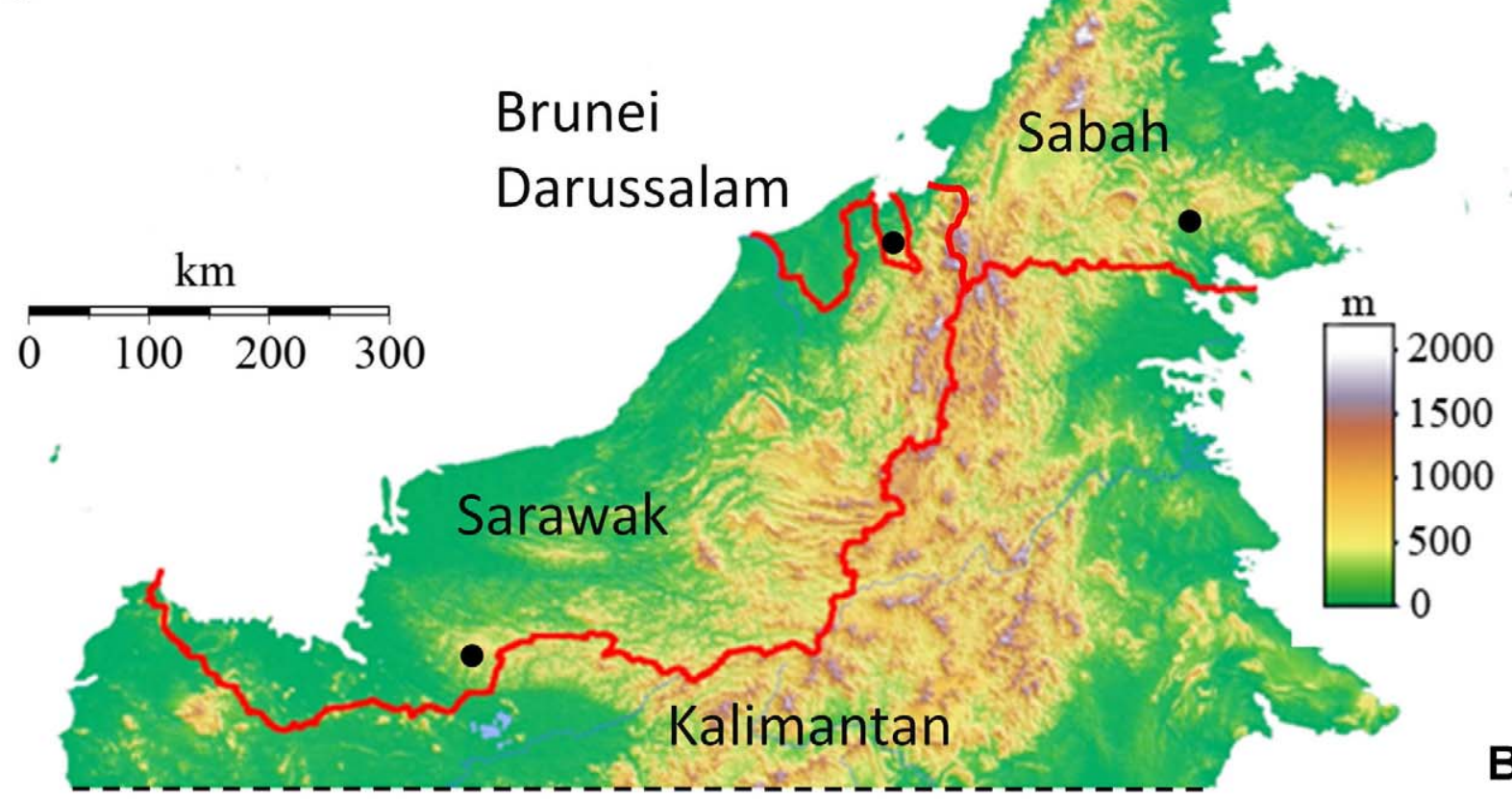

FIGURE 16. A-B. Distributions of species of Corethrella from Borneo. 
- C. pauciseta

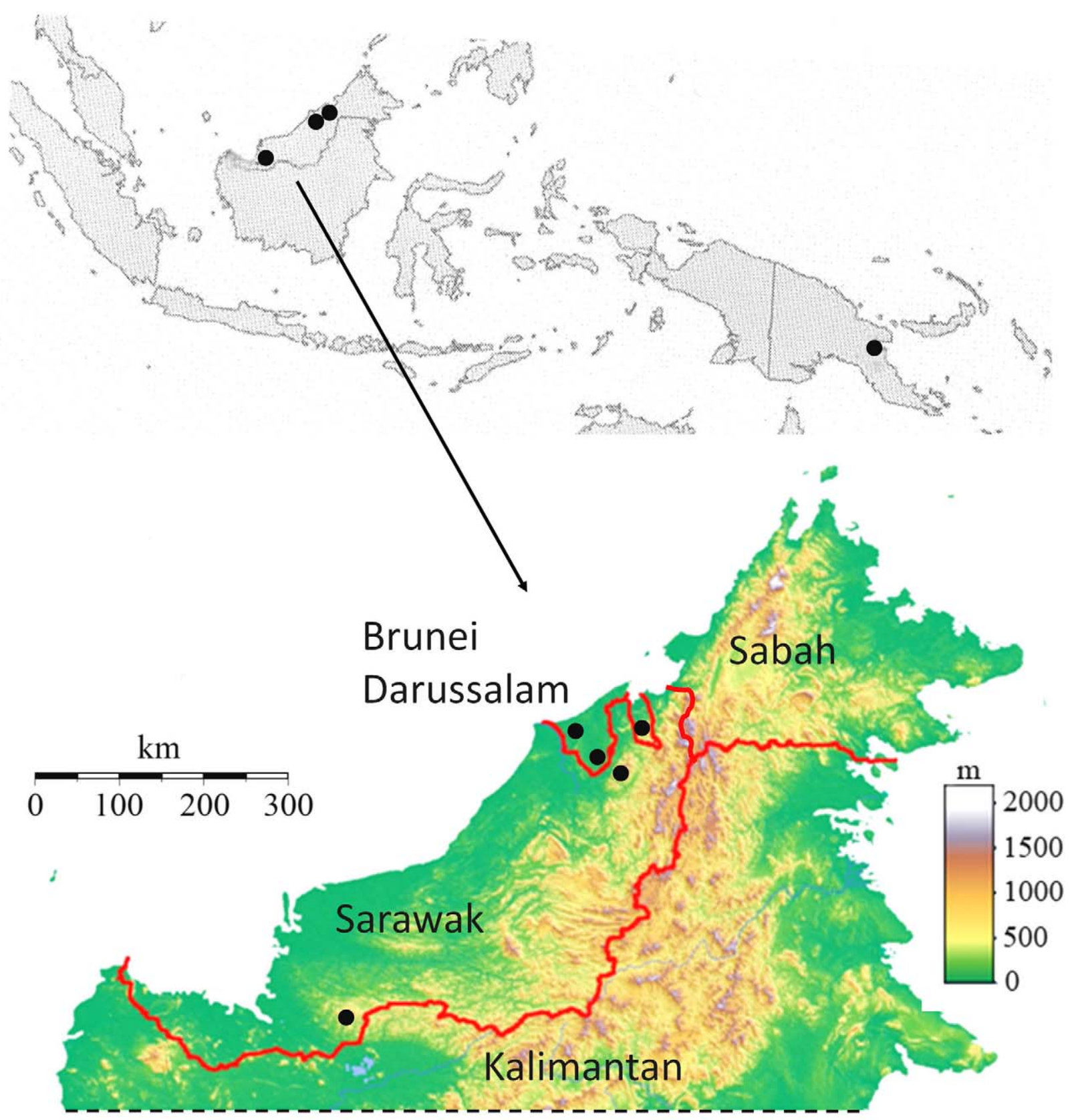

FIGURE 17. Distribution of Corethrella pauciseta. 
- C. calathicola

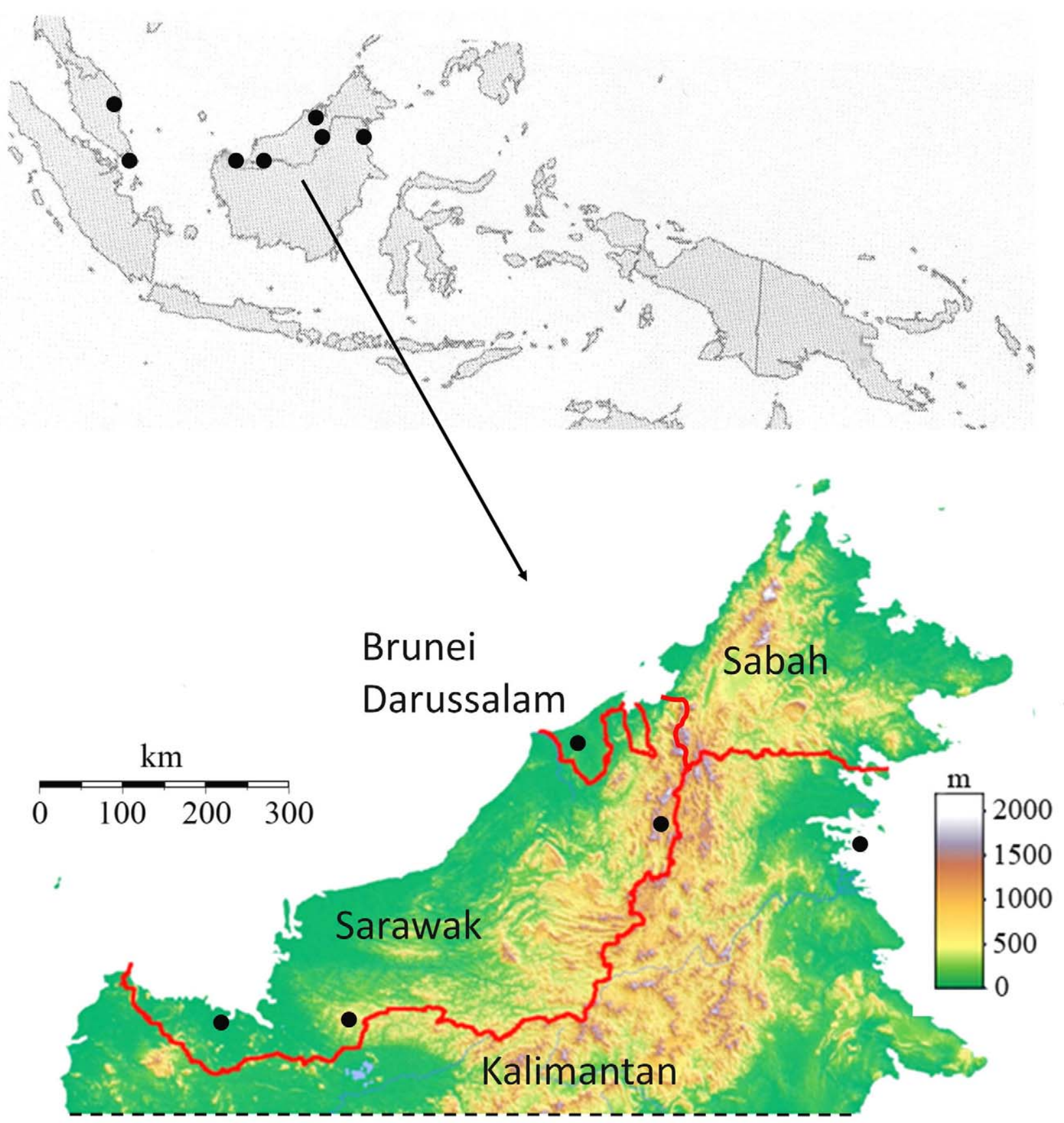

FIGURE 18. Distribution of Corethrella calathicola. 


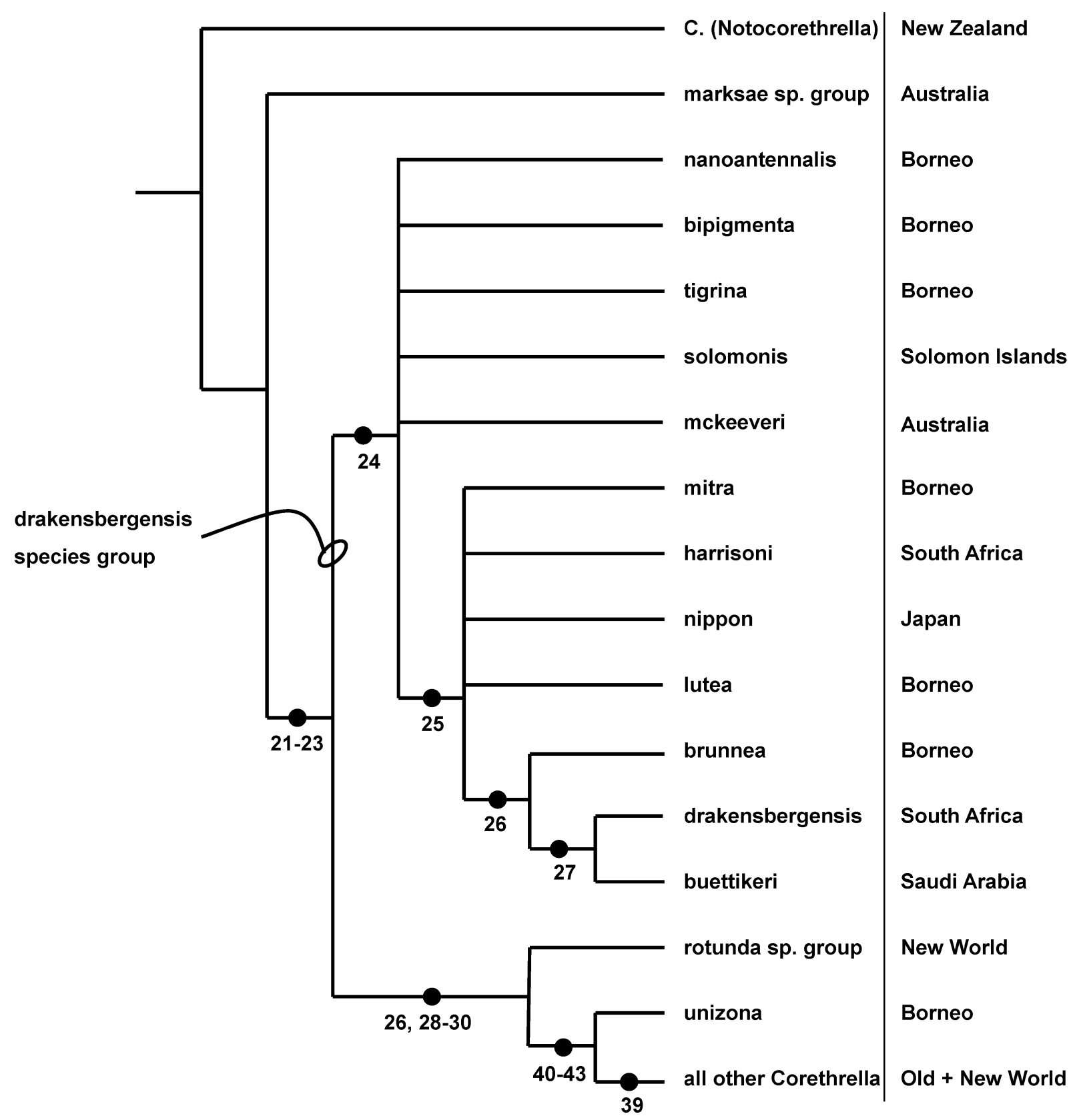

FIGURE 19. Phylogenetic relationships of Corethrella from Borneo to other species and showing their distributions. Numbers refer to character states given in Borkent (2008). Evidence for cladistic relationships given in Borkent (2008). 
TABLE 1. Length (in mm) of wing of females of species of Corethrella.

\begin{tabular}{lllll}
\hline Species & $\mathbf{N}$ & Range & Mean & 1.5 SD \\
\hline tigrina & 9 & $0.99-1.28$ & 1.14 & 0.14 \\
lutea & 11 & $1.22-1.35$ & 1.28 & 0.67 \\
nanoantennalis & 5 & $1.29-1.38$ & 1.32 & - \\
bipigmenta & 3 & $1.29-1.39$ & 1.33 & - \\
brunnea & 1 & 1.30 & 1.30 & - \\
mitra & 3 & $1.13-1.24$ & 1.19 & - \\
unizona & 9 & $1.01-1.35$ & 1.20 & 0.18 \\
calathicola & 9 & $1.13-1.38$ & 1.26 & 0.11 \\
pauciseta & 12 & $0.98-1.63$ & 1.07 & 0.26 \\
bicincta & 9 & $1.19-1.56$ & 1.46 & 0.22 \\
gilva & 9 & $1.01-1.12$ & 1.06 & 0.46 \\
\hline
\end{tabular}

TABLE 2. Ratio of length of $\mathrm{R}_{1} /$ wing length of females of species of Corethrella.

\begin{tabular}{lllll}
\hline Species & N & Range & Mean & 1.5 SD \\
\hline tigrina & 9 & $0.64-0.70$ & 0.684 & 0.028 \\
lutea & 11 & $0.68-0.73$ & 0.710 & 0.019 \\
nanoantennalis & 5 & $0.65-0.71$ & 0.682 & - \\
bipigmenta & 3 & $0.64-0.69$ & 0.673 & - \\
brunnea & 1 & 0.64 & 0.648 & - \\
mitra & 3 & $0.62-0.68$ & 0.653 & - \\
unizona & 9 & $0.67-0.71$ & 0.692 & 0.018 \\
calathicola & 8 & $0.67-0.72$ & 0.691 & 0.025 \\
pauciseta & 12 & $0.61-0.66$ & 0.634 & 0.023 \\
bicincta & 9 & $0.72-0.78$ & 0.754 & 0.025 \\
gilva & 9 & $0.64-0.68$ & 0.662 & 0.011 \\
\hline
\end{tabular}

TABLE 3. Ratio of head capsule width/height of females of species of Corethrella.

\begin{tabular}{llll}
\hline Species & $\mathbf{N}$ & Range & Mean \\
\hline tigrina & 2 & $1.47-0.1 .52$ & 1.49 \\
lutea & 3 & $1.39-0.1 .49$ & 1.44 \\
nanoantennalis & 2 & $1.38-0.1 .40$ & 1.38 \\
bipigmenta & 2 & $1.33-0.1 .36$ & 1.34 \\
brunnea & 0 & - & - \\
mitra & 2 & 1.41 & 1.41 \\
unizona & 2 & $1.50-0.1 .64$ & 1.56 \\
calathicola & 2 & $1.60-0.1 .63$ & 1.61 \\
pauciseta & 11 & $1.40-0.1 .68$ & 1.55 \\
bicincta & 2 & $1.50-1.53$ & 1.51 \\
gilva & 2 & $1.41-0.1 .44$ & 1.42 \\
\hline
\end{tabular}


TABLE 4. Number of setae on the clypeus of females of species of Corethrella. The number does not include those that were on the very margin (or within one setal socket diameter from the margin).

\begin{tabular}{lllll}
\hline Species & N & Range & Mean & 1.5 SD \\
\hline tigrina & 8 & $2-4$ & 3.00 & 0.80 \\
lutea & 11 & $15-25$ & 20.00 & 5.02 \\
nanoantennalis & 6 & $11-18$ & 14.50 & - \\
bipigmenta & 3 & $19-21$ & 19.66 & - \\
brunnea & 1 & 23 & 23.00 & - \\
mitra & 3 & $15-17$ & 16.33 & - \\
unizona & 9 & $0-1$ & 0.88 & 0.50 \\
calathicola & 9 & $1-2$ & 1.22 & 0.66 \\
pauciseta & 13 & 1 & 2.92 & 1.13 \\
bicincta & 9 & $13-25$ & 1.00 & 0.00 \\
gilva & 9 & 15.77 & 5.55 \\
\hline
\end{tabular}

TABLE 5. Number of anepimeral setae of females of species of Corethrella.

\begin{tabular}{lllll}
\hline Species & N & MIN & Mean & 1.5 SD \\
\hline tigrina & 9 & 0 & 0.00 & 0.00 \\
lutea & 11 & $1-2$ & 1.09 & 0.45 \\
nanoantennalis & 6 & 1 & 1.00 & - \\
bipigmenta & 3 & 1 & 1.00 & - \\
brunnea & 1 & 1 & 1.00 & - \\
mitra & 3 & 1 & 1.00 & - \\
unizona & 9 & $0-3$ & 2.00 & 1.50 \\
calathicola & 10 & $5-16$ & 13.00 & 5.65 \\
pauciseta & 13 & $1-5$ & 3.23 & 1.74 \\
bicincta & 9 & $0-4$ & 1.44 & 2.38 \\
gilva & 9 & 1 & 1.00 & 0.00
\end{tabular}

TABLE 6. Identity of species of Corethrella studied by Grafe et al. (2008) (their morphotype number and characterization).

\begin{tabular}{cll}
\hline Morphotype \# & Morphotype characterization & Identification here \\
\hline $\mathbf{1}$ & brown, "eye-lash" & C. pauciseta \\
$\mathbf{2}$ & yellow, "blondies" & C. lutea \\
$\mathbf{3}$ & medium yellowish & C. gilva, C. unizona \\
$\mathbf{4}$ & large brown with striped legs & C. calathicola, C. unizona \\
$\mathbf{5}$ & striped, "tiger" & C. tigrina \\
$\mathbf{6}$ & very small banded & Culicoides maculatus \\
$\mathbf{7}$ & banded & Culicoides maculatus \\
$\mathbf{8}$ & black and white striped, "zebra" & Chaoborus sp. \\
$\mathbf{9}$ & light brown with single band on wing & C. unizona \\
$\mathbf{1 0}$ & reddish brown without banded legs & Chironomidae \\
$\mathbf{1 1}$ & hairless & C. pauciseta \\
\hline
\end{tabular}


TABLE 7. Records of species of Corethrella collected from frog species in Borneo. BD stands for Brunei Darussalam, UTNP for Ulu Temburong National Park, Brunei Darussalam, SICF for Sungai Ingei Conservation Forest, Brunei Darussalam, GMNP for Gunung Mulu National Park, Sarawak, Malaysia, and Sg for Sungai (meaning stream or river in Malay).

\begin{tabular}{|c|c|c|c|c|c|c|c|}
\hline $\begin{array}{l}\text { Corethrella } \\
\text { species }\end{array}$ & $\begin{array}{l}\text { Collected } \\
\text { with } \\
\text { frog-call } \\
\text { trap }\end{array}$ & Collected from frog species & $\begin{array}{l}\text { Area of frog } \\
\text { bitten }\end{array}$ & Locality & $\begin{array}{c}\text { Elevation } \\
\text { (meters) }\end{array}$ & $\begin{array}{l}\text { Dates of } \\
\text { collection }\end{array}$ & Latitude and Longitude \\
\hline \multirow[t]{3}{*}{ C. tigrina } & yes & Metaphrynella sundana & unknown & $\begin{array}{r}\text { Ashton Trail, } \\
\text { UTNP, BD }\end{array}$ & 220 & $\begin{array}{r}24-\mathrm{V}-2010, \\
15-\mathrm{VI}-2010, \\
22-\mathrm{VII}-2008 \\
\end{array}$ & N4 32.692 E115 09.315 \\
\hline & & Philautus hosii & head & $\begin{array}{r}\text { lower Sg Apan, } \\
\text { UTNP, BD }\end{array}$ & 110 & 8-VII-2008 & N4 33.446 E115 08.957 \\
\hline & & Philautus hosii & unknown & $\begin{array}{r}\text { Sg Baki, UTNP, } \\
\text { BD }\end{array}$ & 120 & $18-\mathrm{VII}-2008$ & N4 33.470 E115 10.010 \\
\hline \multirow[t]{5}{*}{ C. lutea } & yes & Hylarana baramica & $\begin{array}{r}\text { body and } \\
\text { legs }\end{array}$ & $12 \mathrm{~km}$ S. Liang, BD & 30 & $\begin{array}{r}\text { 12-II-2009, } \\
21-\mathrm{IV}-2007, \\
30-\mathrm{IV}-2007, \\
9-\mathrm{V}-2007 \\
\end{array}$ & N4 35.164 E114 30.486 \\
\hline & & Hylarana baramica & $\begin{array}{r}\text { body and } \\
\text { legs }\end{array}$ & 15 km S. Liang, BD & 40 & $9-\mathrm{V}-2007$ & N4 33.380 E114 29.202 \\
\hline & & Hylarana glandulosa & body & 12 km S. Liang, BD & 30 & $\begin{array}{r}10-\mathrm{V}-2007, \\
15-\mathrm{V}-2007\end{array}$ & N4 35.164 E114 30.486 \\
\hline & & Hylarana glandulosa & $\begin{array}{r}\text { body and } \\
\text { legs }\end{array}$ & $\begin{array}{r}\text { Headquarters, } \\
\text { GMNP, Sarawak, } \\
\text { Malaysia }\end{array}$ & 30 & $\begin{array}{r}26-\mathrm{IX}-2009, \\
14-\mathrm{XI}-2009\end{array}$ & N4 03.365 E114 48.546 \\
\hline & & Rhacophorus appendiculatus & body & $\begin{array}{r}\text { SICF, } 8.2 \mathrm{~km} \text { south } \\
\text { of Melilas, BD }\end{array}$ & 50 & $\begin{array}{l}\text { 9-VII-2010, } \\
17-\mathrm{VII}-2010\end{array}$ & N4 11.191 E114 40.984 \\
\hline \multirow[t]{2}{*}{ C. nanoantennalis } & yes & Ansonia longidigita & $\begin{array}{r}\text { body and } \\
\text { legs }\end{array}$ & $\begin{array}{r}\text { Lanjak Entimau, } \\
\text { Sarawak, Malaysia }\end{array}$ & 200 & $\begin{array}{r}\text { 18-VI-2008, } \\
24-\mathrm{VI}-2008\end{array}$ & N1 38.000 E112 16.000 \\
\hline & & Megophrys nasuta & $\begin{array}{r}\text { body and } \\
\text { legs } \\
\end{array}$ & $\begin{array}{r}\text { Sg Mata Ikan, } \\
\text { UTNP, BD }\end{array}$ & 110 & 10-VII-2008 & N4 32.835 E115 09.395 \\
\hline \multirow[t]{4}{*}{ C. bipigmenta } & no & Ansonia longidigita & body & $\begin{array}{r}\text { Sg Mata Ikan, } \\
\text { UTNP, BD }\end{array}$ & 110 & 23-VII-2007 & N4 32.835 E115 09.395 \\
\hline & & Megophrys nasuta & $\begin{array}{r}\text { body and } \\
\text { legs on } \\
11-\text { VII } \\
\end{array}$ & $\begin{array}{r}\text { tributary of Sg } \\
\text { Temburong, } \\
\text { Temburong, BD } \\
\end{array}$ & 110 & $\begin{array}{l}\text { 11-VII-2008, } \\
\text { 22-VII-2006 }\end{array}$ & N4 33.438 E115 09.770 \\
\hline & & Megophrys nasuta & unknown & $\begin{array}{r}\text { Sg Mata Ikan, } \\
\text { UTNP, BD }\end{array}$ & 110 & $10-\mathrm{VII}-2008$ & N4 32.835 E115 09.395 \\
\hline & & Megophrys nasuta & unknown & $\begin{array}{r}\text { Sg Baki, UTNP, } \\
\text { BD }\end{array}$ & 120 & $18-\mathrm{VII}-2008$ & N4 33.470 E115 10.010 \\
\hline C. brunnea & no & no & & & & & \\
\hline \multirow[t]{5}{*}{ C. mitra } & no & Limnonectes leporinus & $\begin{array}{r}\text { around nares/ } \\
\text { above eye }\end{array}$ & $\begin{array}{r}\text { lower Sg Apan and } \\
\text { Sg Baki, UTNP, } \\
\text { BD }\end{array}$ & 110 & $\begin{array}{r}1-\mathrm{VII}-2008, \\
4-\mathrm{VII}-2008, \\
18-\mathrm{VII}-2008 \\
\end{array}$ & N4 33.446 E11508.957 \\
\hline & & Limnonectes leporinus & around nares & $\begin{array}{r}\text { Lanjak Entimau, } \\
\text { Sarawak, Malaysia }\end{array}$ & 200 & 25-VI-2008 & N1 38.000 E112 16.000 \\
\hline & & Limnonectes leporinus & around nares & $\begin{array}{r}30 \mathrm{~km} \mathrm{NE} \\
\text { Kalabakan, Sabah, } \\
\text { Malaysia }\end{array}$ & 300 & $17-V-2011$ & N4 42.053 E117 34.403 \\
\hline & & Meristogenys orphnocnemus & unknown & $\begin{array}{r}34 \text { km NE } \\
\text { Kalabakan, Sabah, } \\
\text { Malaysia } \\
\end{array}$ & 340 & 26-VIII-2011 & N4 43.503 E117 35.776 \\
\hline & & Philautus hosii & head & $\begin{array}{r}\text { lower Sg Apan, } \\
\text { UTNP, BD }\end{array}$ & 120 & 8-VII-2008 & N4 33.446 E115 08.957 \\
\hline C. unizona & yes & no & & & & & \\
\hline C. calathicola & yes & Hylarana glandulosa & body & $12 \mathrm{~km} \mathrm{~S}$. Liang, BD & 30 & $15-\mathrm{V}-2007$ & N4 35.164 E114 30.486 \\
\hline \multirow[t]{5}{*}{ C. pauciseta } & yes & Ansonia leptopus & body & $\begin{array}{r}\text { lower Sg Apan, } \\
\text { UTNP, BD }\end{array}$ & 110 & 9-II-2010 & N4 33.446 E115 08.957 \\
\hline & & Hylarana baramica & body & 12 km S. Liang, BD & 30 & $\begin{array}{r}\text { 12-II-2009, } \\
24-\mathrm{IV}-2007, \\
4-\mathrm{V}-2007, \\
5-\mathrm{VII}-2010 \\
\end{array}$ & N4 35.164 E114 30.486 \\
\hline & & Hylarana glandulosa & body & 12 km S. Liang, BD & 30 & $15-V-2007$ & N4 35.164 E114 30.486 \\
\hline & & Hylarana glandulosa & body & $\begin{array}{r}\text { Headquarters, } \\
\text { GMNP, Sarawak, } \\
\text { Malaysia } \\
\end{array}$ & 30 & $\begin{array}{r}\text { 23-IX-2009, } \\
\text { 26-IX-2009, } \\
14-X I-2009 \\
\end{array}$ & N4 03.365 E114 48.546 \\
\hline & & Megophrys nasuta & unknown & $\begin{array}{r}\text { Sg Baki, UTNP, } \\
\text { BD }\end{array}$ & 120 & $18-\mathrm{VII}-2008$ & N4 33.470 E115 10.010 \\
\hline C. bicincta & yes & Hylarana glandulosa & body & $\begin{array}{r}\text { Headquarters, } \\
\text { GMNP, Sarawak, } \\
\text { Malaysia }\end{array}$ & 30 & 14-XI-2009 & N4 03.365 E114 48.546 \\
\hline \multirow[t]{5}{*}{ C. gilva } & yes & Ansonia leptopus & body & $\begin{array}{r}\text { lower Sg Apan, } \\
\text { UTNP, BD }\end{array}$ & 110 & 9-II-2010 & N4 33.446 E11508.957 \\
\hline & & Hylarana glandulosa & body & $12 \mathrm{~km} \mathrm{~S}$. Liang, BD & 30 & $\begin{array}{r}10-\mathrm{V}-2010, \\
15-\mathrm{V}-2007 \\
\end{array}$ & N4 35.164 E114 30.486 \\
\hline & & Hylarana glandulosa & body & 15 km S. Liang, BD & 40 & $\begin{array}{r}\text { 9-V-2007, } \\
12-\mathrm{V}-2007 \\
\end{array}$ & N4 33.380 E114 29.202 \\
\hline & & Hylarana glandulosa & body & 17 km N. Labi, BD & 40 & $14-\mathrm{V}-2007$ & N4 29.432 E114 27.340 \\
\hline & & Ingerophrynus divergens & unknown & $\begin{array}{r}\text { lower Sg Apan, } \\
\text { UTNP, BD }\end{array}$ & 110 & $5-\mathrm{II}-2010$ & N4 33.446 E11508.957 \\
\hline
\end{tabular}

